Supporting Information

$$
\text { for }
$$

\title{
Oxidative Cyclization of Kynuramine and Ynones Enabling Collective Syntheses of Pyridoacridine Alkaloids
}

\author{
Dongfang Jiang and Shaozhong Wang*
}

State Key Laboratory of Coordination Chemistry, Jiangsu Key Laboratory of Advanced Organic

Materials, School of Chemistry and Chemical Engineering, Nanjing University, Nanjing 210023, China.

E-mail:wangsz@nju.edu.cn 


\section{Contents}

1. Copies of NMR spectra

SI-3

SI-2 
1. Copies of NMR spectra

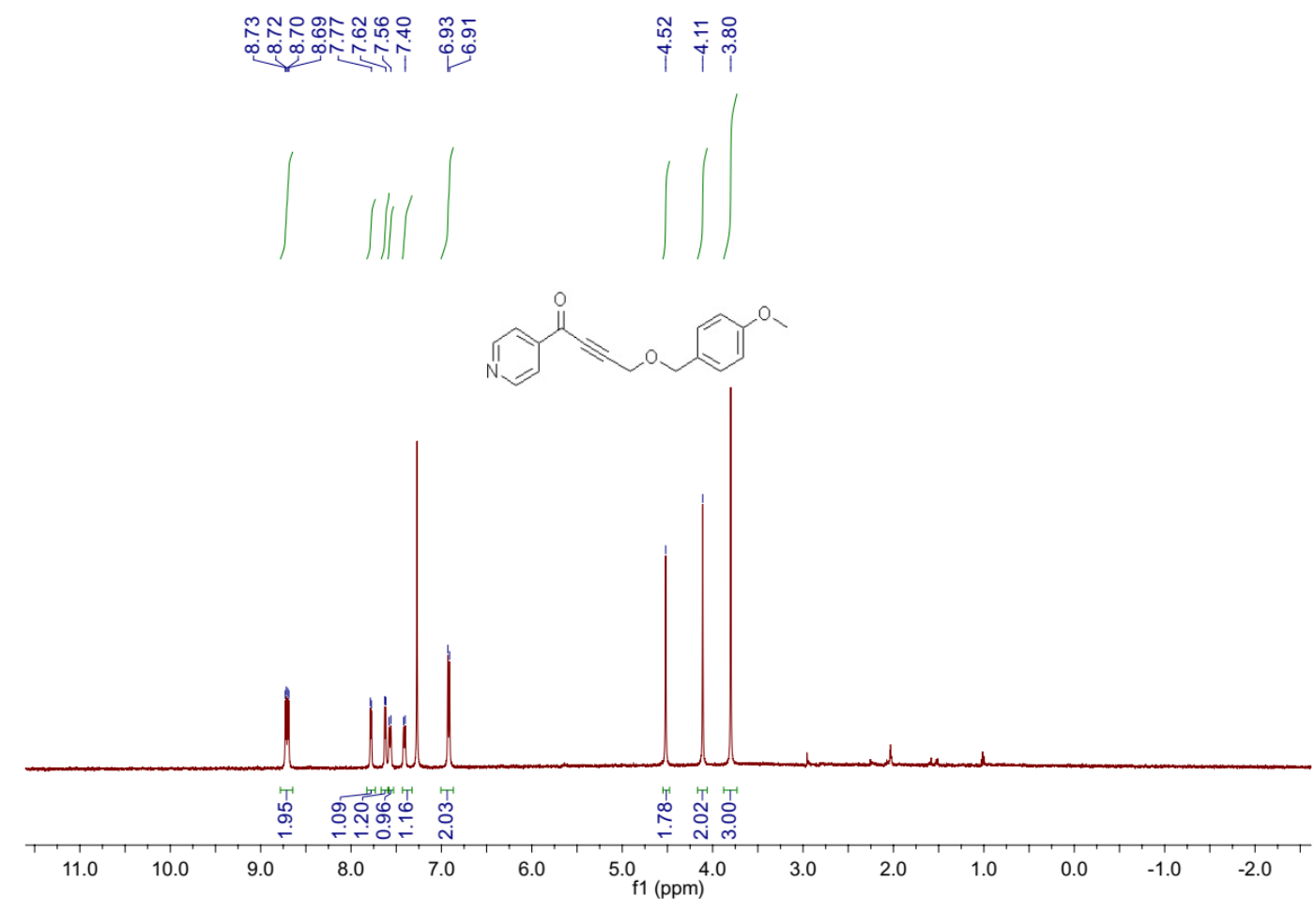

${ }^{1} \mathrm{H}$ NMR Spectrum of Compound 10a (400 $\left.\mathrm{MHz}, \mathrm{CDCl}_{3}\right)$

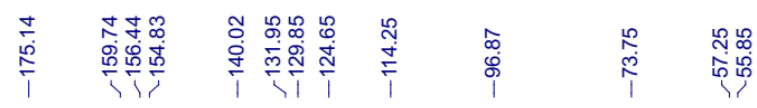
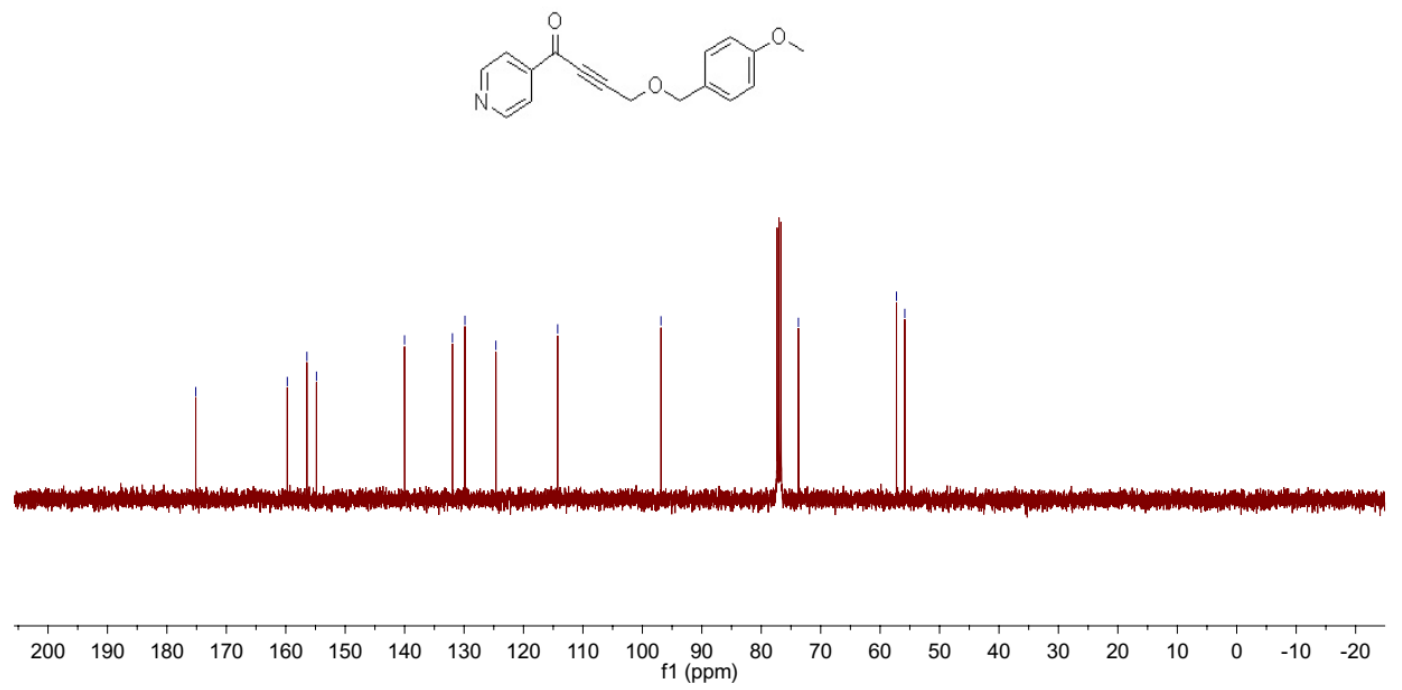

${ }^{13} \mathrm{C}\left\{{ }^{1} \mathrm{H}\right\}$ NMR Spectrum of Compound $10 \mathrm{a}\left(100 \mathrm{MHz}, \mathrm{CDCl}_{3}\right)$ 


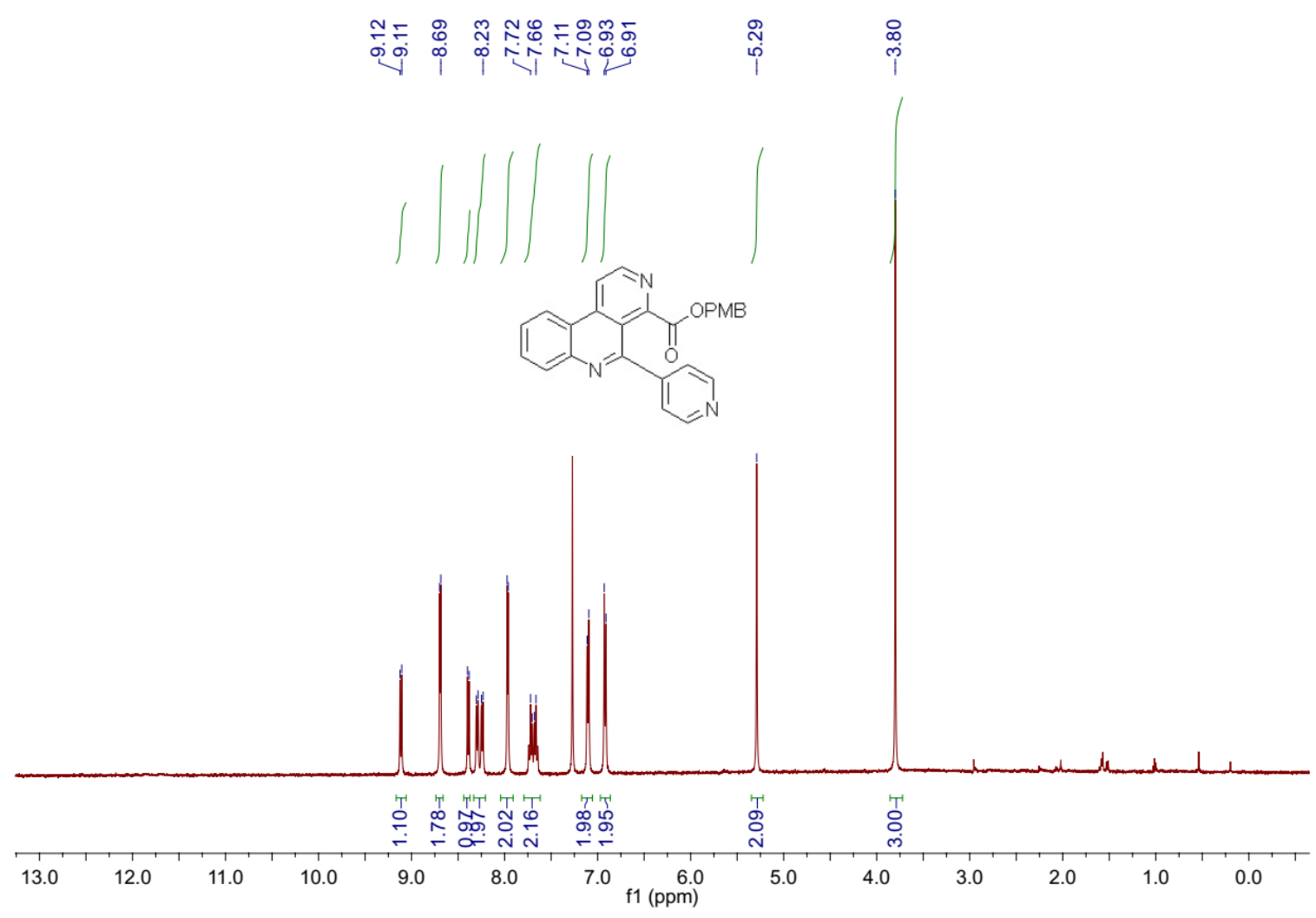

${ }^{1} \mathrm{H}$ NMR Spectrum of Compound $11 \mathrm{a}\left(400 \mathrm{MHz}, \mathrm{CDCl}_{3}\right)$

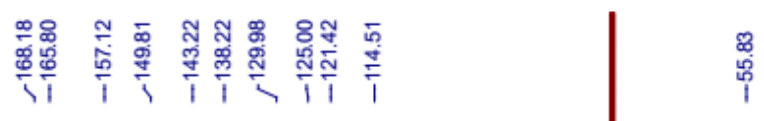
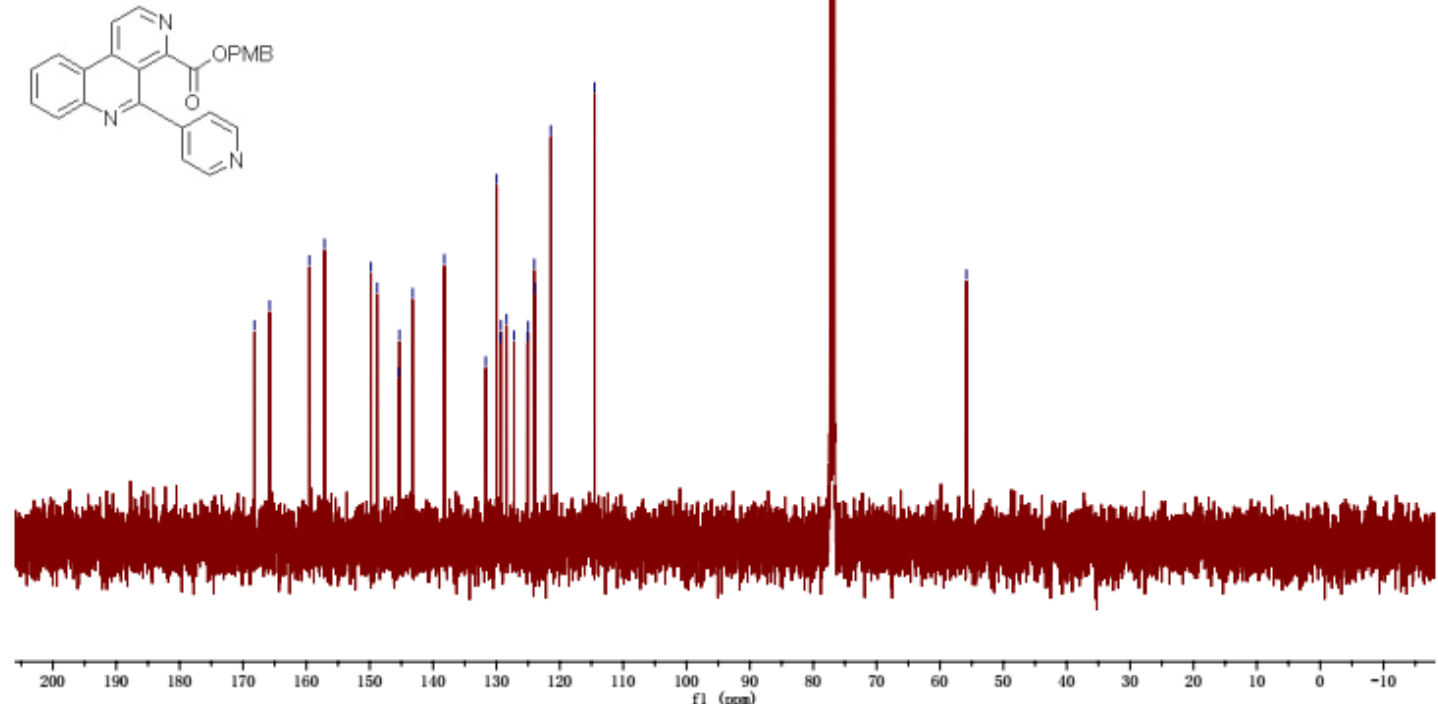

${ }^{13} \mathrm{C}\left\{{ }^{1} \mathrm{H}\right\}$ NMR Spectrum of Compound 11a $\left(100 \mathrm{MHz}, \mathrm{CDCl}_{3}\right)$ 


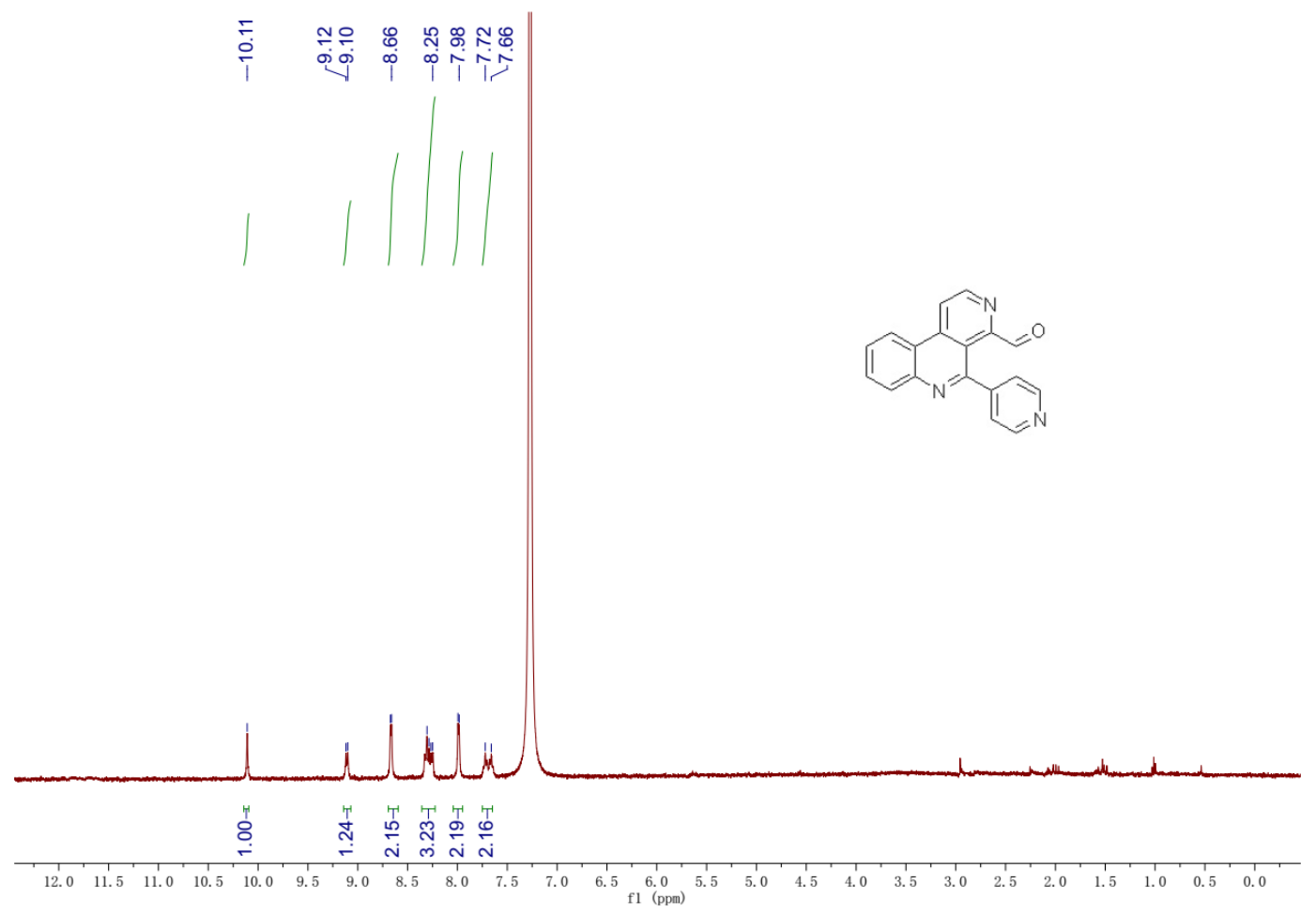

${ }^{1} \mathrm{H}$ NMR Spectrum of Compound 12a $\left(400 \mathrm{MHz}, \mathrm{CDCl}_{3}\right)$

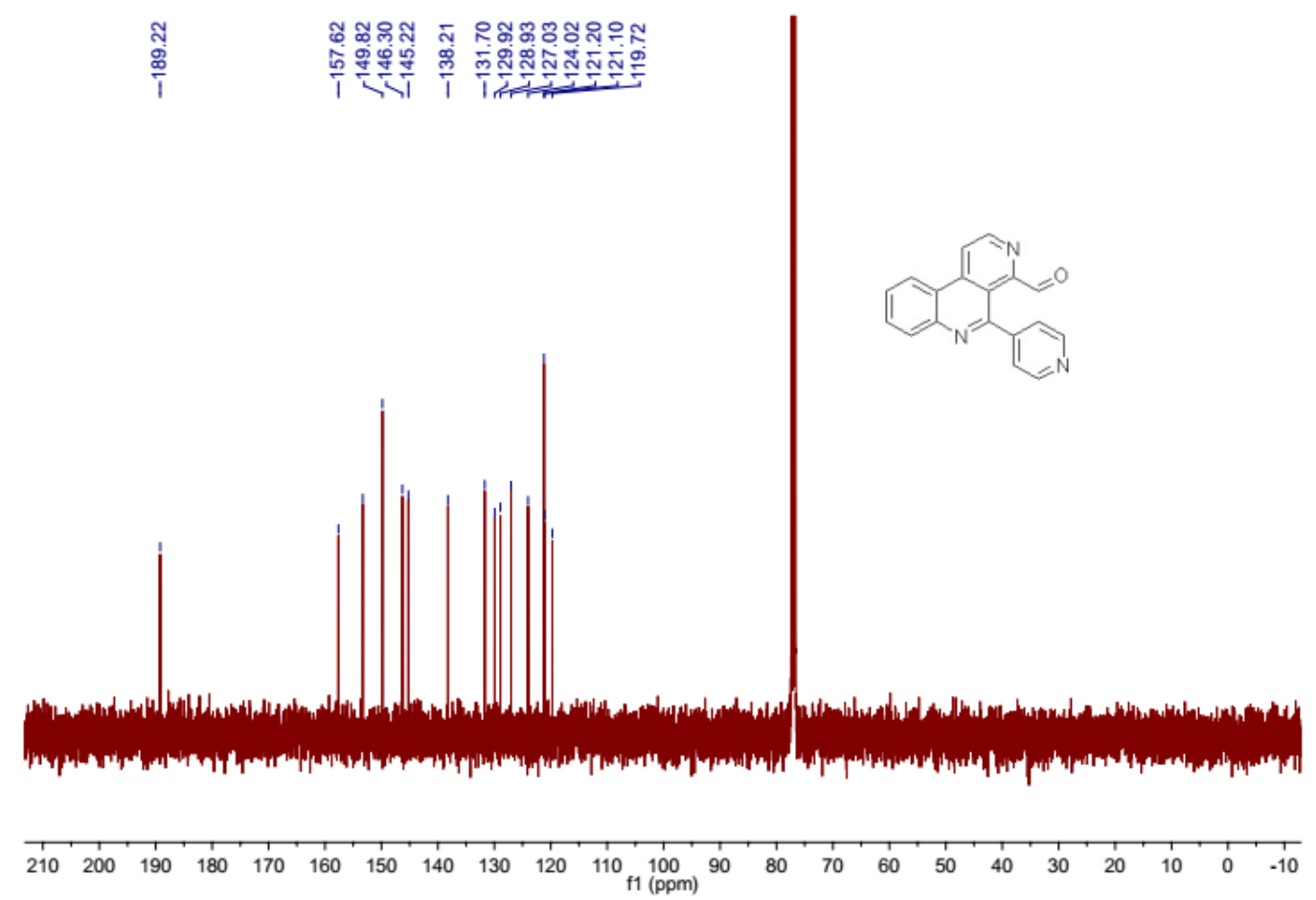

${ }^{13} \mathrm{C}\left\{{ }^{1} \mathrm{H}\right\}$ NMR Spectrum of Compound 12a $\left(100 \mathrm{MHz}, \mathrm{CDCl}_{3}\right)$ 


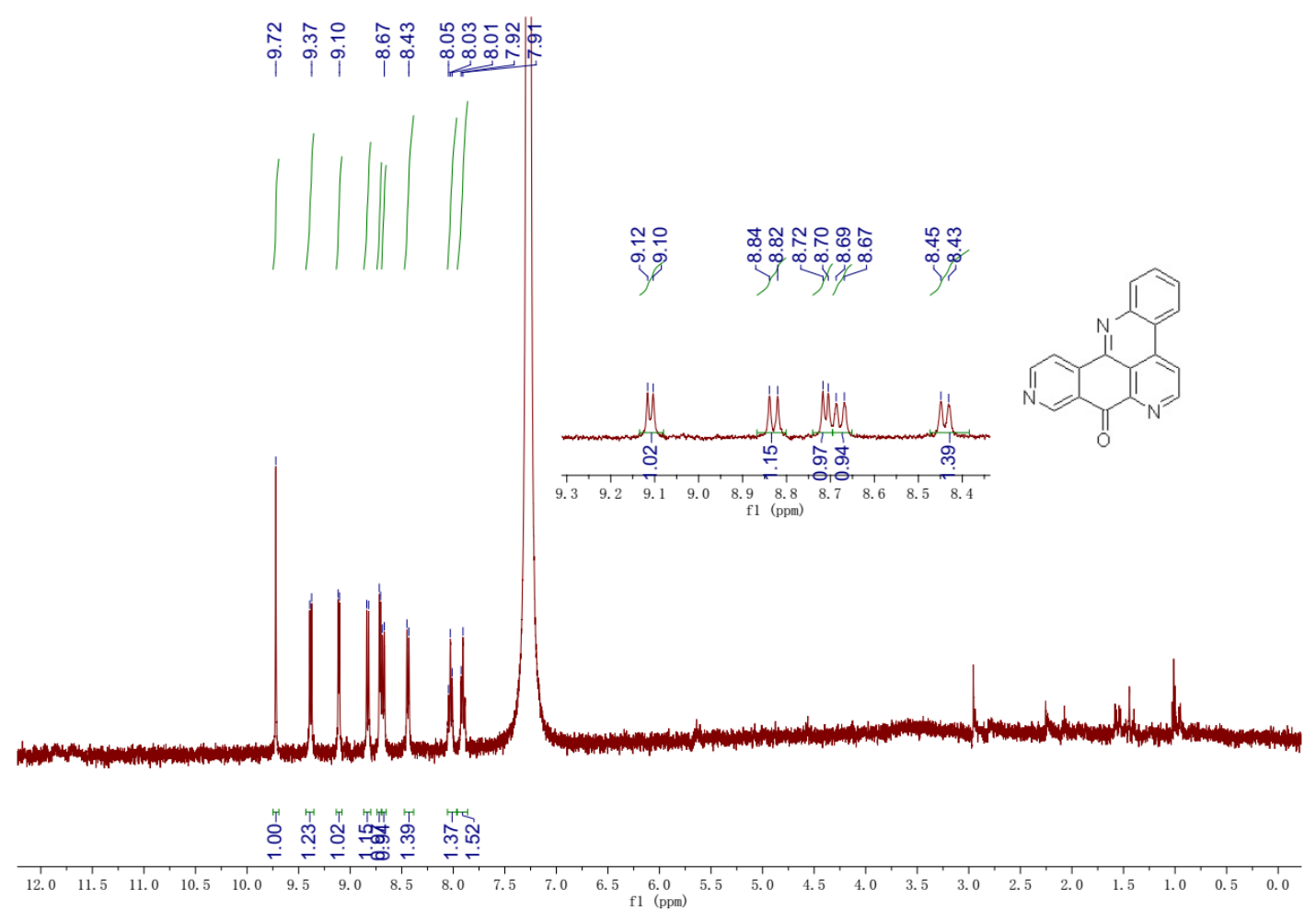

${ }^{1} \mathrm{H}$ NMR Spectrum of Demethyldeoxyamphimedine (1) (400 MHz, $\left.\mathrm{CDCl}_{3}\right)$
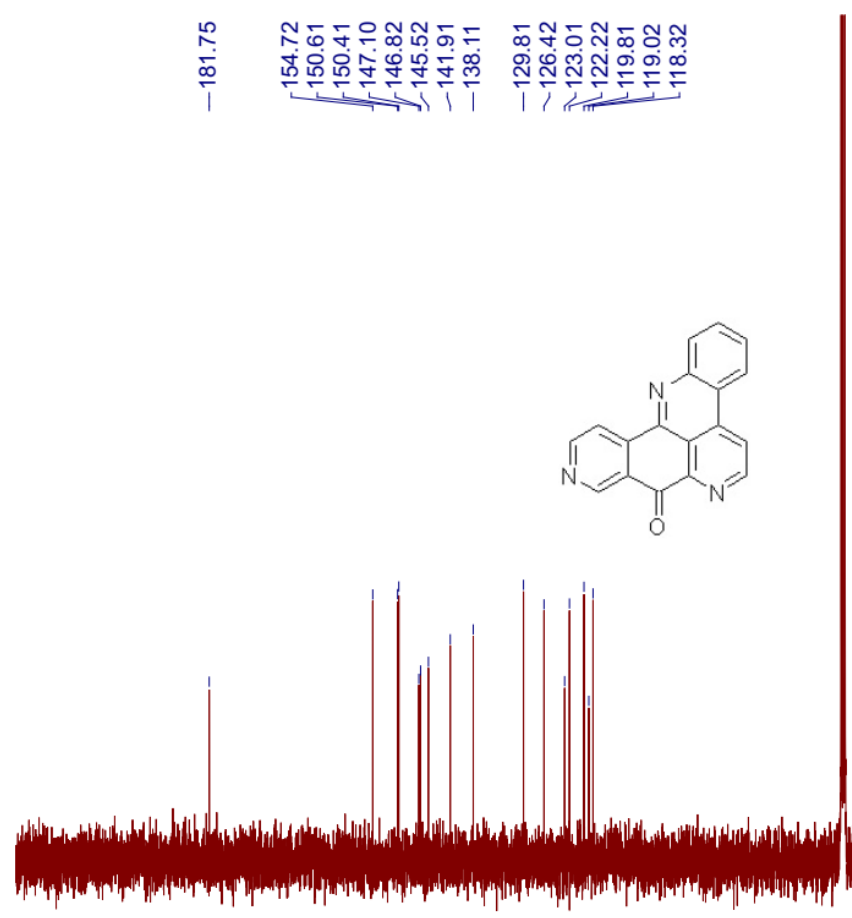

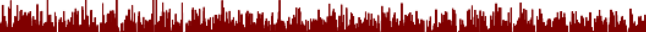

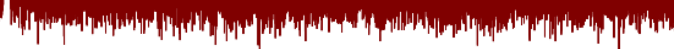

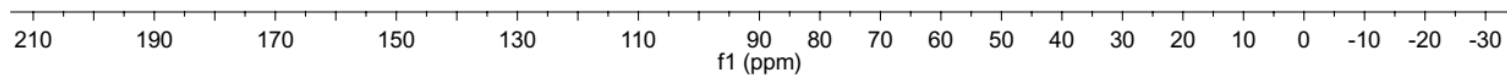

${ }^{13} \mathrm{C}\left\{{ }^{1} \mathrm{H}\right\}$ NMR Spectrum of Demethyldeoxyamphimedine (1) (100 $\left.\mathrm{MHz}, \mathrm{CDCl}_{3}\right)$ 


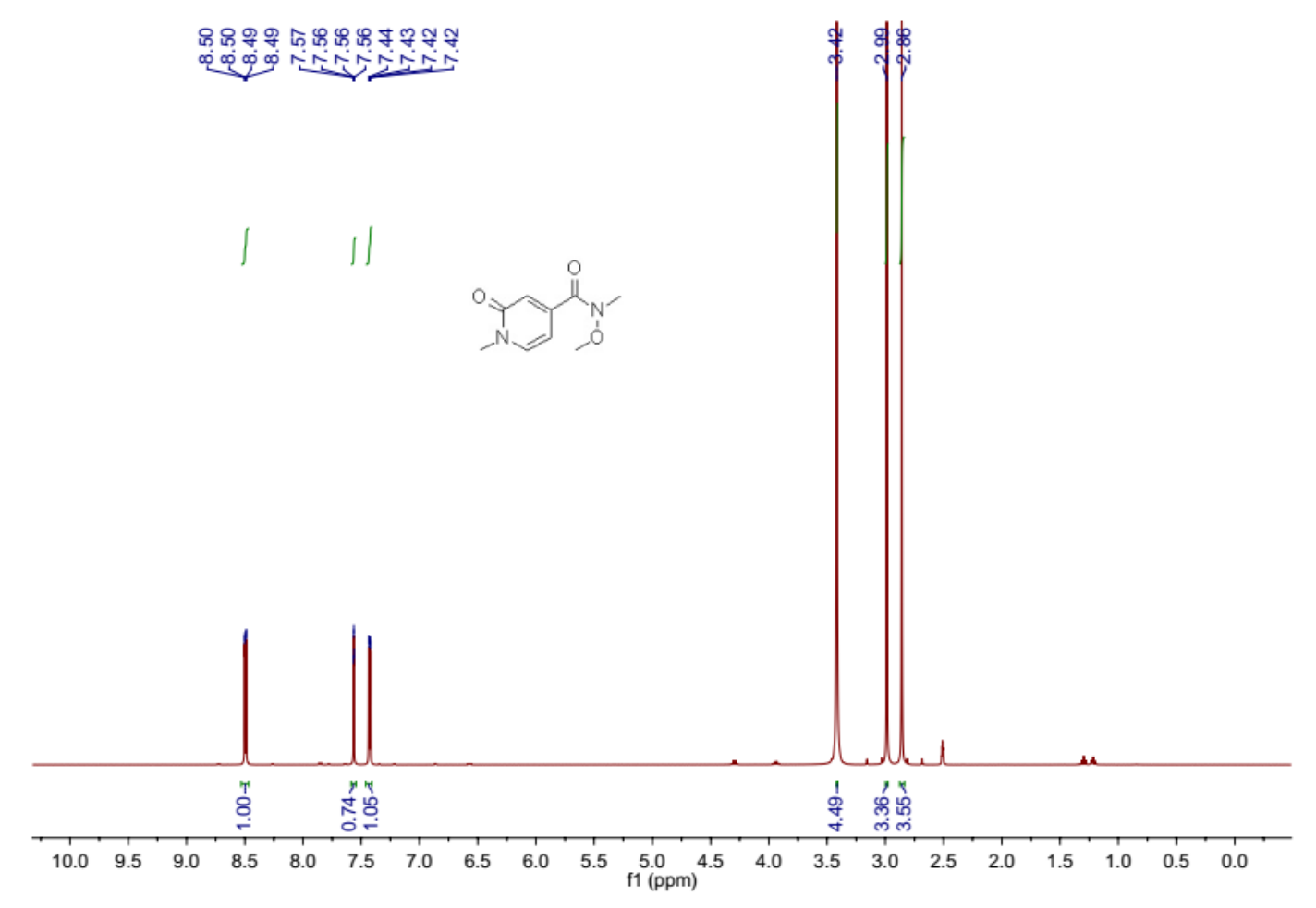

${ }^{1} \mathrm{H}$ NMR Spectrum of $N$-Methoxy- $N$,1-Dimethyl-2-Oxo-1,2-Dihydropyridine-4-Carboxamide (400 MHz, DMSO- $d_{6}$ )

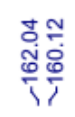

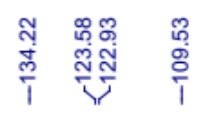

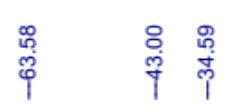
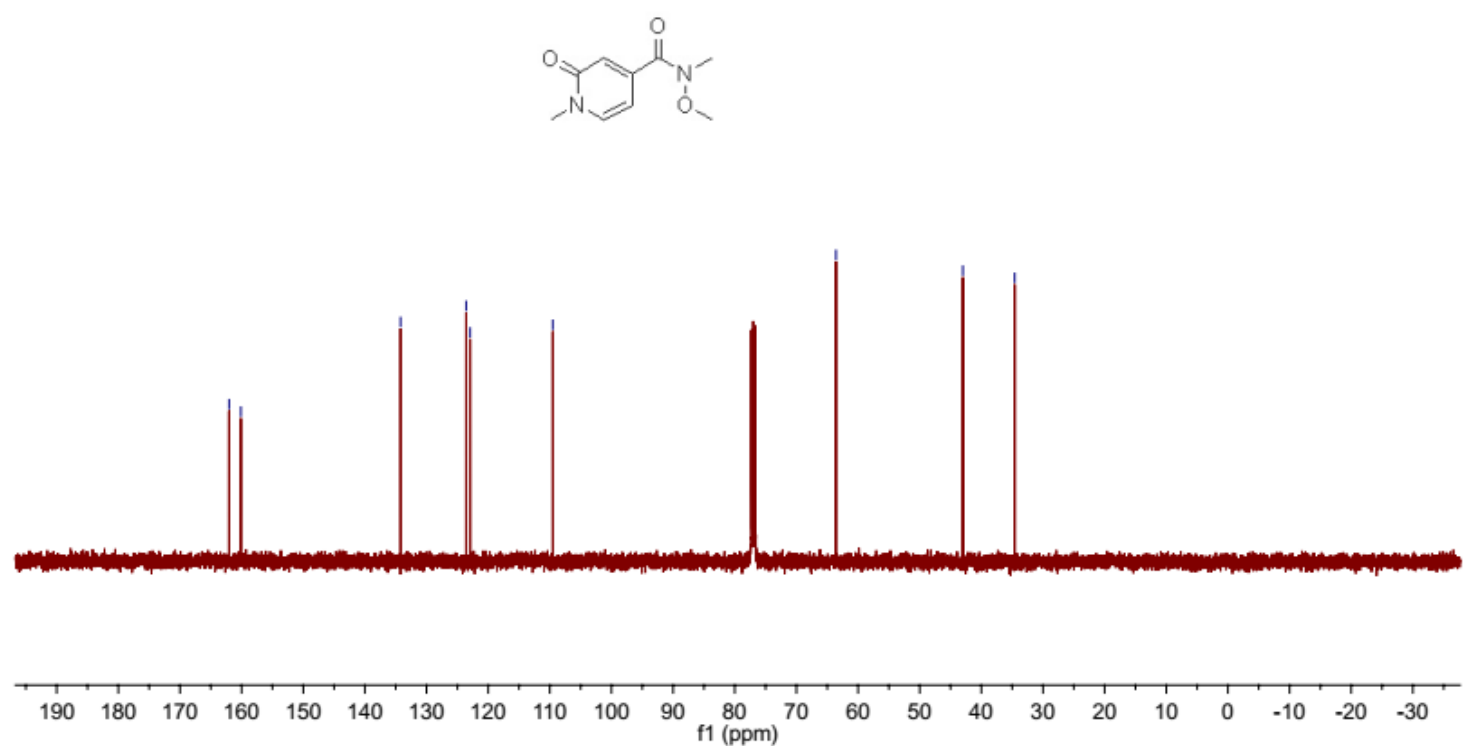

${ }^{13} \mathrm{C}\left\{{ }^{1} \mathrm{H}\right\}$ NMR Spectrum of $N$-Methoxy- $N$,1-Dimethyl-2-Oxo-1,2-Dihydropyridine-4-

Carboxamide (100 MHz, $\left.\mathrm{CDCl}_{3}\right)$ 


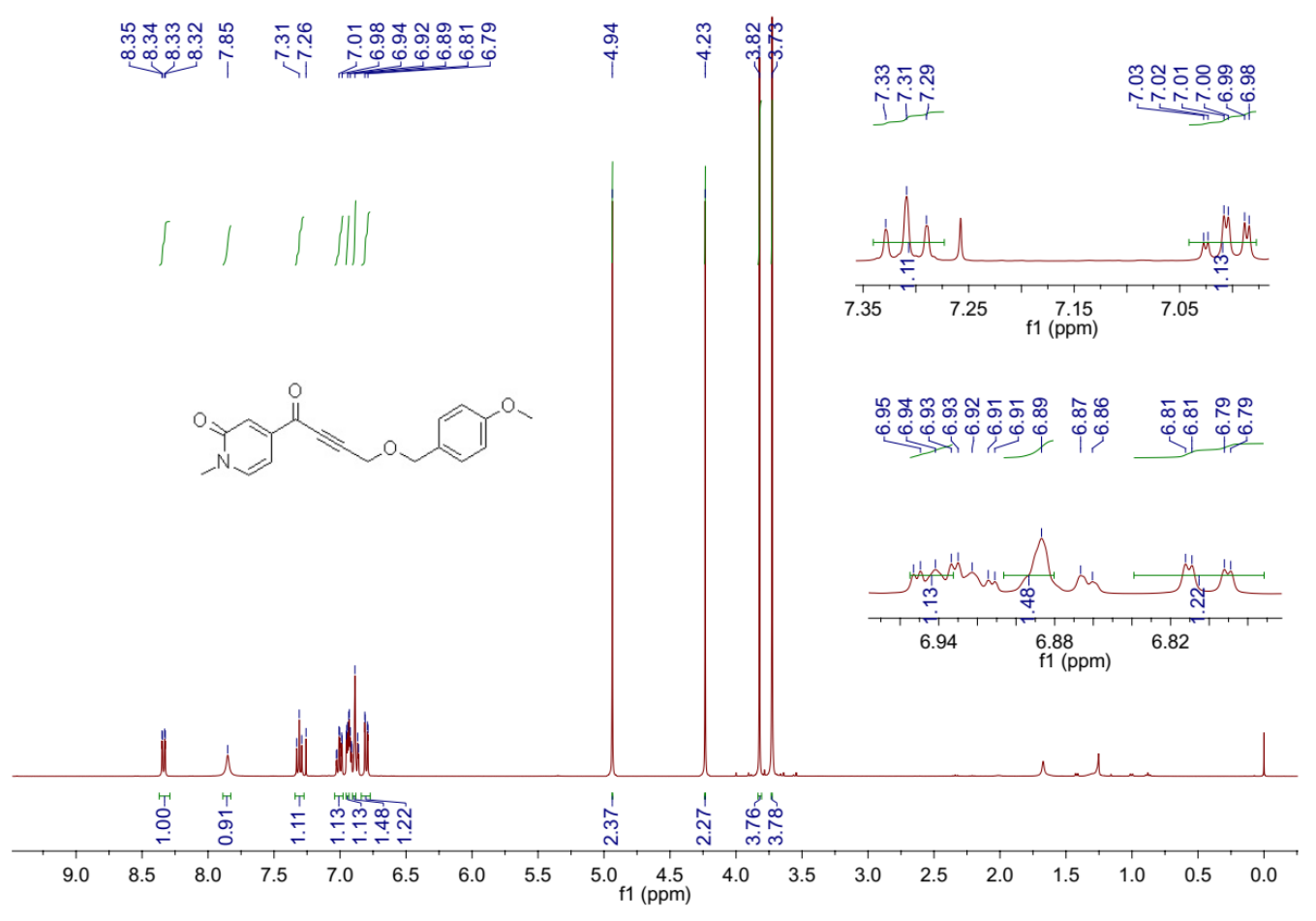

${ }^{1} \mathrm{H}$ NMR Spectrum of Compound $10 \mathrm{~b}\left(400 \mathrm{MHz}, \mathrm{CDCl}_{3}\right)$

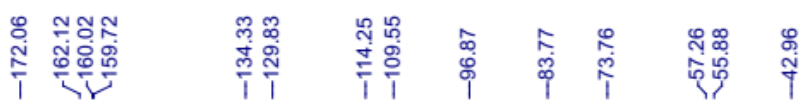
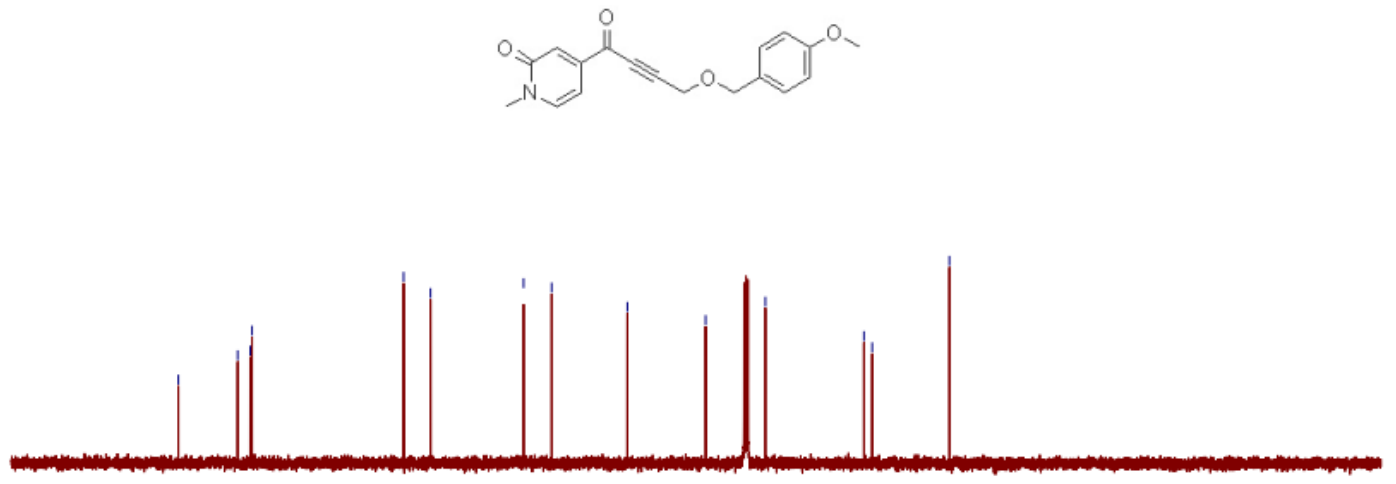

$\begin{array}{llllllllllllllllllllll}90 & 180 & 170 & 160 & 150 & 140 & 130 & 120 & 110 & 100 & \underset{\mathrm{f} 1(\mathrm{ppm})}{80} & 70 & 60 & 50 & 40 & 30 & 20 & 10 & 0 & -10 & -20\end{array}$

${ }^{13} \mathrm{C}\left\{{ }^{1} \mathrm{H}\right\}$ NMR Spectrum of Compound $10 \mathrm{~b}\left(100 \mathrm{MHz}, \mathrm{CDCl}_{3}\right)$ 


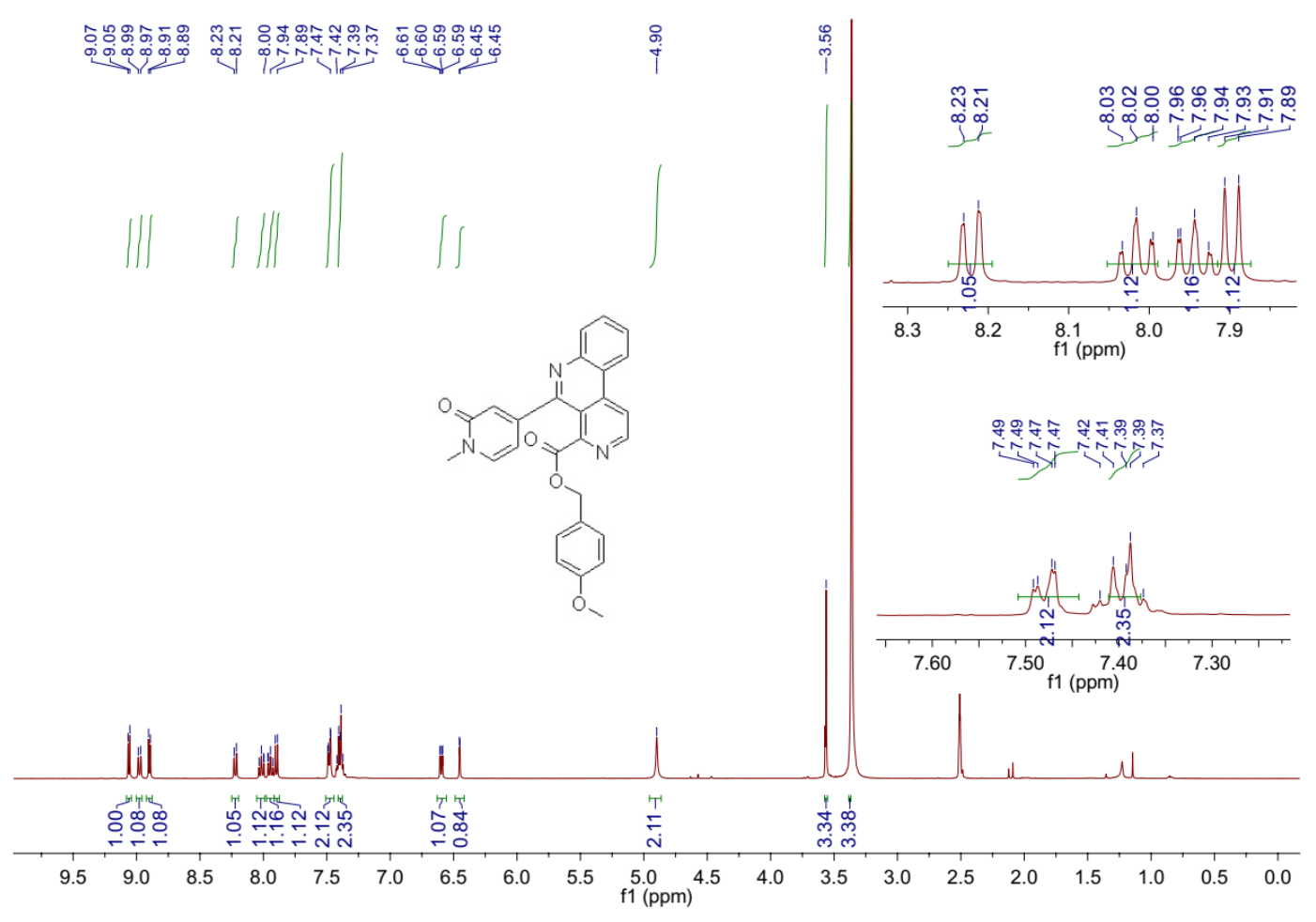

${ }^{1} \mathrm{H}$ NMR Spectrum of Compound $11 \mathrm{~b}\left(400 \mathrm{MHz}, \mathrm{CDCl}_{3}\right)$

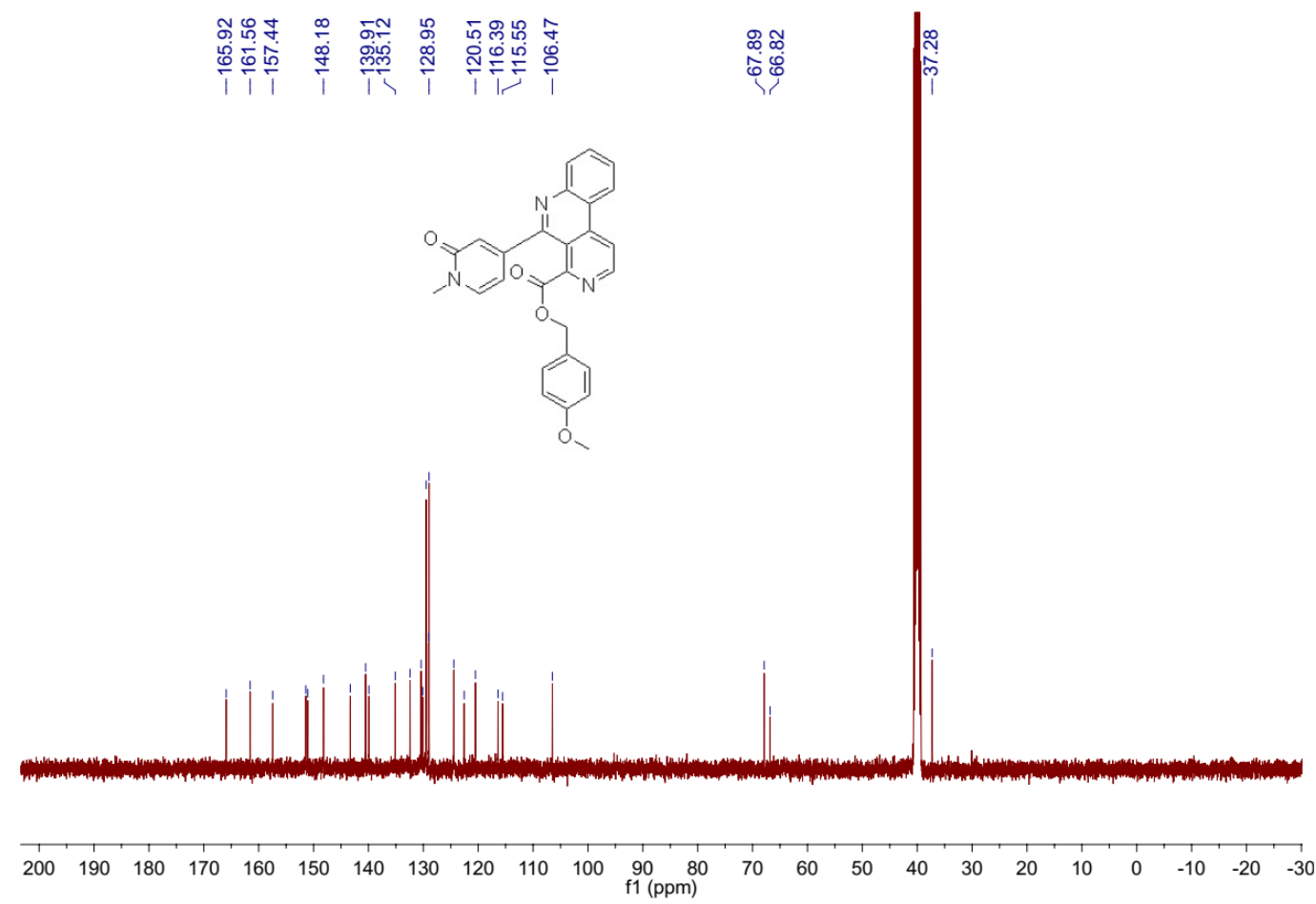

${ }^{13} \mathrm{C}\left\{{ }^{1} \mathrm{H}\right\}$ NMR Spectrum of Compound $11 \mathrm{~b}\left(100 \mathrm{MHz}\right.$, DMSO- $\left.d_{6}\right)$ 


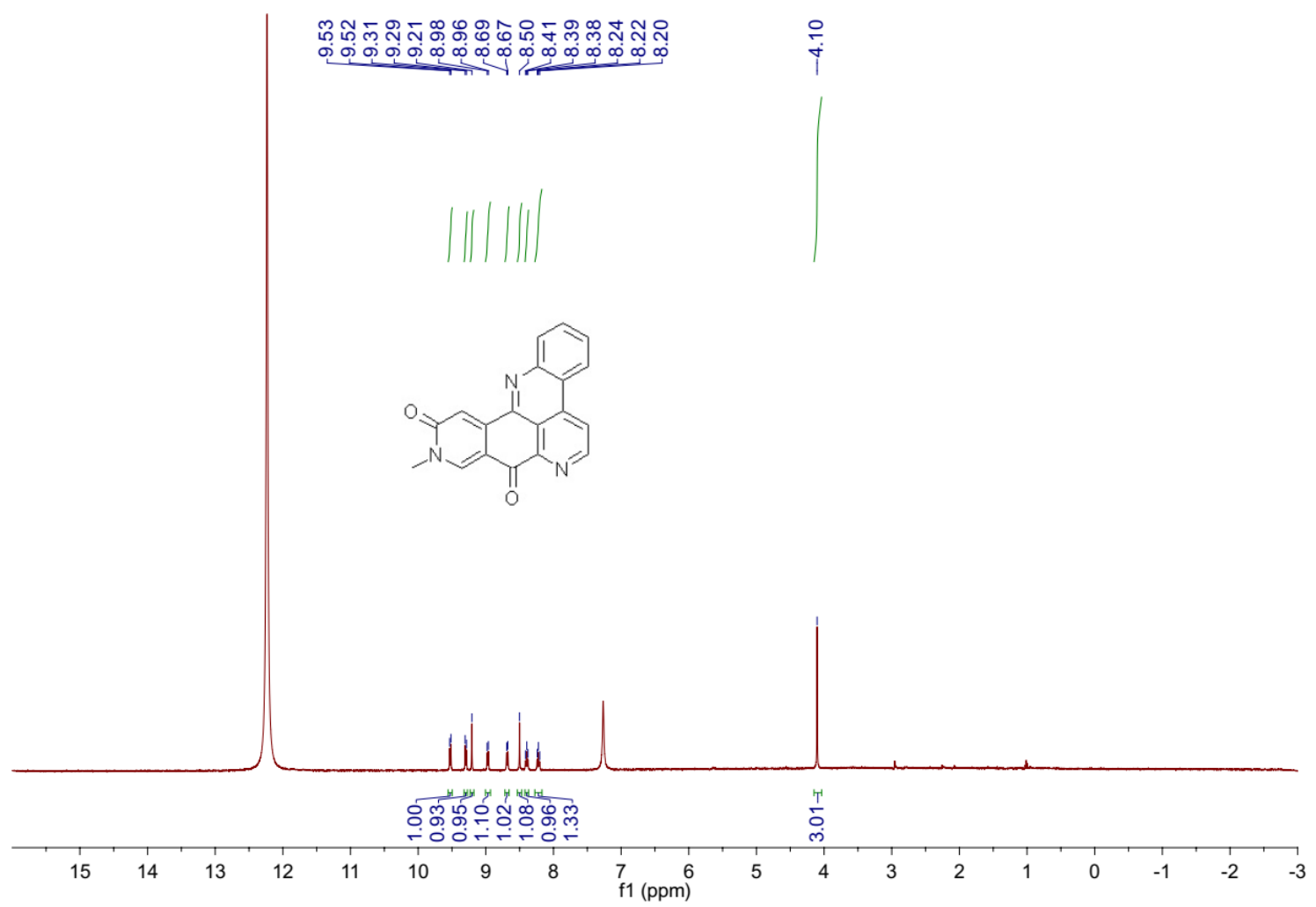

${ }^{1} \mathrm{H}$ NMR Spectrum of Amphimedine (2) $\left(400 \mathrm{MHz}, d-\mathrm{TFA} / \mathrm{CDCl}_{3}=2: 1\right)$

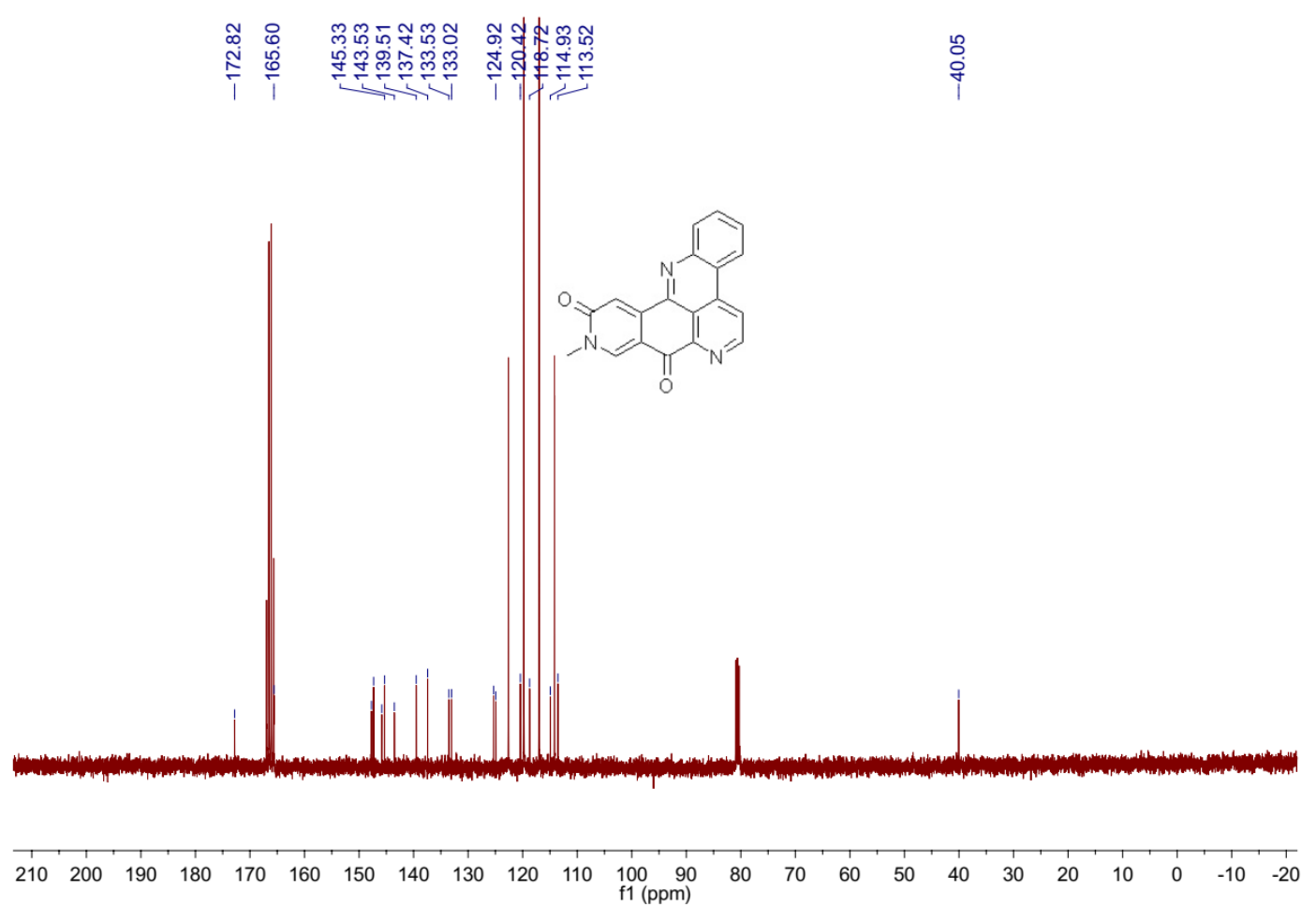

${ }^{13} \mathrm{C}\left\{{ }^{1} \mathrm{H}\right\}$ NMR Spectrum of Amphimedine (2) (100 MHz, $d$-TFA/CDCl $\left.3=2: 1\right)$ 


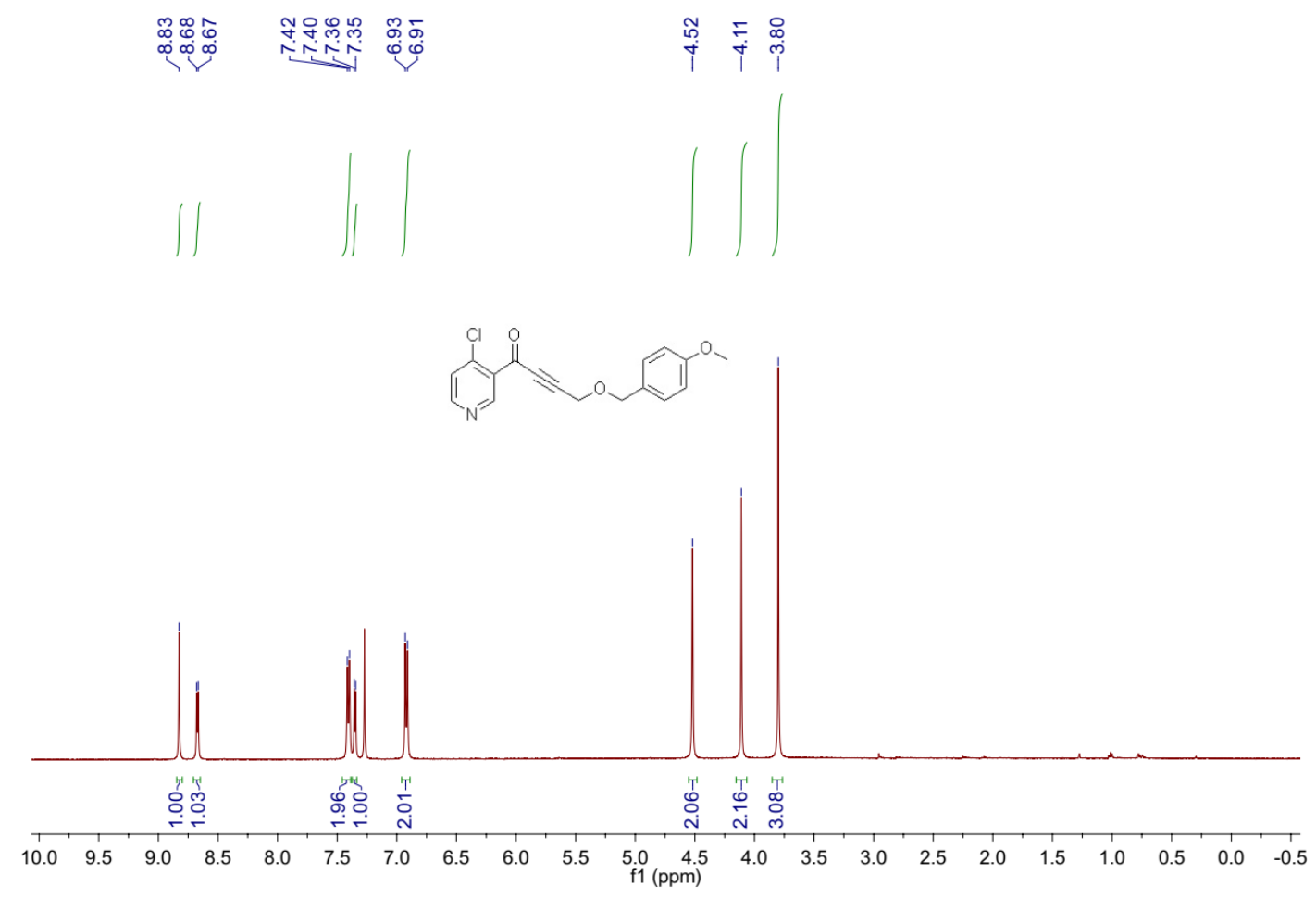

${ }^{1} \mathrm{H}$ NMR Spectrum of Compound $10 \mathrm{c}\left(400 \mathrm{MHz}, \mathrm{CDCl}_{3}\right)$
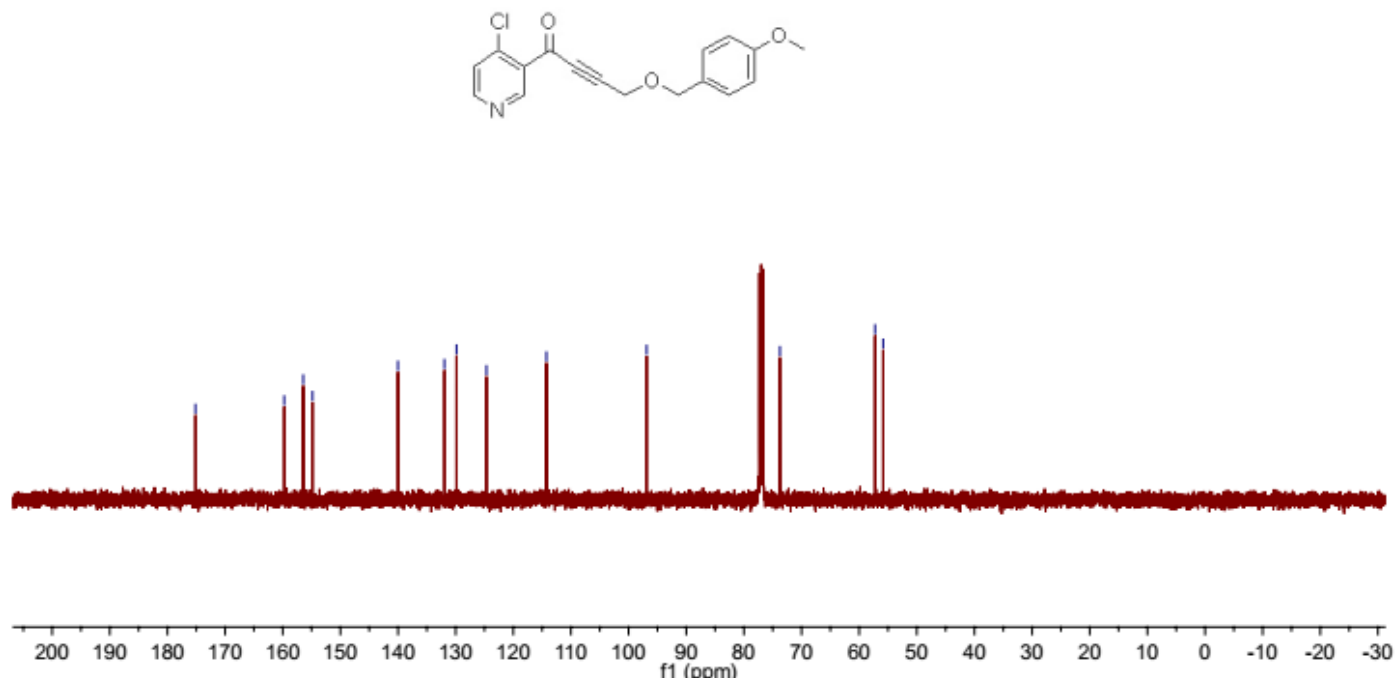

${ }^{13} \mathrm{C}\left\{{ }^{1} \mathrm{H}\right\}$ NMR Spectrum of Compound $10 \mathrm{c}\left(100 \mathrm{MHz}, \mathrm{CDCl}_{3}\right)$ 

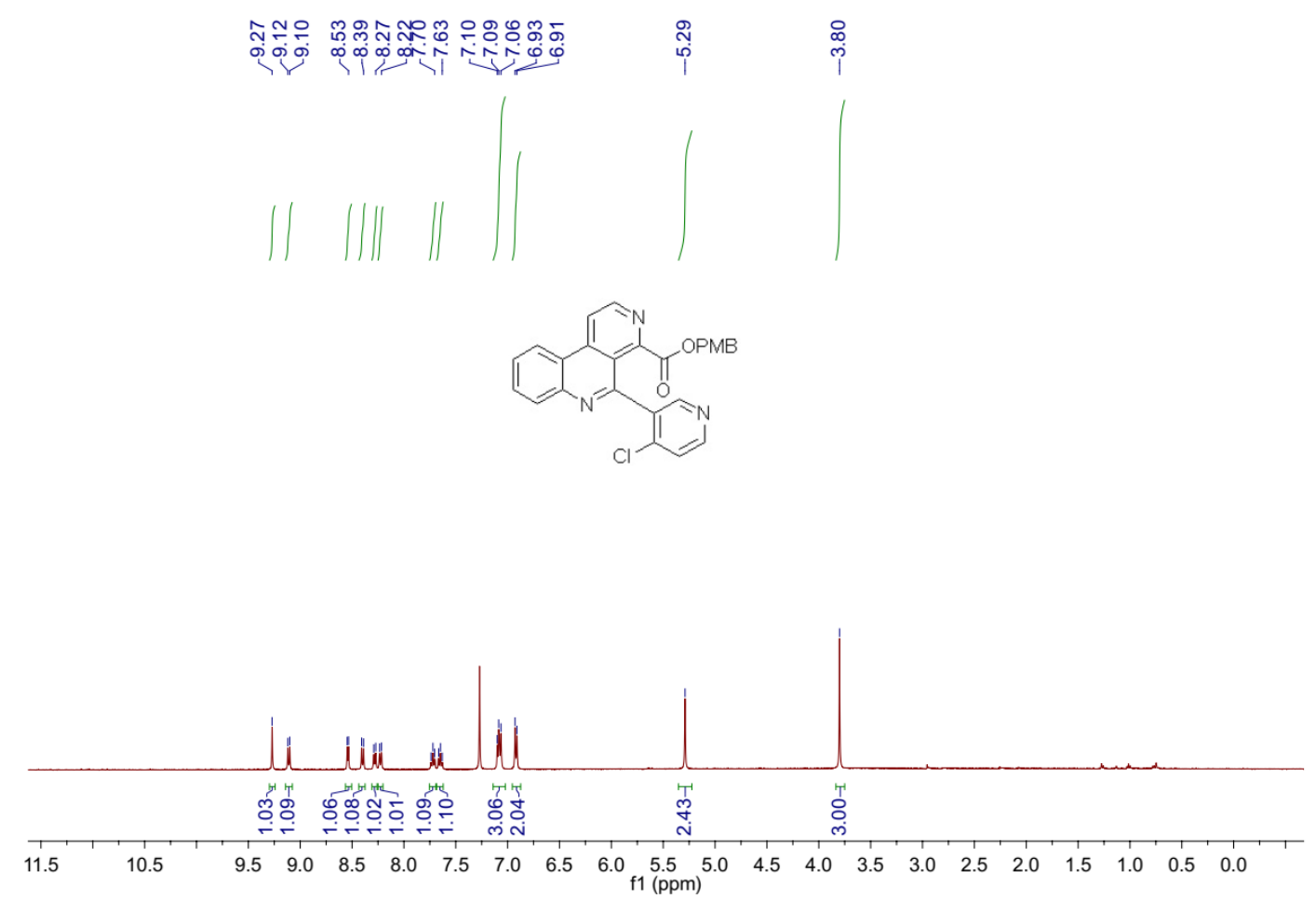

${ }^{1} \mathrm{H}$ NMR Spectrum of Compound $11 \mathrm{c}\left(400 \mathrm{MHz}, \mathrm{CDCl}_{3}\right)$

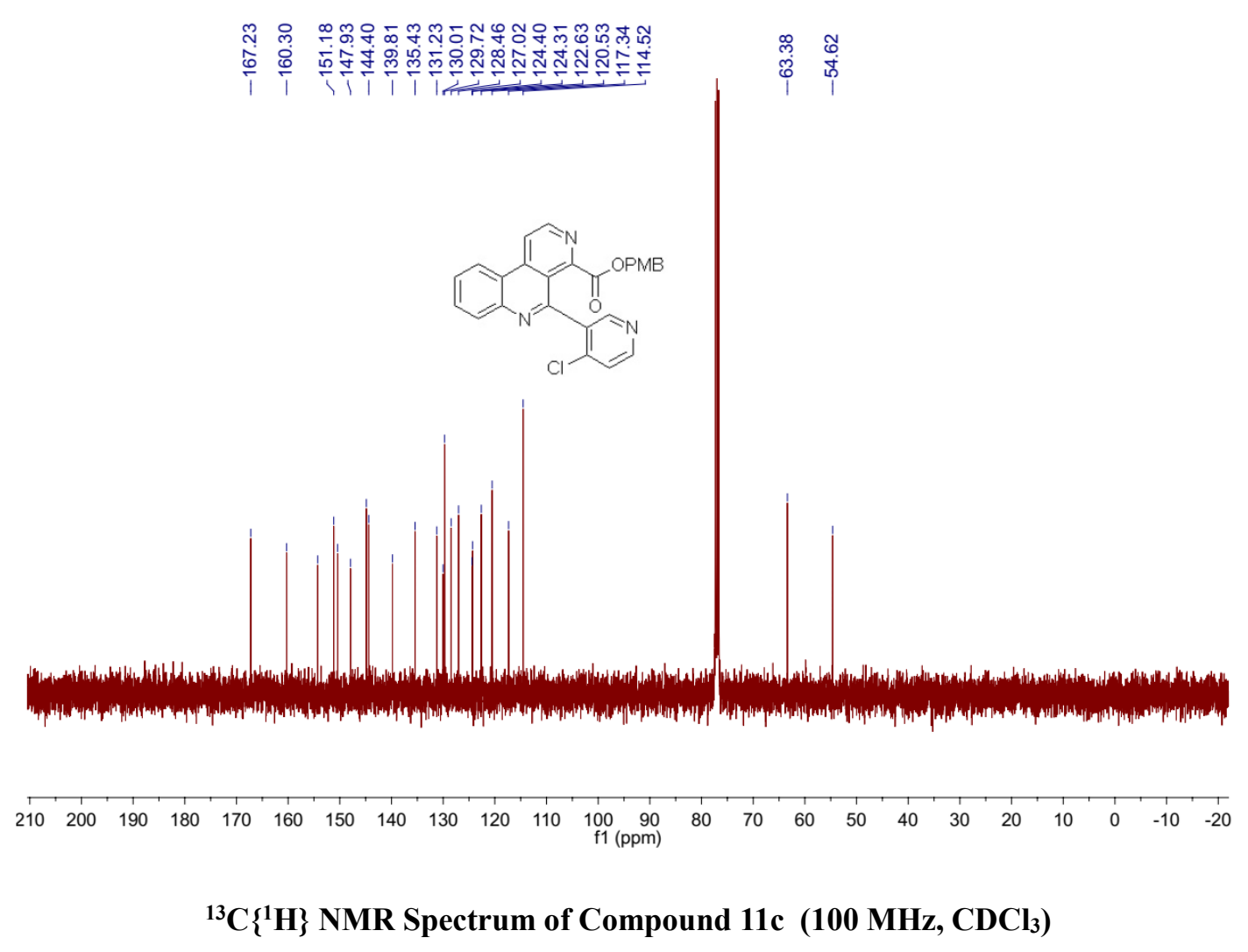




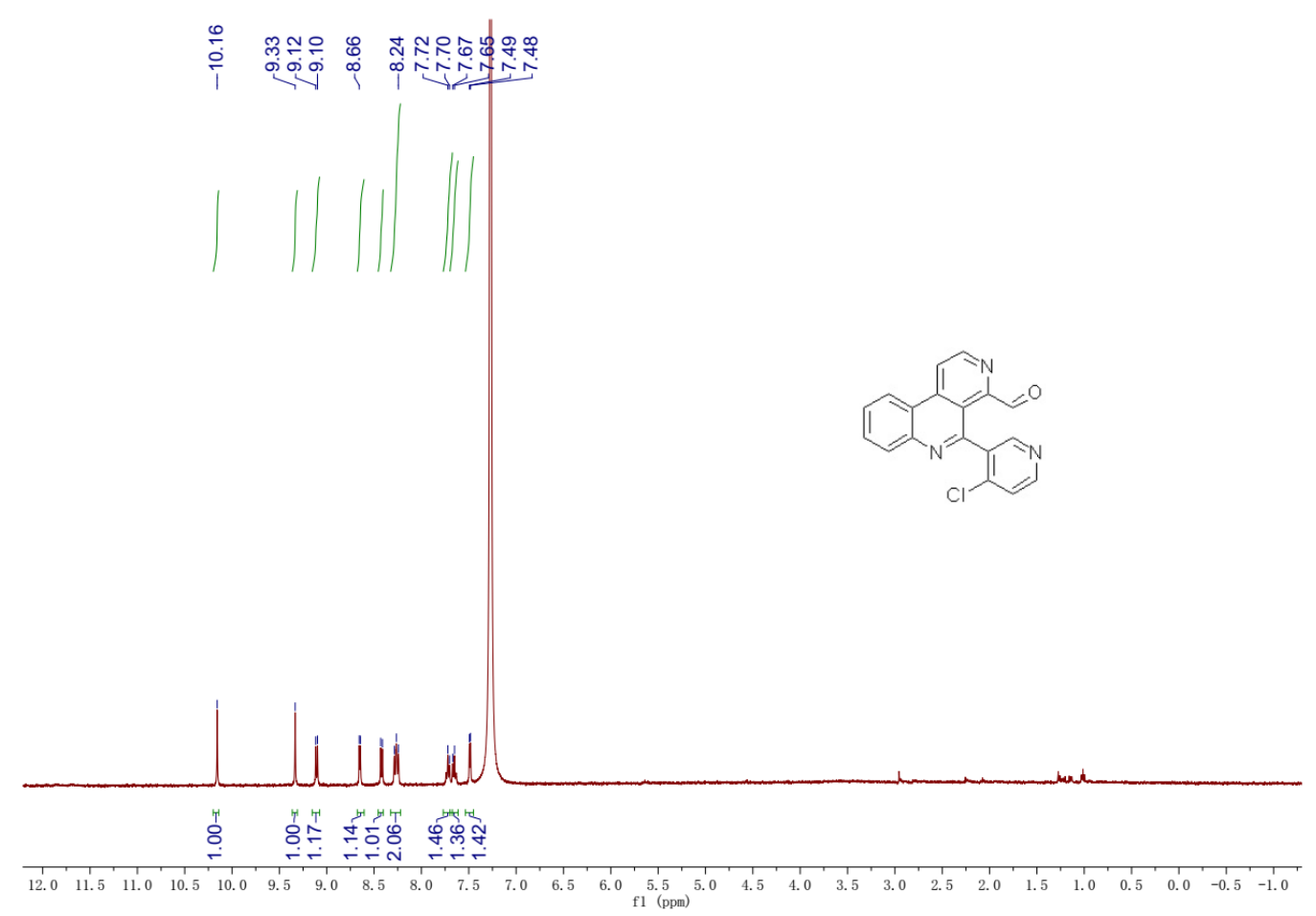

${ }^{1} \mathrm{H}$ NMR Spectrum of Compound $12 \mathrm{c}\left(400 \mathrm{MHz}, \mathrm{CDCl}_{3}\right)$

एా<smiles>O=Cc1ccnc(-c2nc3ccccc3c3ccnc(Cl)c23)c1</smiles>

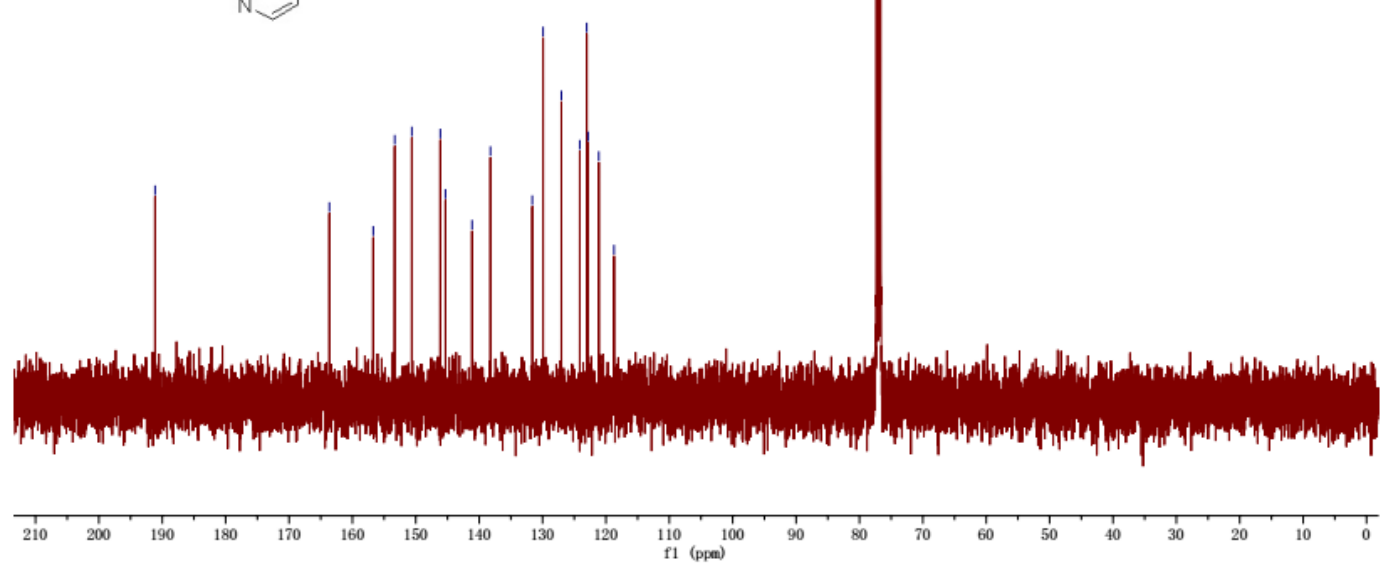

${ }^{13} \mathrm{C}\left\{{ }^{1} \mathrm{H}\right\}$ NMR Spectrum of Compound $12 \mathrm{c}\left(100 \mathrm{MHz}, \mathrm{CDCl}_{3}\right)$ 


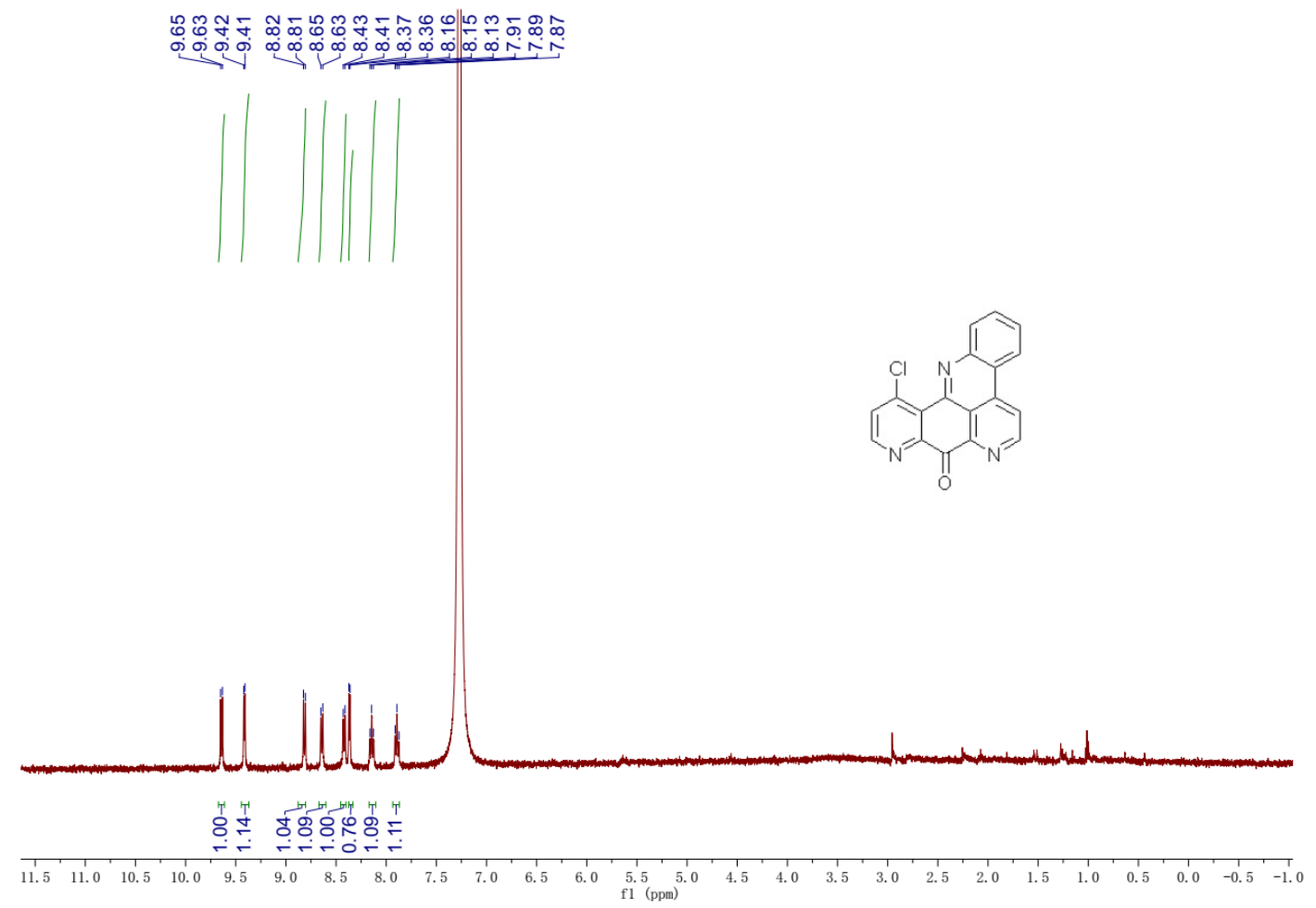

${ }^{1} \mathrm{H}$ NMR Spectrum of Compound 13 (400 $\left.\mathrm{MHz}, \mathrm{CDCl}_{3}\right)$
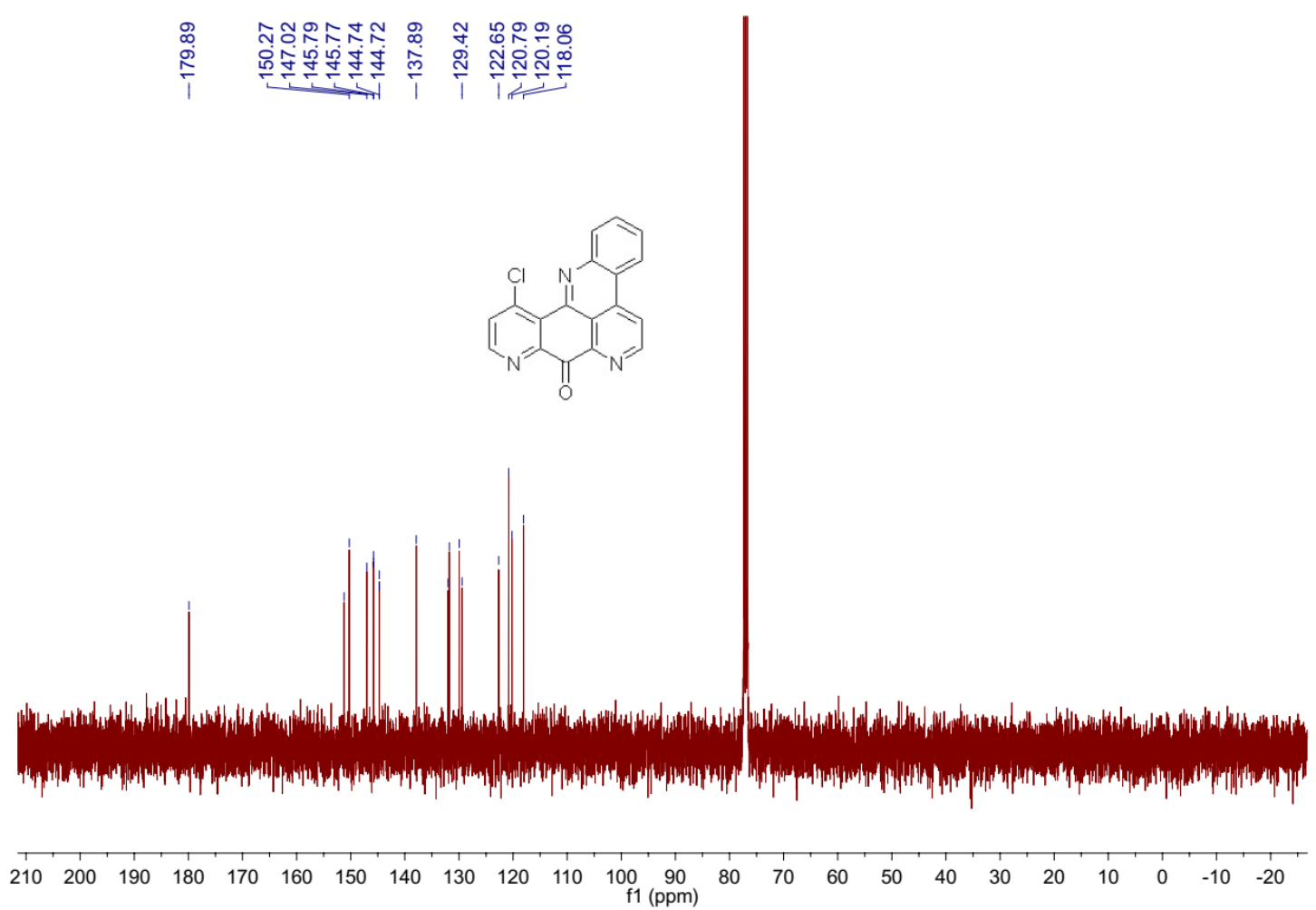

${ }^{13} \mathrm{C}\left\{{ }^{1} \mathrm{H}\right\}$ NMR Spectrum of Compound $13\left(100 \mathrm{MHz}, \mathrm{CDCl}_{3}\right)$ 


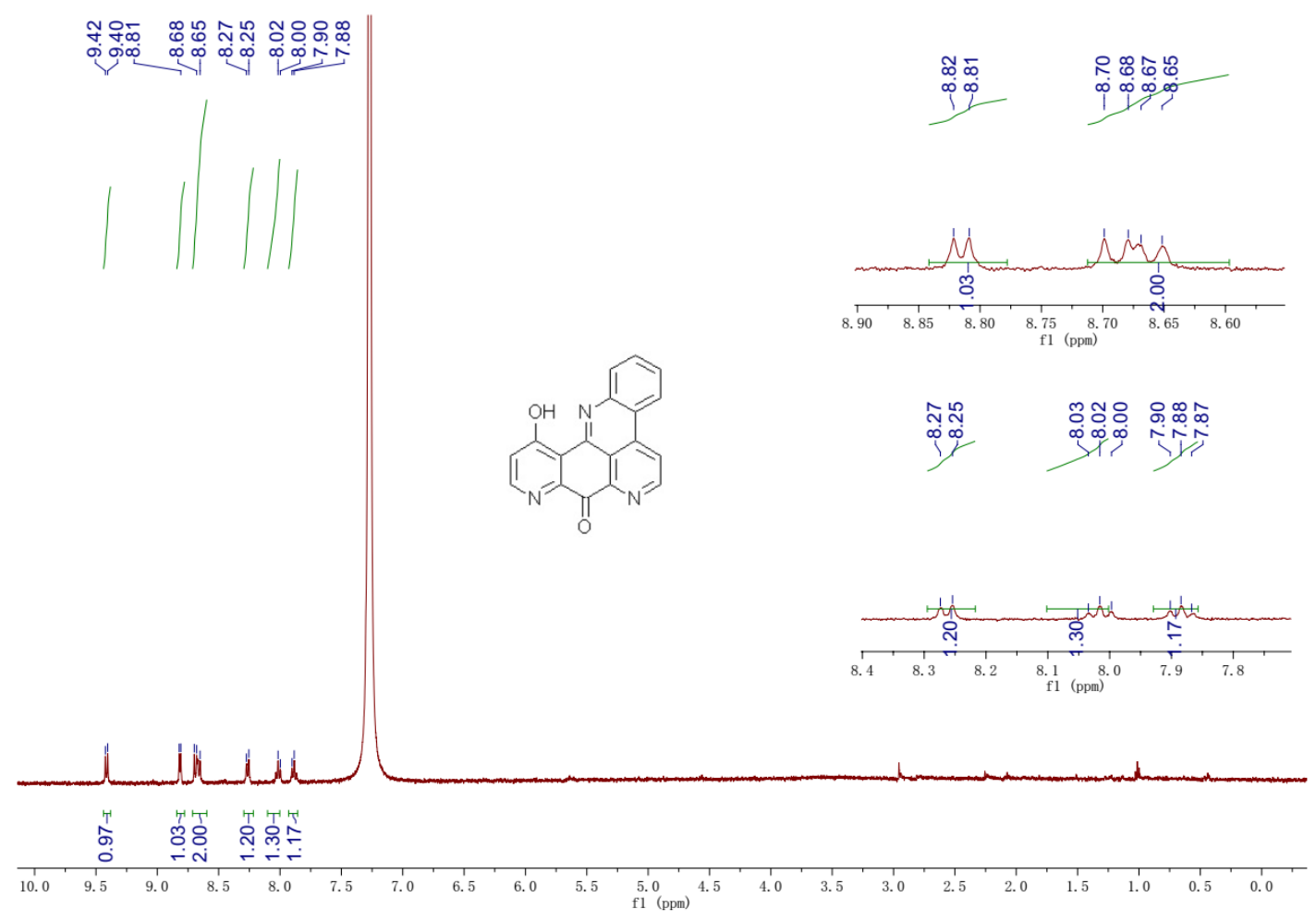

${ }^{1} \mathrm{H}$ NMR Spectrum of Meridine (3) (400 $\left.\mathrm{MHz}, \mathrm{CDCl}_{3}\right)$

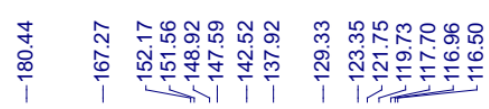
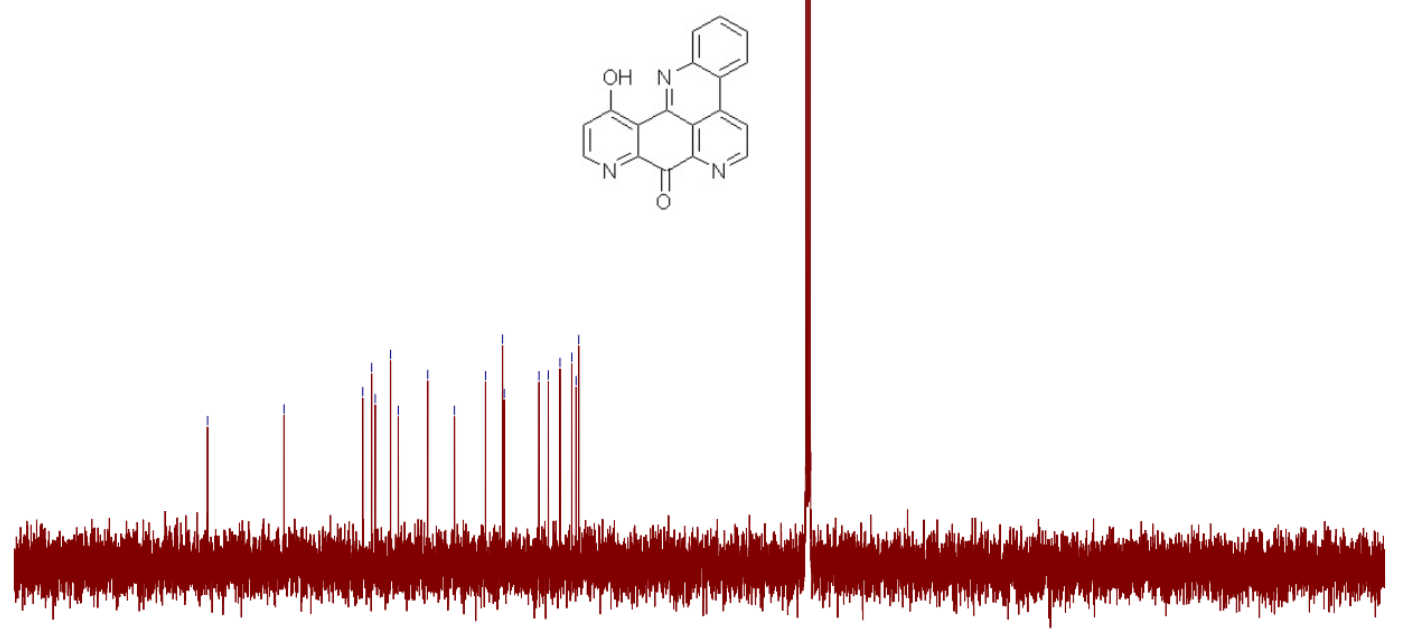

$\begin{array}{lllllllllllllllllllllll}210 & 200 & 190 & 180 & 170 & 160 & 150 & 140 & 130 & 120 & 110 & \begin{array}{l}100 \\ \mathrm{f} 1(\mathrm{ppm})\end{array} & 80 & 70 & 60 & 50 & 40 & 30 & 20 & 10 & 0 & -10 & -20\end{array}$

${ }^{13} \mathrm{C}\left\{{ }^{1} \mathrm{H}\right\}$ NMR Spectrum of Meridine (3) (100 $\left.\mathrm{MHz}, \mathrm{CDCl}_{3}\right)$ 


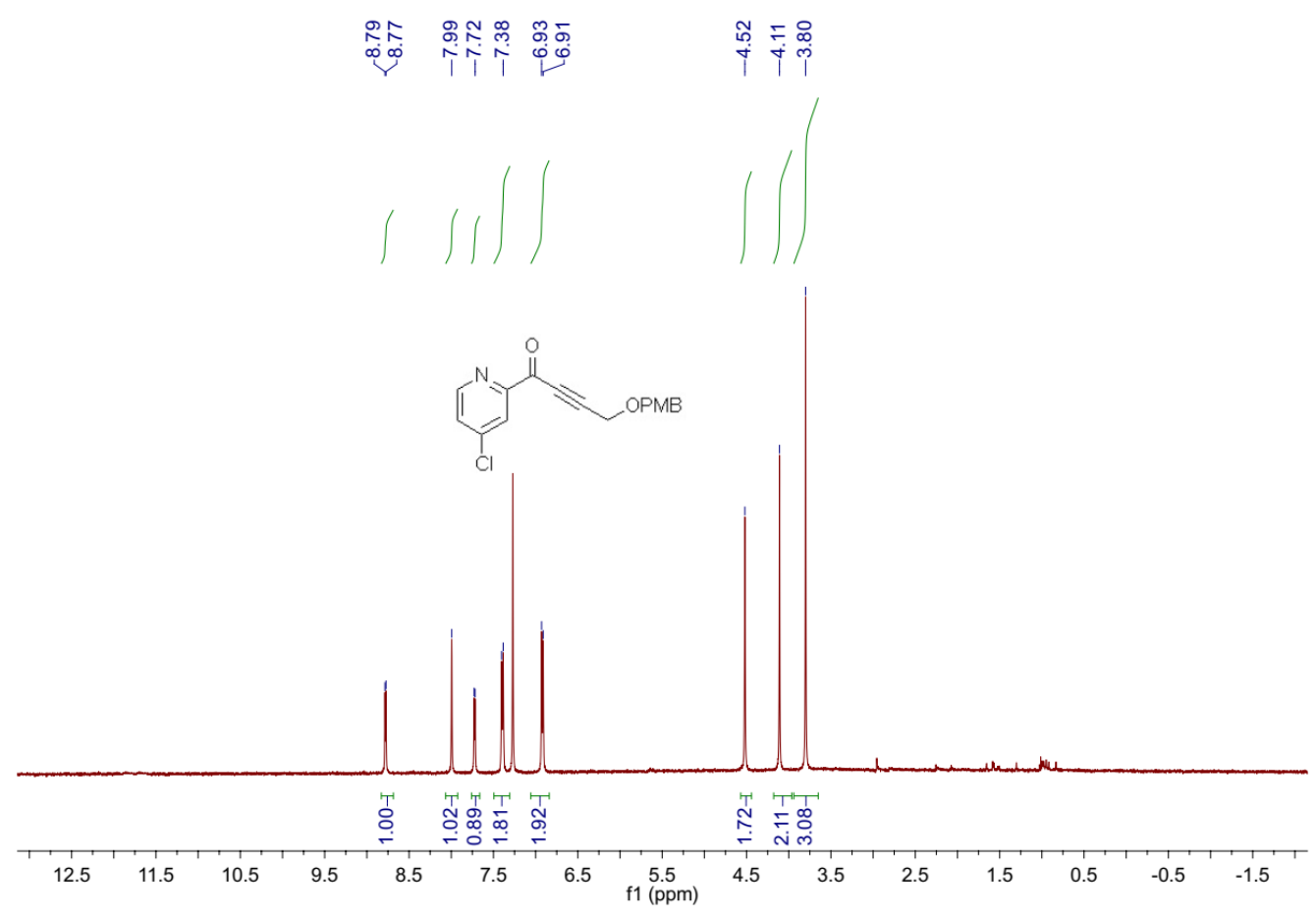

${ }^{1} \mathrm{H}$ NMR Spectrum of Compound $10 \mathrm{~d}\left(400 \mathrm{MHz}, \mathrm{CDCl}_{3}\right)$

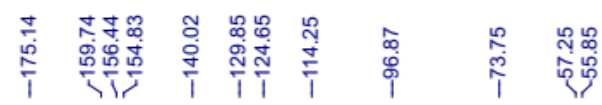
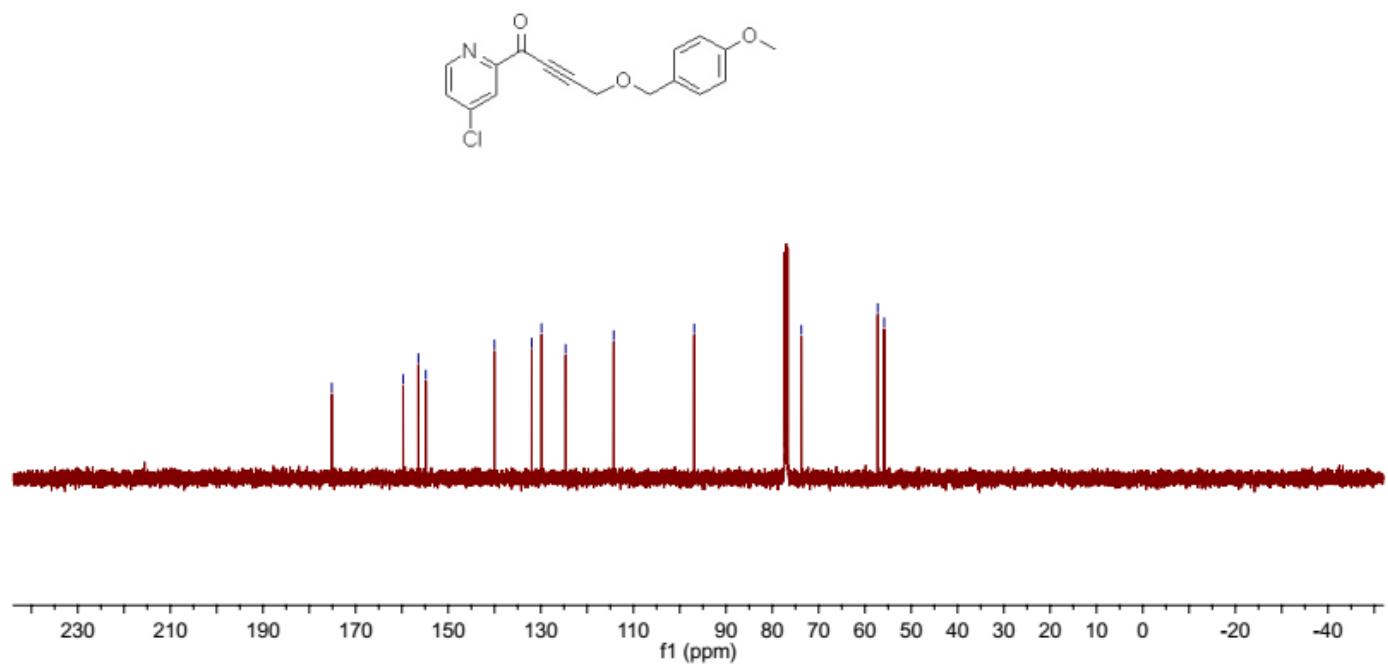

${ }^{13} \mathrm{C}\left\{{ }^{1} \mathrm{H}\right\}$ NMR Spectrum of Compound $10 d\left(100 \mathrm{MHz}, \mathrm{CDCl}_{3}\right)$ 


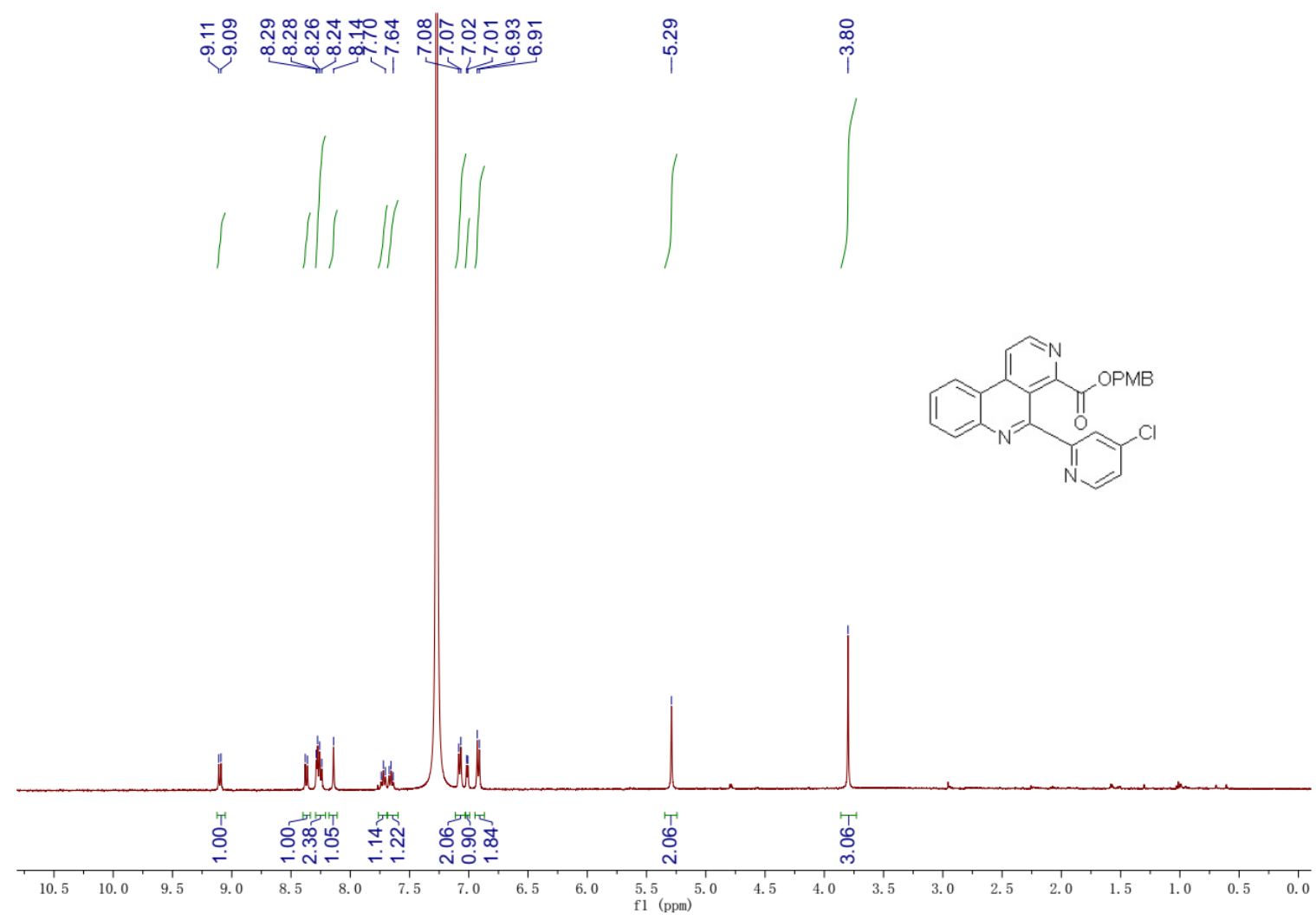

${ }^{1} \mathrm{H}$ NMR Spectrum of Compound $11 \mathrm{~d}\left(400 \mathrm{MHz}, \mathrm{CDCl}_{3}\right)$

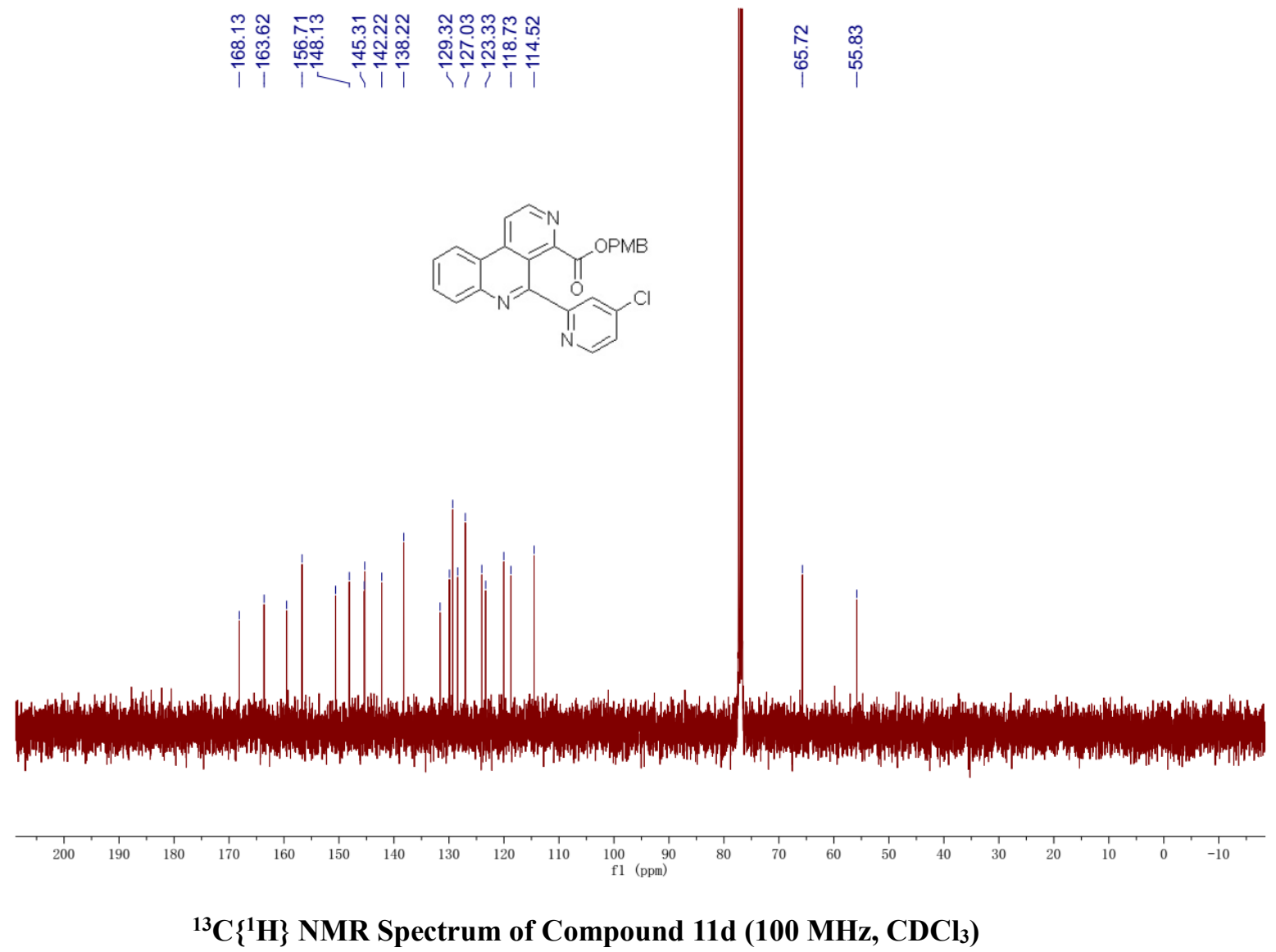




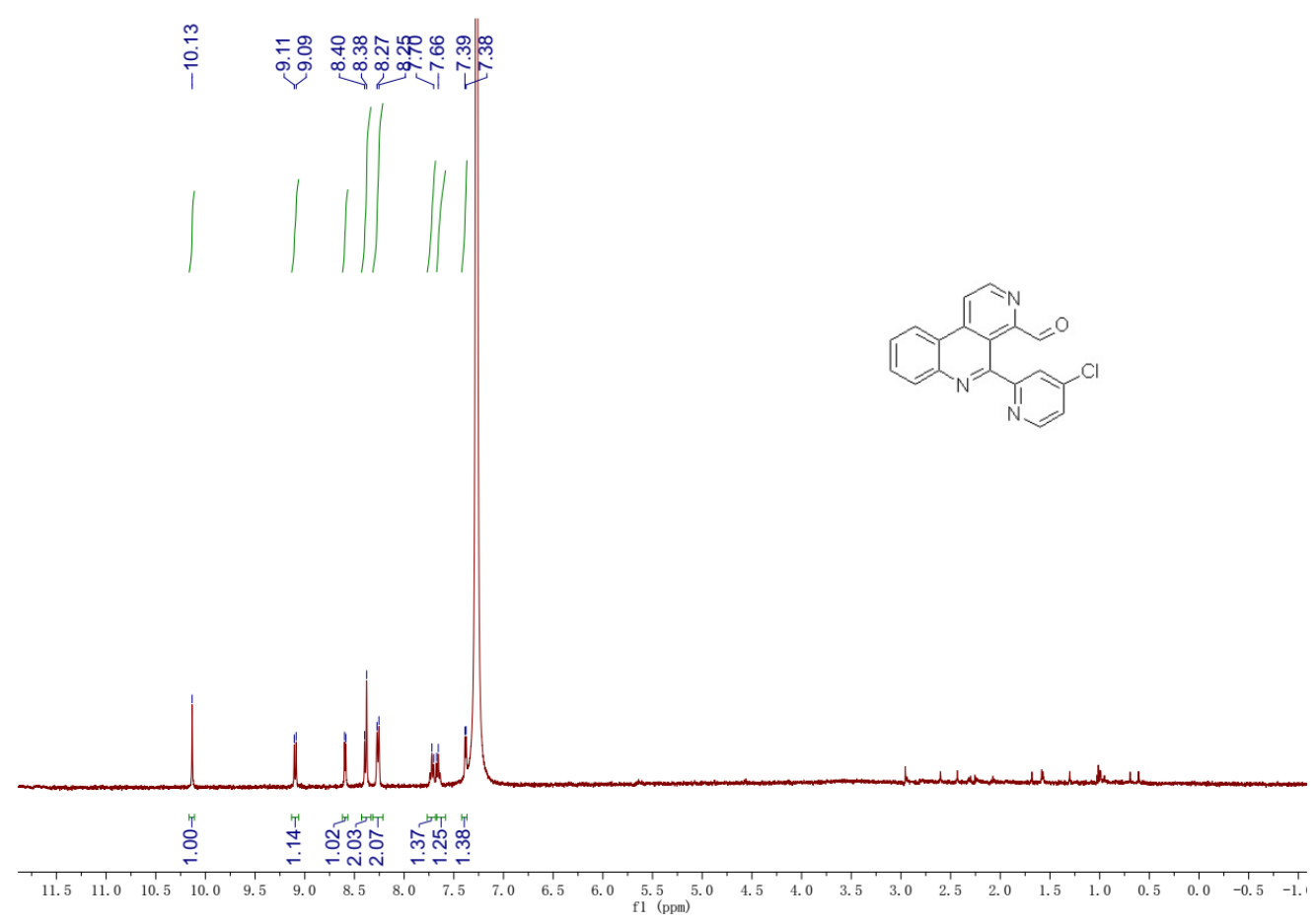

${ }^{1} \mathrm{H}$ NMR Spectrum of Compound $12 \mathrm{~d}\left(400 \mathrm{MHz}, \mathrm{CDCl}_{3}\right)$

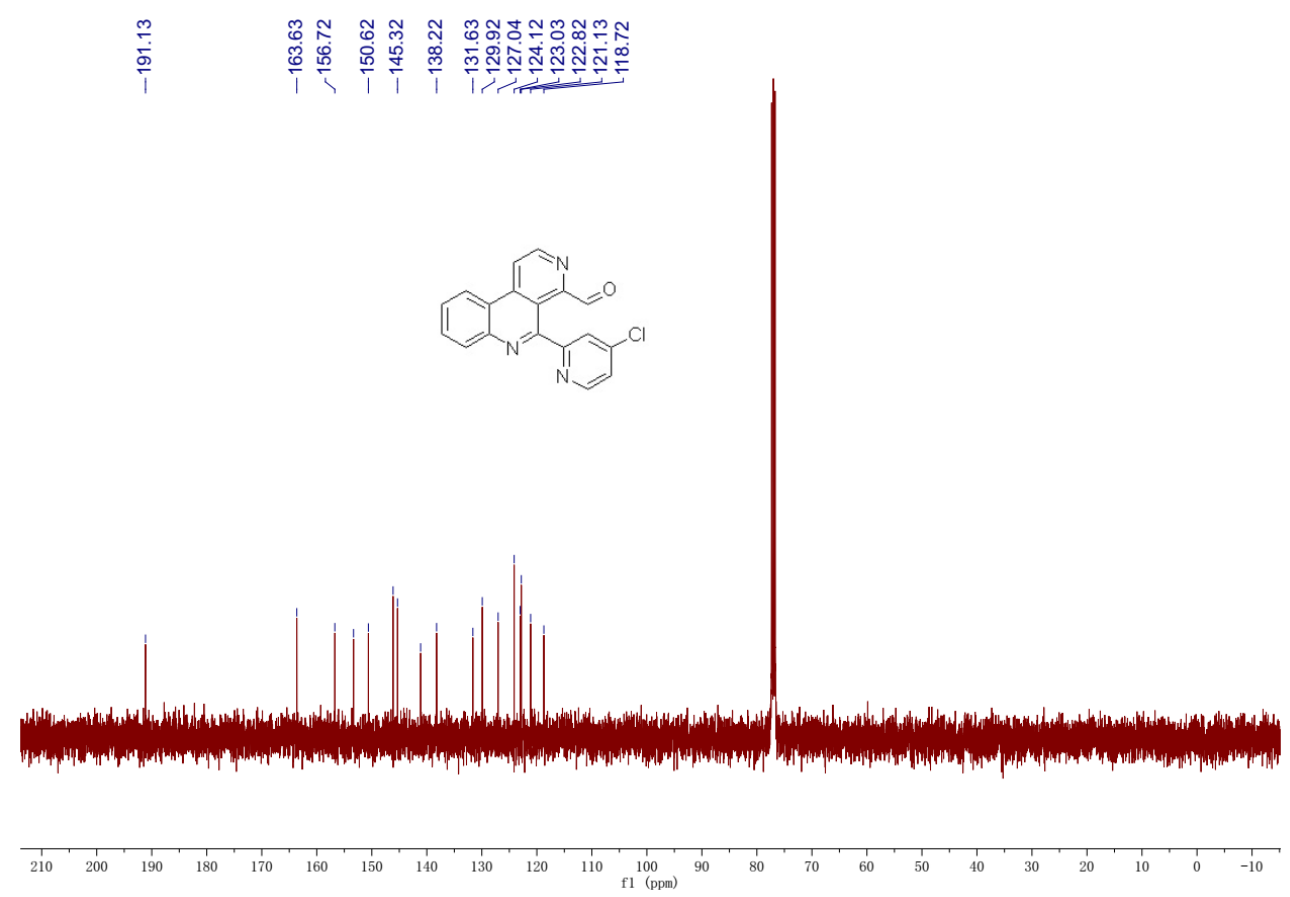

${ }^{13} \mathrm{C}\left\{{ }^{1} \mathrm{H}\right\}$ NMR Spectrum of Compound $12 \mathrm{~d}\left(100 \mathrm{MHz}, \mathrm{CDCl}_{3}\right)$ 


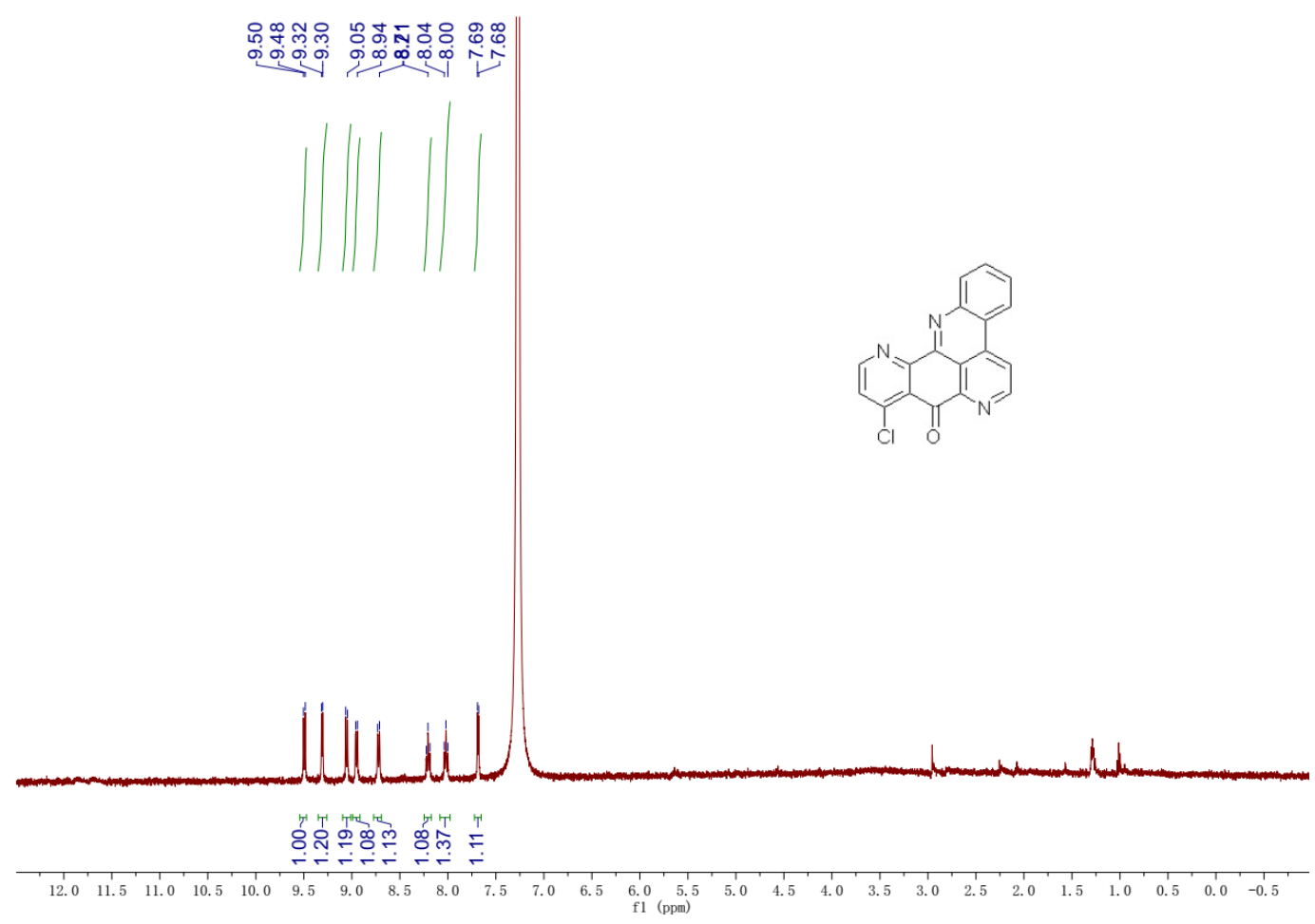

${ }^{1} \mathrm{H}$ NMR Spectrum of Compound $14\left(400 \mathrm{MHz}, \mathrm{CDCl}_{3}\right)$

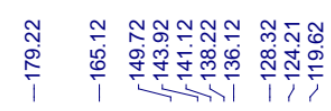
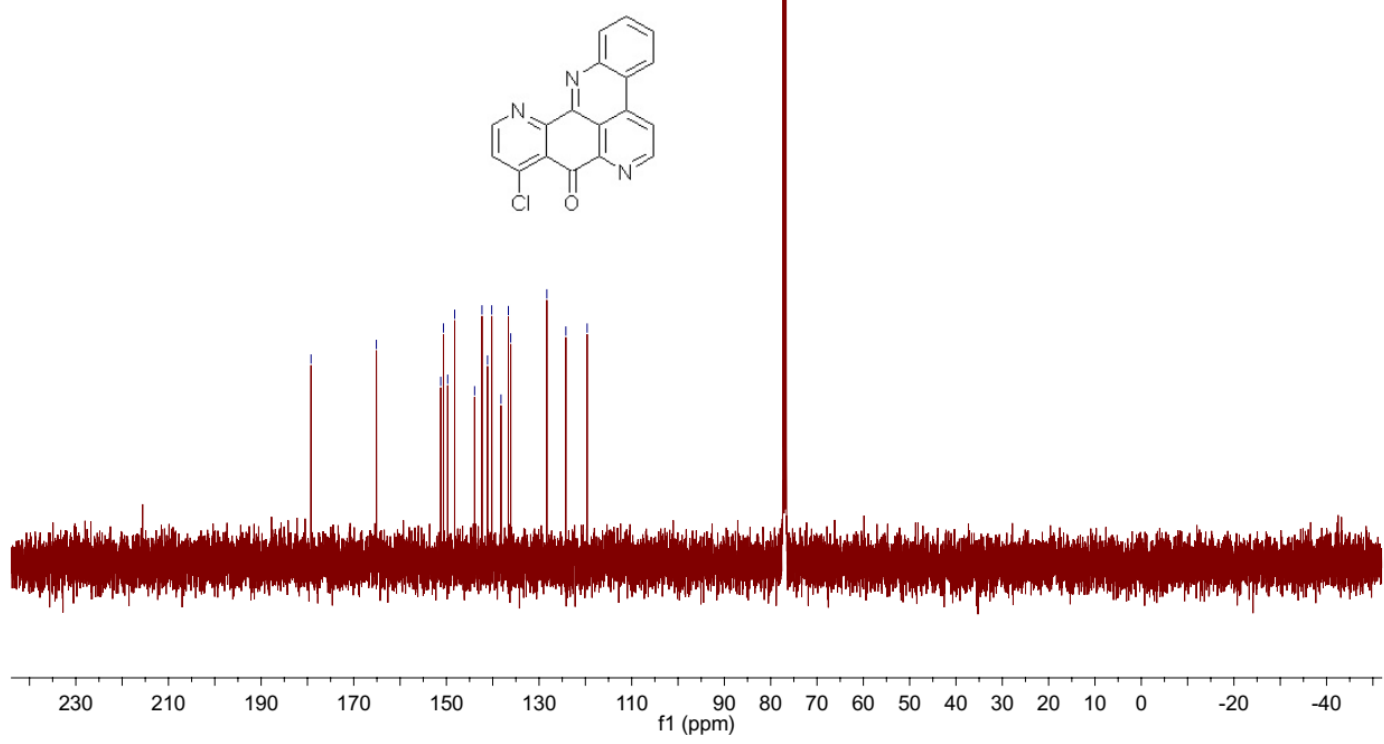

${ }^{13} \mathrm{C}\left\{{ }^{1} \mathrm{H}\right\}$ NMR Spectrum of Compound $14\left(100 \mathrm{MHz}, \mathrm{CDCl}_{3}\right)$ 


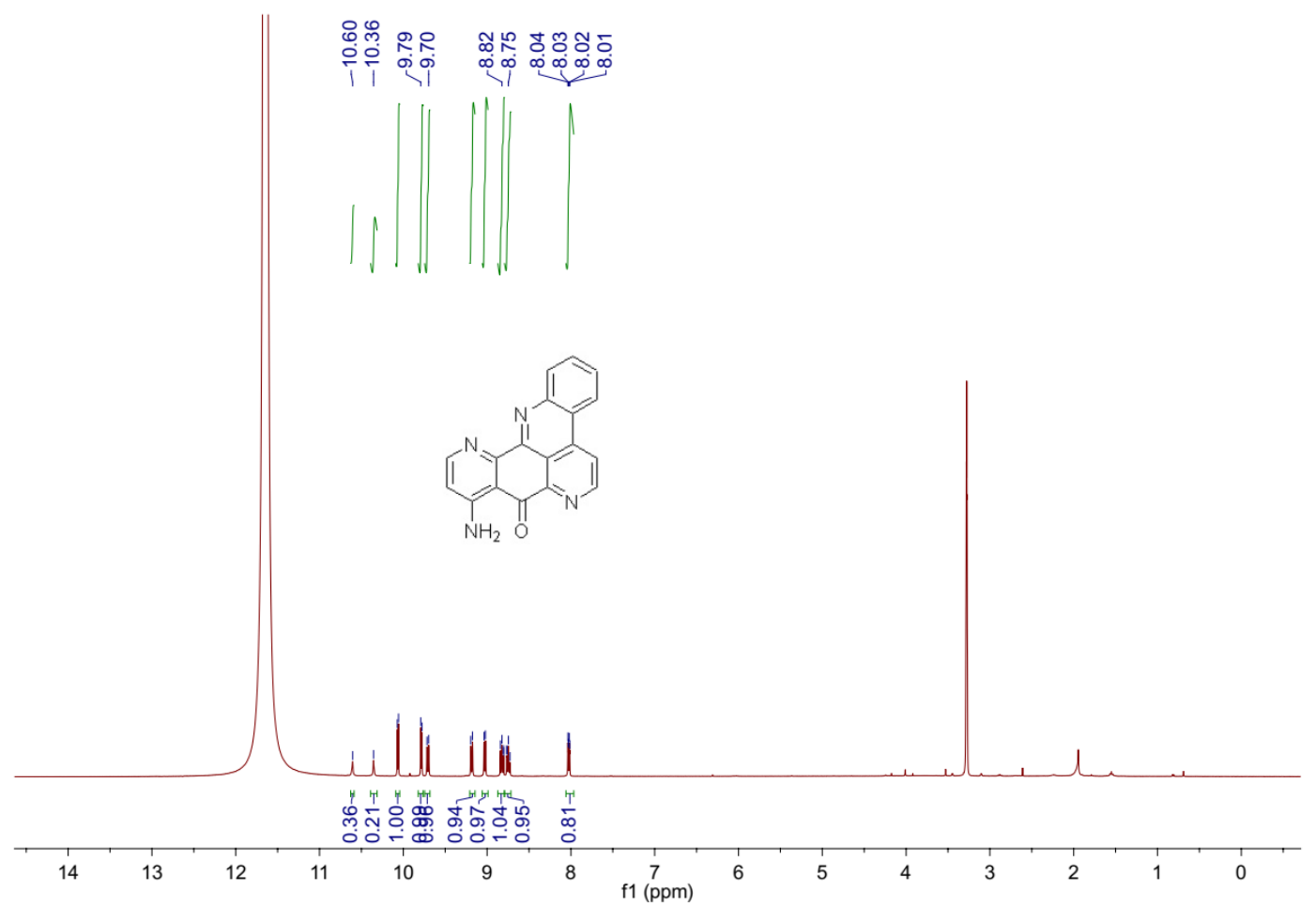

${ }^{1} \mathrm{H}$ NMR Spectrum of Isocystodamine (4) $\left(400 \mathrm{MHz}, \mathrm{CF}_{3} \mathrm{CO}_{2} \mathrm{D} / \mathrm{DMSO}-d_{6}=2: 1\right)$

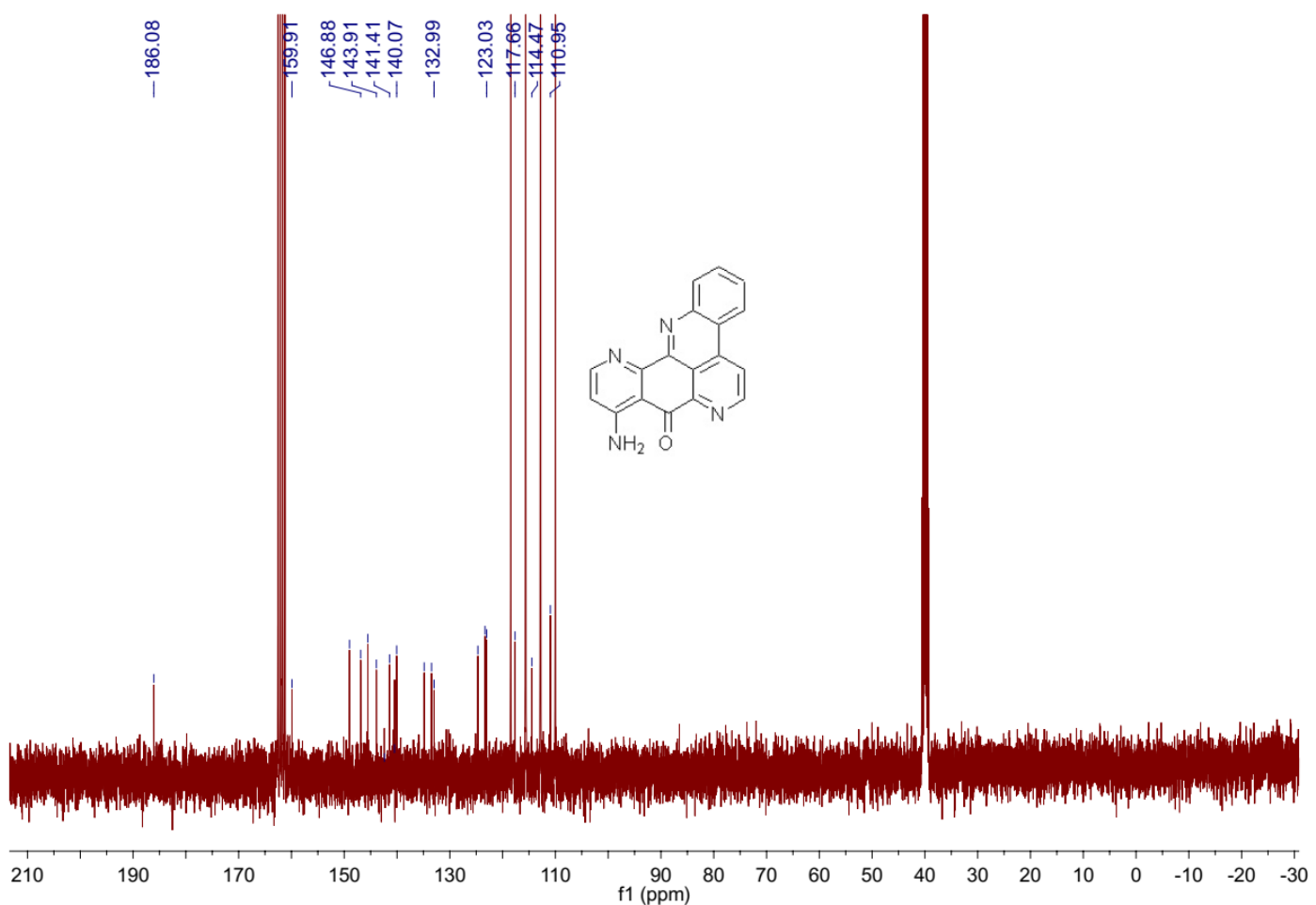

${ }^{13} \mathrm{C}\left\{{ }^{1} \mathrm{H}\right\}$ NMR Spectrum of Isocystodamine (4) $\left(100 \mathrm{MHz}, \mathrm{CF}_{3} \mathrm{CO}_{2} \mathrm{D} / \mathrm{DMSO}-d_{6}=2: 1\right)$ 


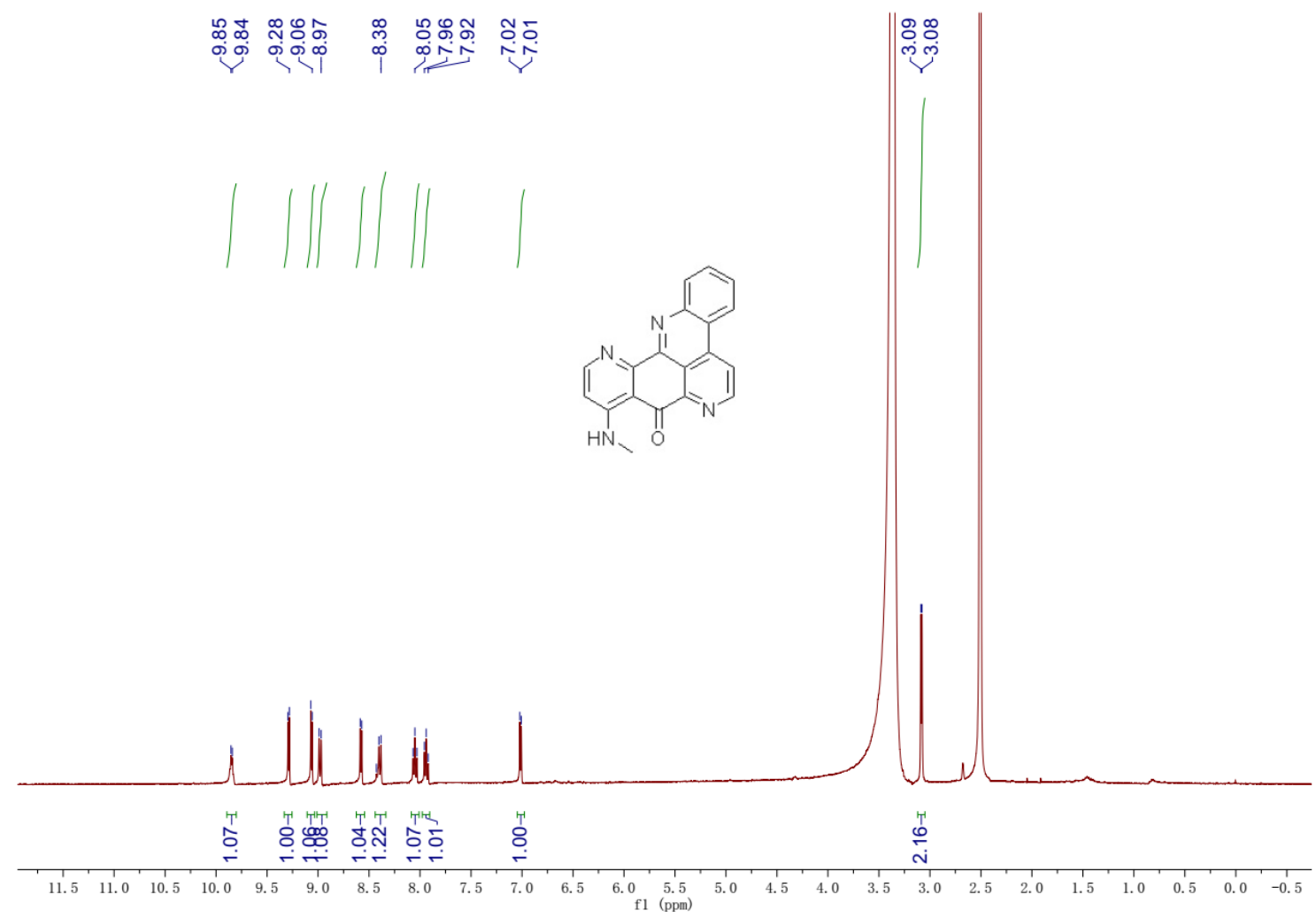

${ }^{1} \mathrm{H}$ NMR Spectrum of $N$-Methylisocystodamine (5) (400 MHz, DMSO- $\left.d_{6}\right)$
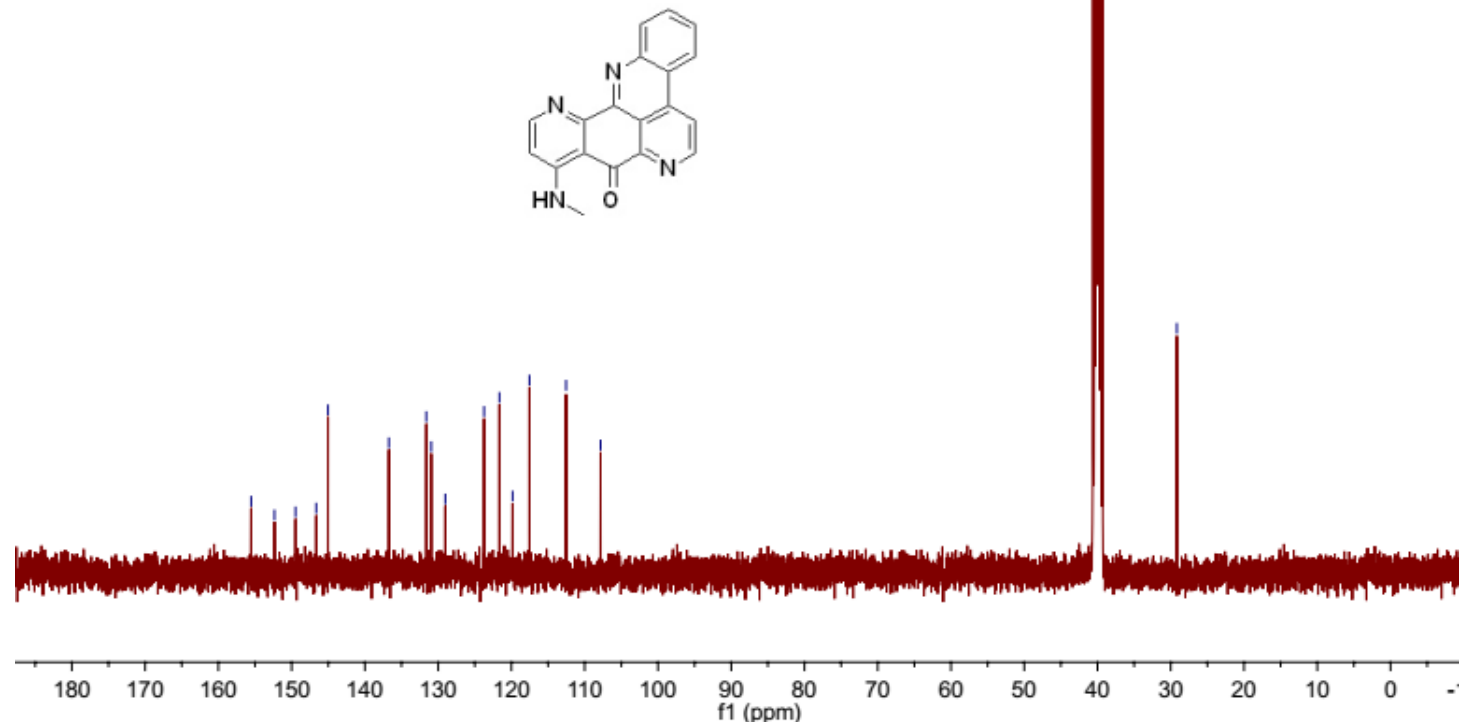

${ }^{13} \mathrm{C}\left\{{ }^{1} \mathrm{H}\right\}$ NMR Spectrum of $N$-Methylisocystodamine (5) (100 MHz, DMSO- $\left.d_{6}\right)$ 


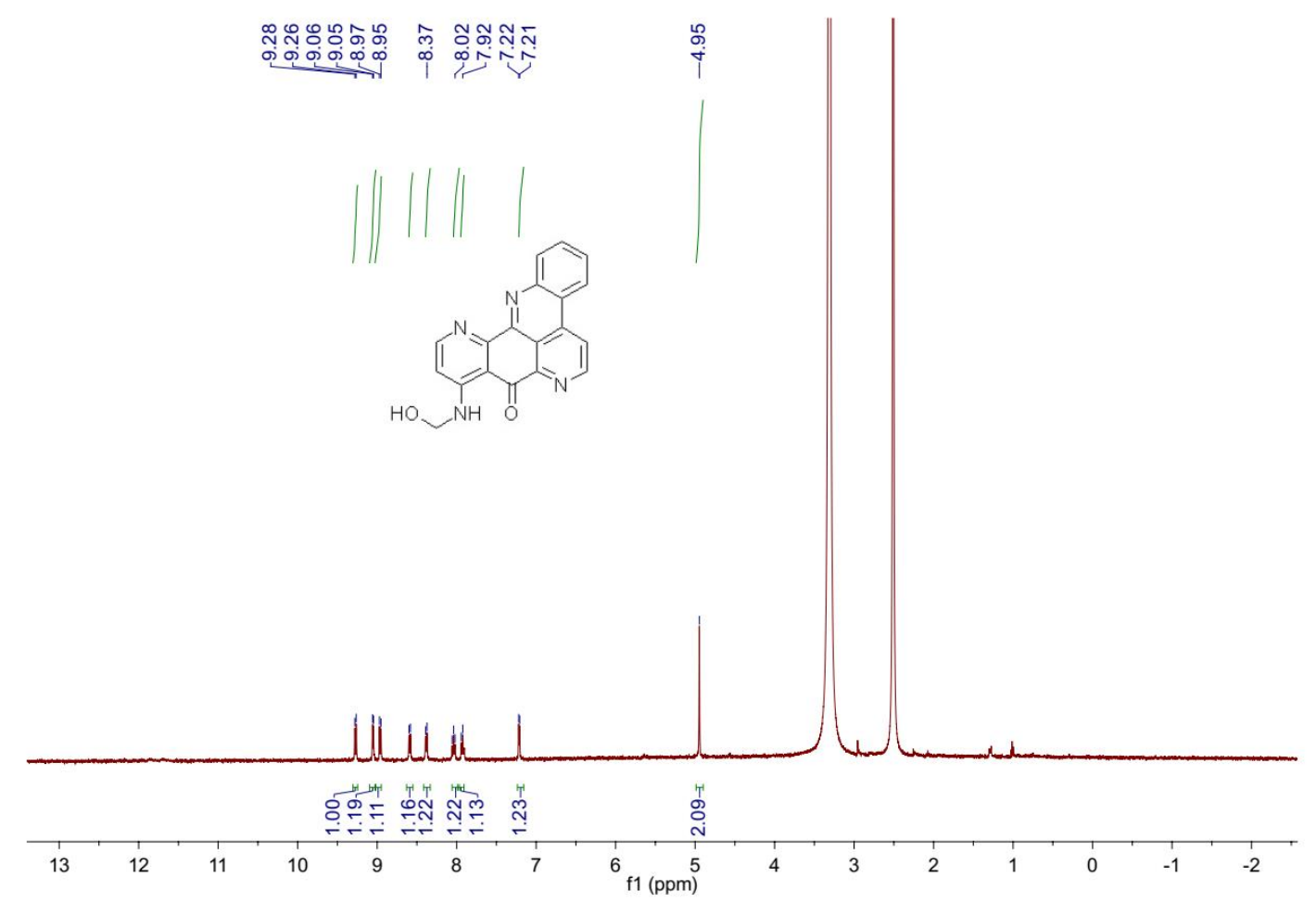

${ }^{1} \mathrm{H}$ NMR Spectrum of $N$-Hydroxymethylisocystodamine (6) (400 MHz, DMSO- $d_{6}$ )

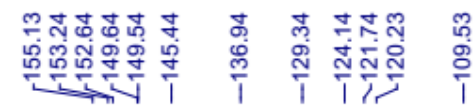

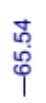
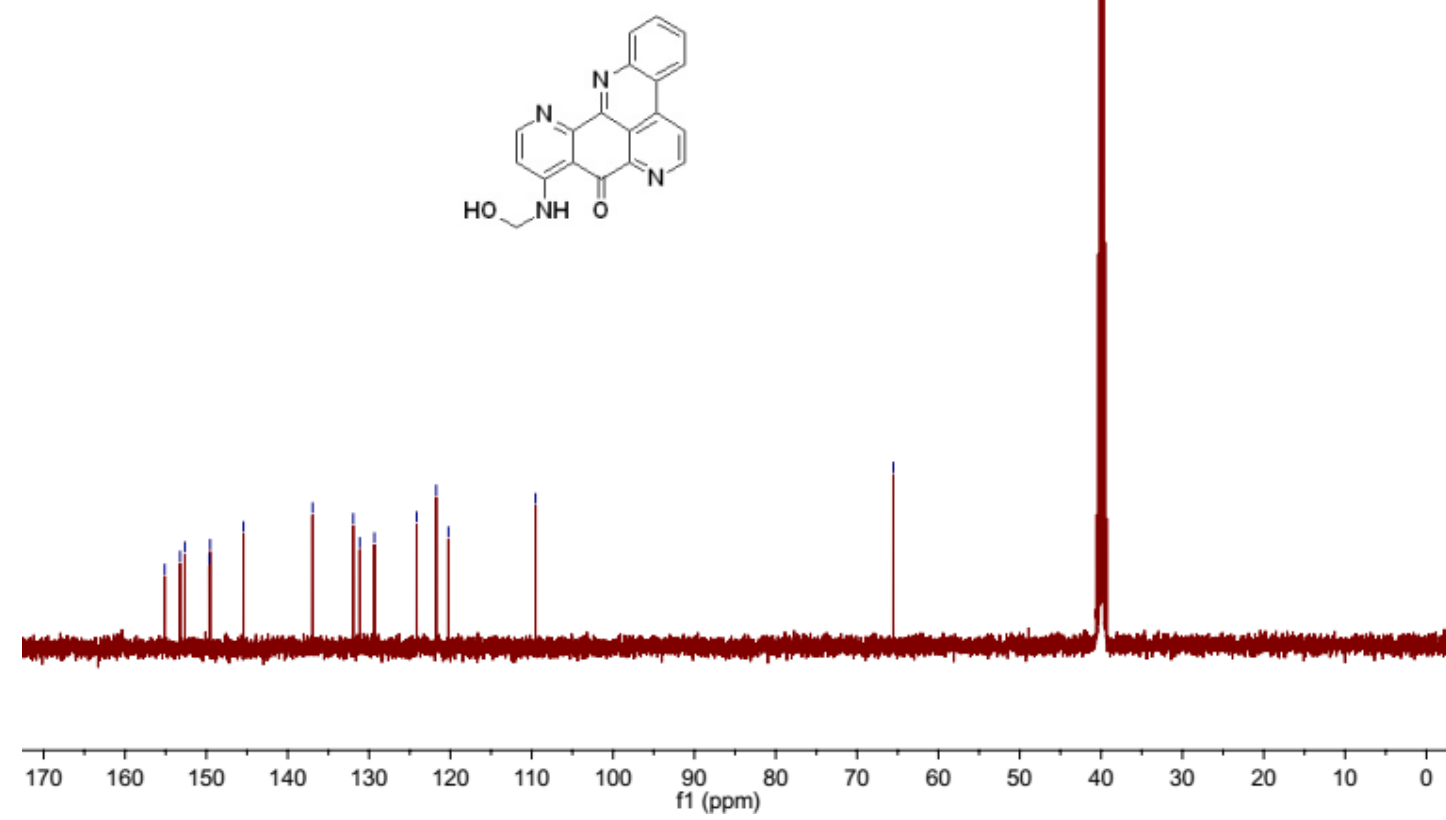

${ }^{13} \mathrm{C}\left\{{ }^{1} \mathrm{H}\right\}$ NMR Spectrum of $N$-Hydroxymethylisocystodamine (6) (100 MHz, DMSO- $d_{6}$ ) 


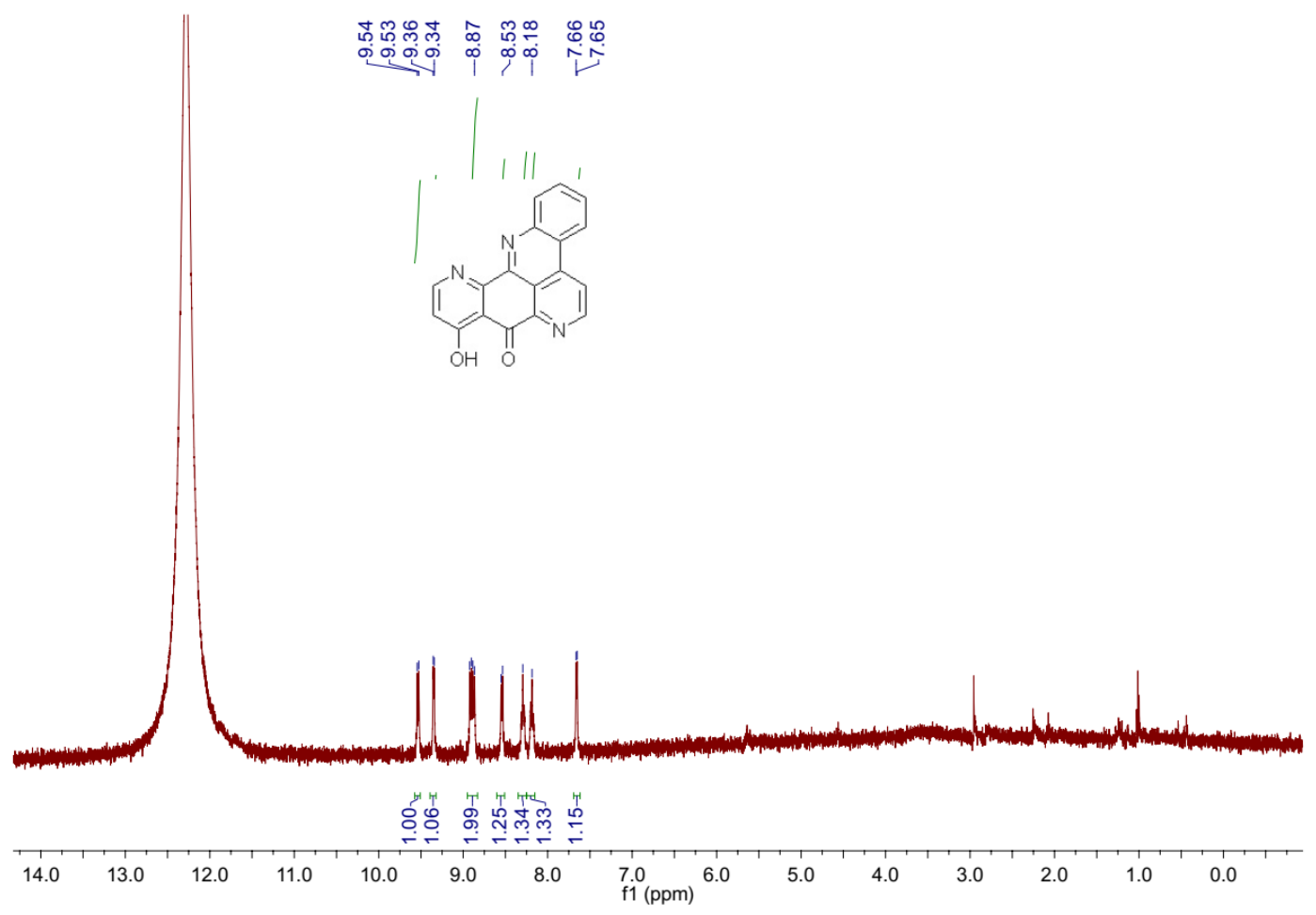

${ }^{1} \mathrm{H}$ NMR Spectrum of 9-Hydroxyisoascididemin (7) (400 MHz, $\left.\mathrm{CF}_{3} \mathrm{CO}_{2} \mathrm{D}\right)$

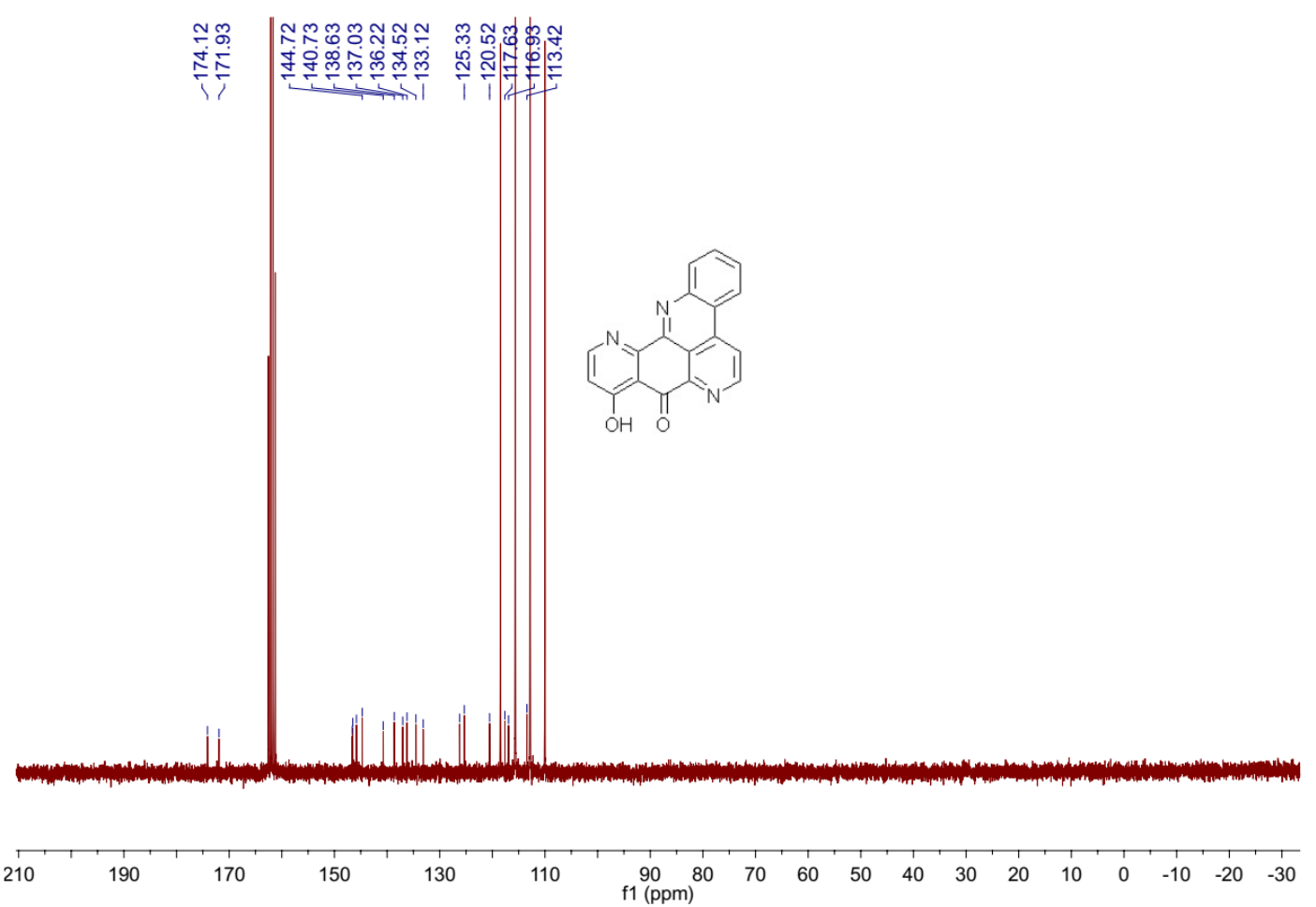

${ }^{13} \mathrm{C}\left\{{ }^{1} \mathrm{H}\right\}$ NMR Spectrum of 9-hydroxyisoascididemin (7) $\left(100 \mathrm{MHz}, \mathrm{CF}_{3} \mathrm{CO}_{2} \mathrm{D}\right)$ 


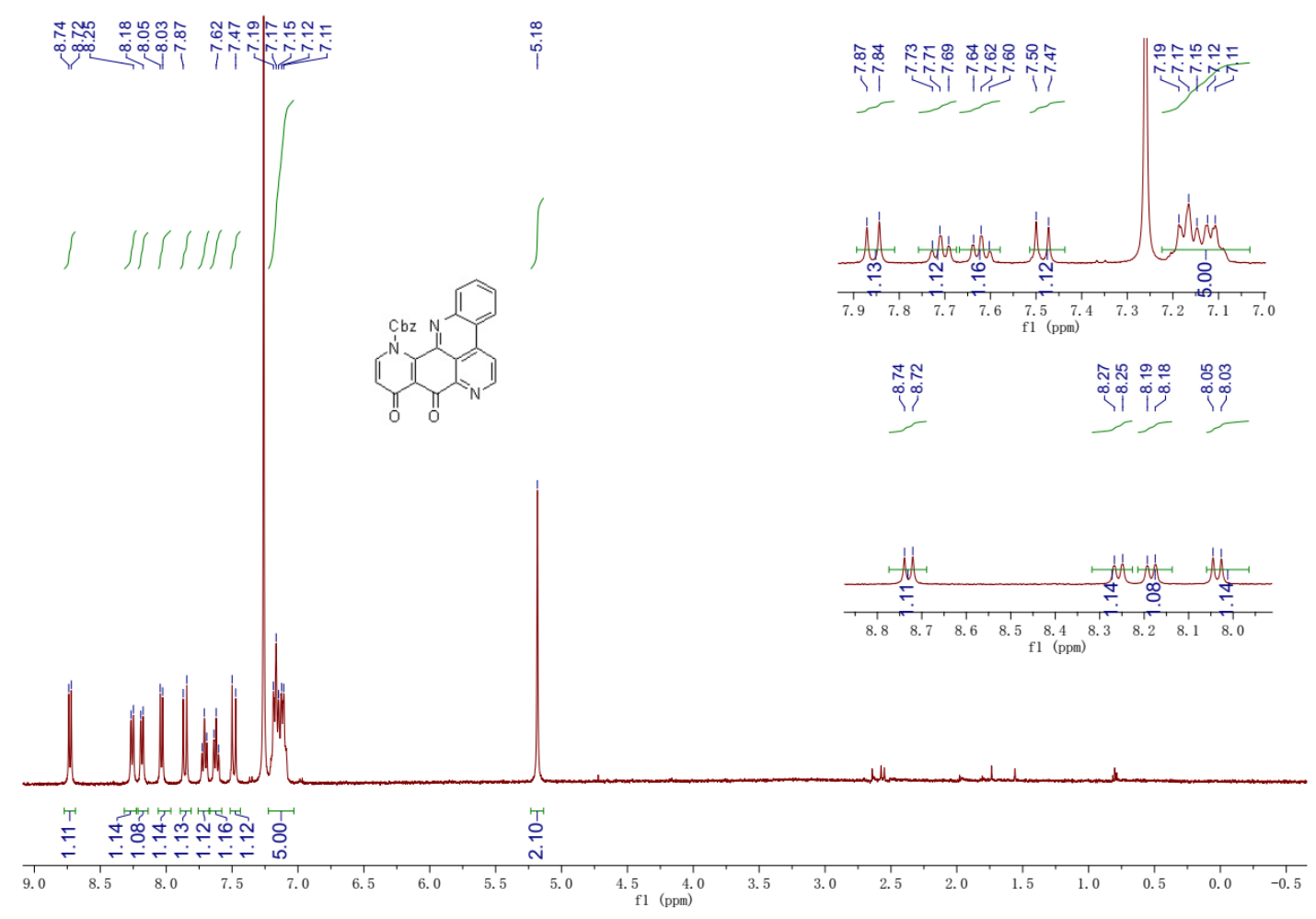

${ }^{1} \mathrm{H}$ NMR Spectrum of Compound 8-1 (400 $\mathrm{MHz}^{\left.\mathrm{CDCl}_{3}\right)}$

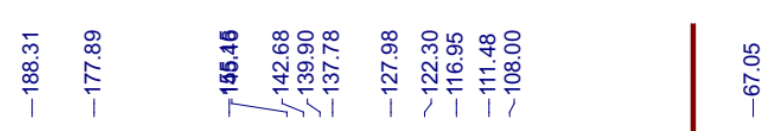

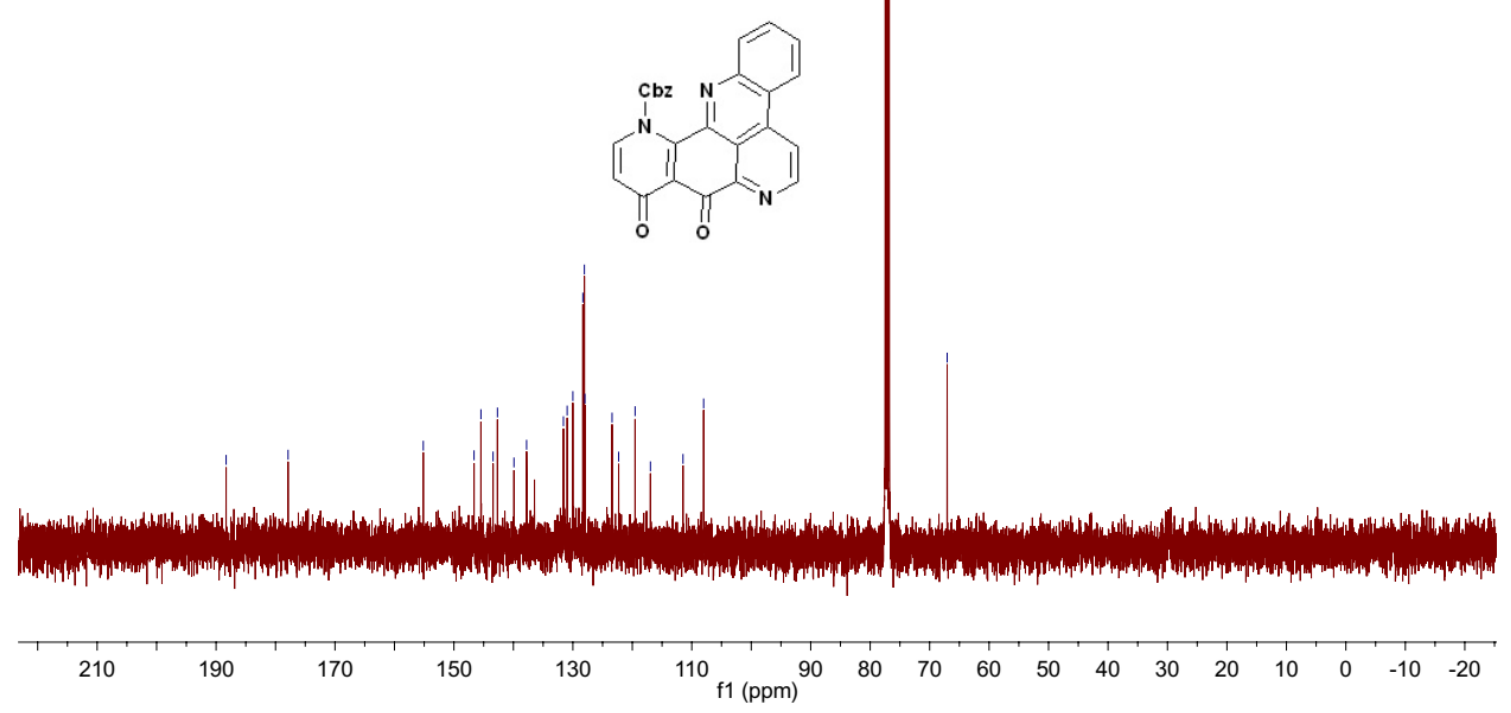

${ }^{13} \mathrm{C}\left\{{ }^{1} \mathrm{H}\right\}$ NMR Spectrum of Compound 8-1 (100 $\left.\mathrm{MHz}, \mathrm{CDCl}_{3}\right)$ 


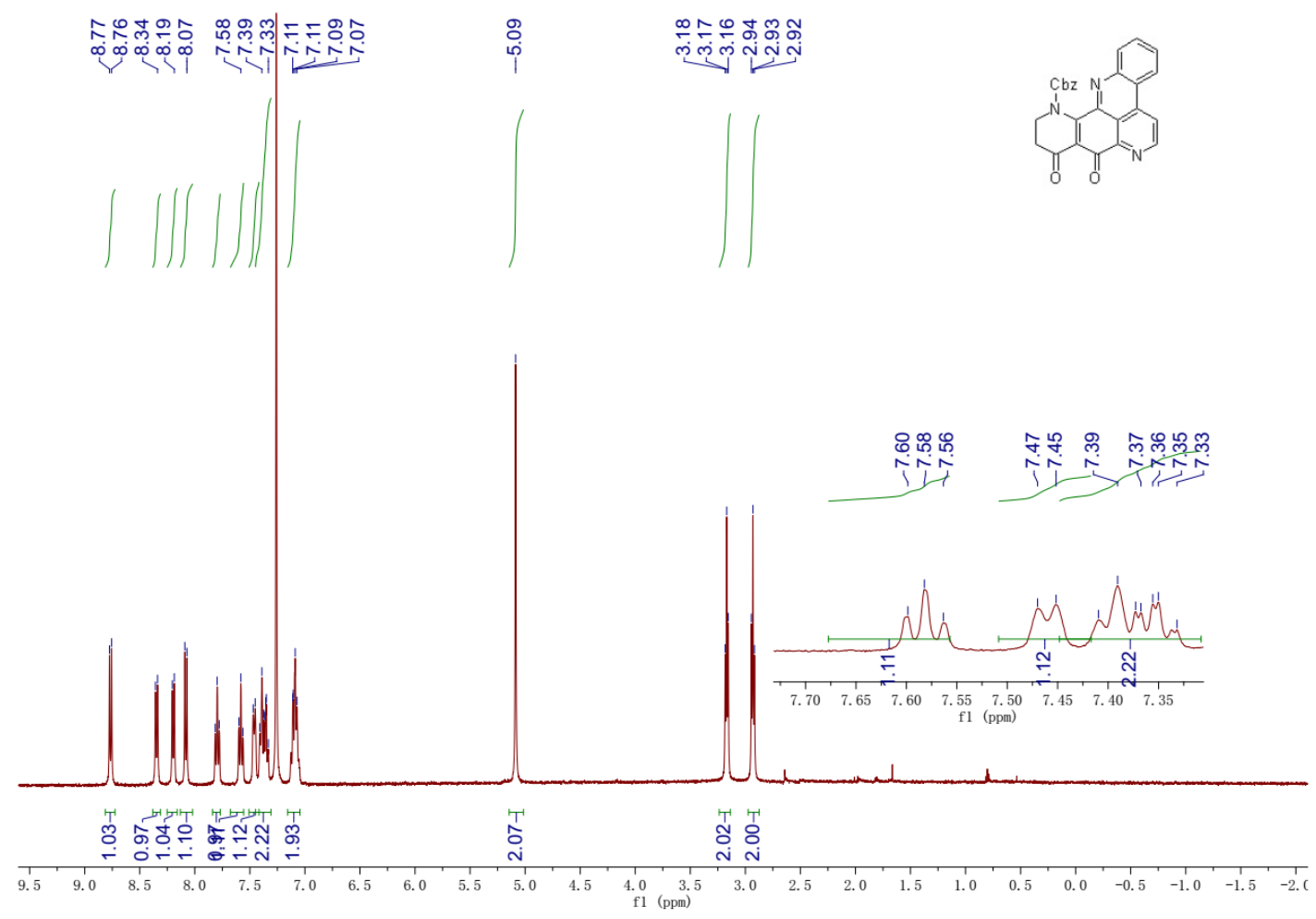

${ }^{1} \mathrm{H}$ NMR Spectrum of Compound 8-2 (400 $\mathrm{MHz}^{\left.\mathrm{CDCl}_{3}\right)}$

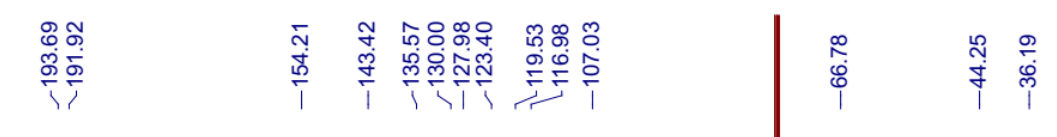

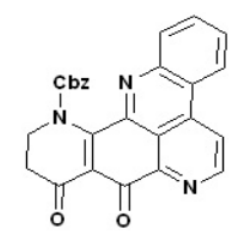

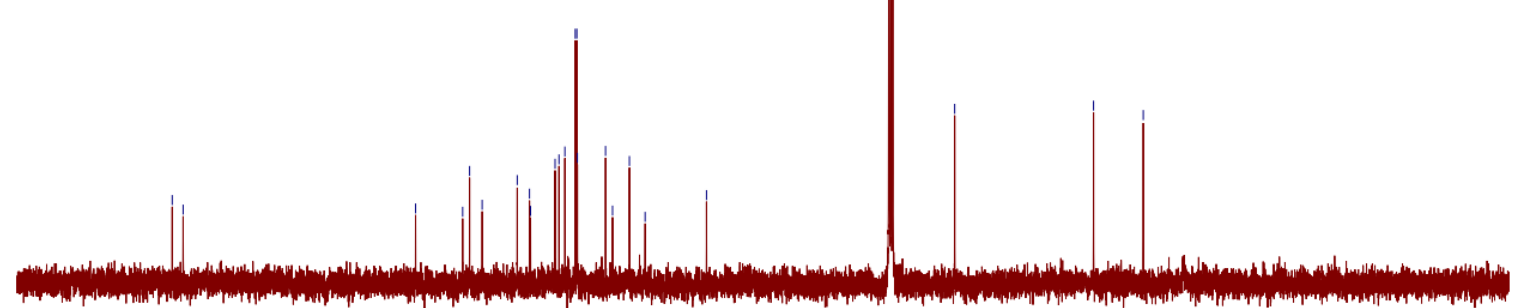

$\begin{array}{llllllllllllllllllllllllll}210 & 200 & 190 & 180 & 170 & 160 & 150 & 140 & 130 & 120 & 110 & \begin{array}{l}100 \\ \mathrm{f} 1\end{array}(\mathrm{ppm}) & 90 & 80 & 60 & 50 & 40 & 30 & 20 & 10 & 0 & -10 & -20\end{array}$

${ }^{13} \mathrm{C}\left\{{ }^{1} \mathrm{H}\right\}$ NMR Spectrum of Compound 8-2 (100 $\left.\mathrm{MHz}, \mathrm{CDCl}_{3}\right)$ 


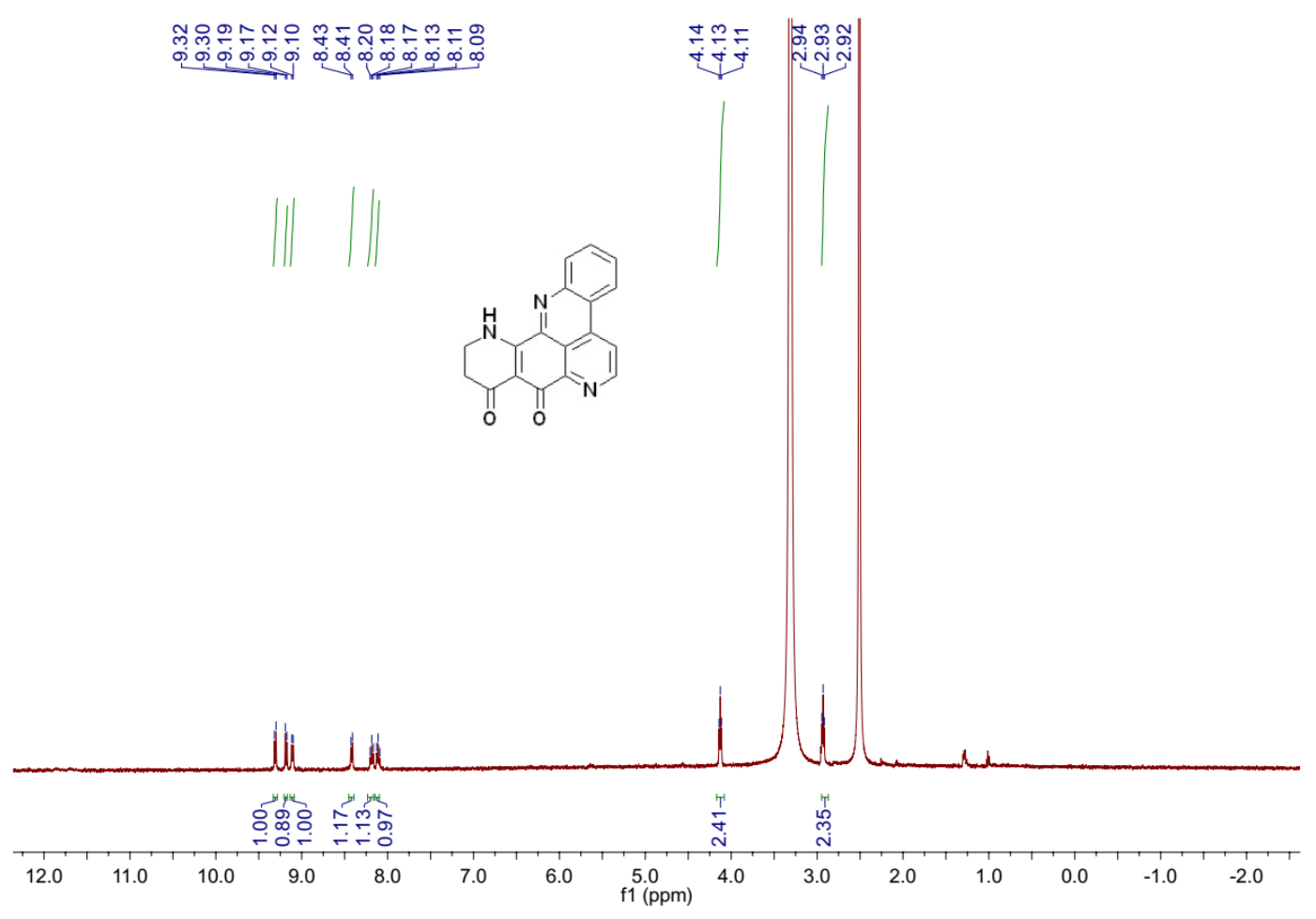

${ }^{1} \mathrm{H}$ NMR Spectrum of Neolabuanine A (8) (400 MHz, DMSO- $\left.d_{6}\right)$

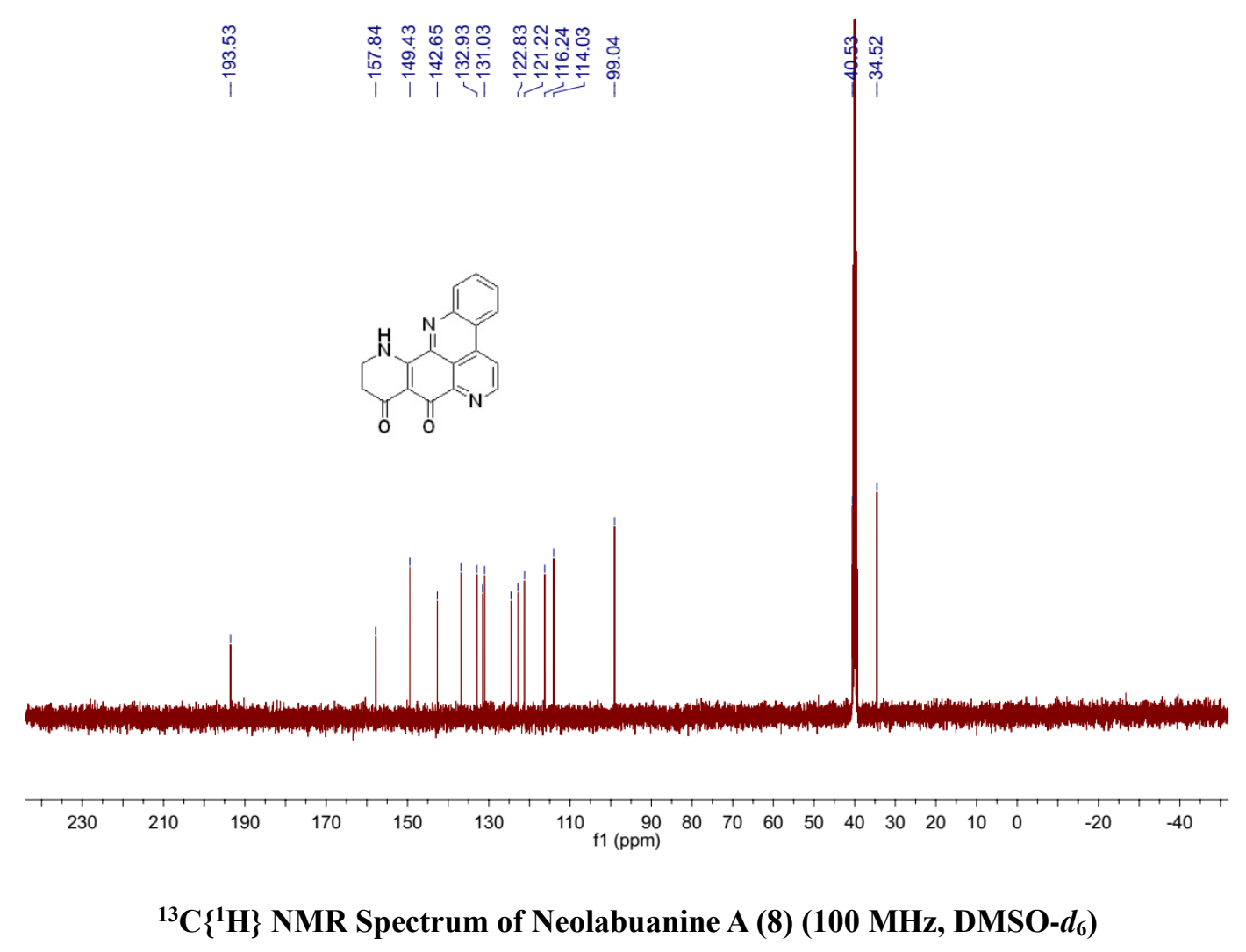




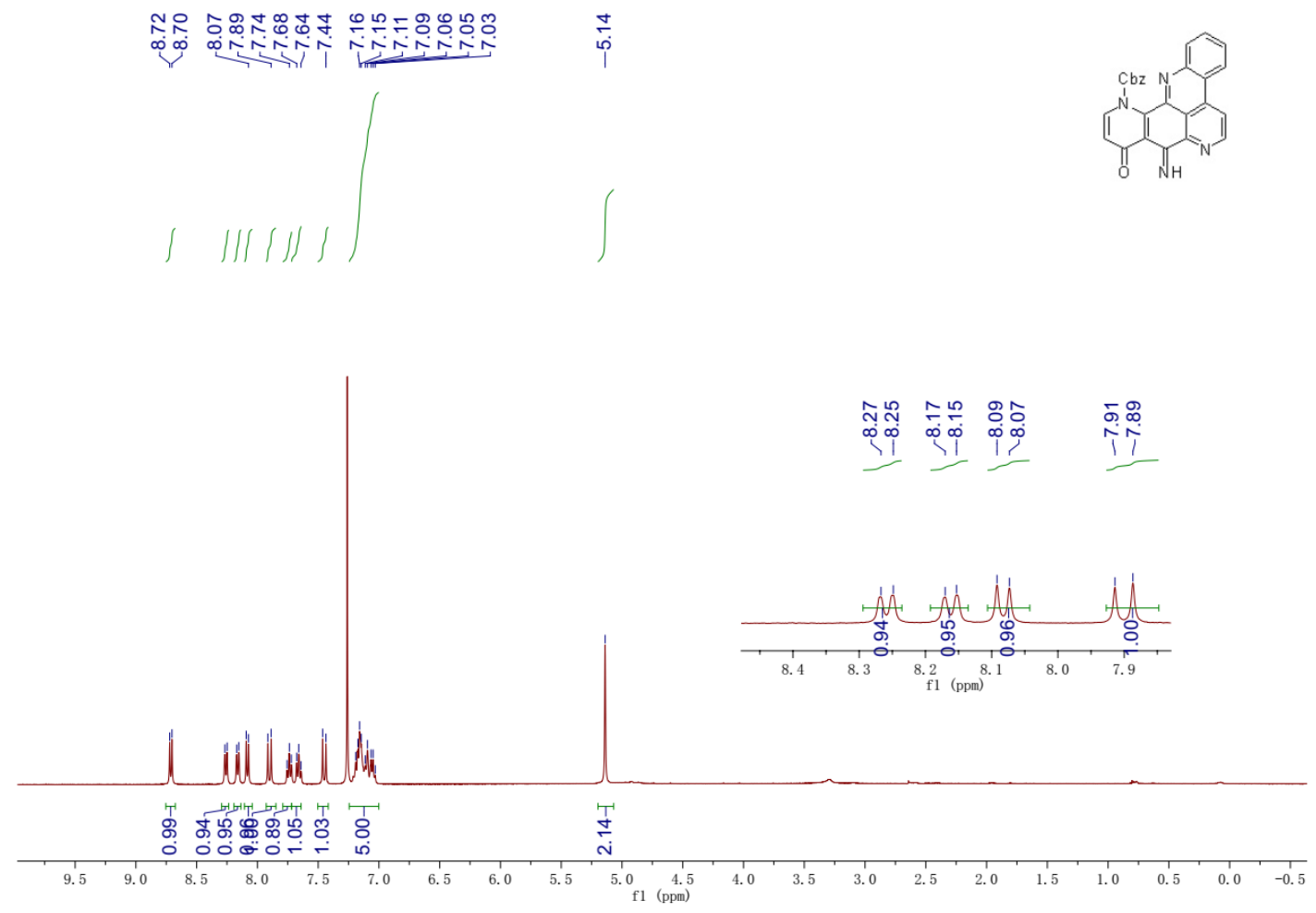

${ }^{1} \mathrm{H}$ NMR Spectrum of Compound 9-1 (400 $\left.\mathrm{MHz}, \mathrm{CDCl}_{3}\right)$
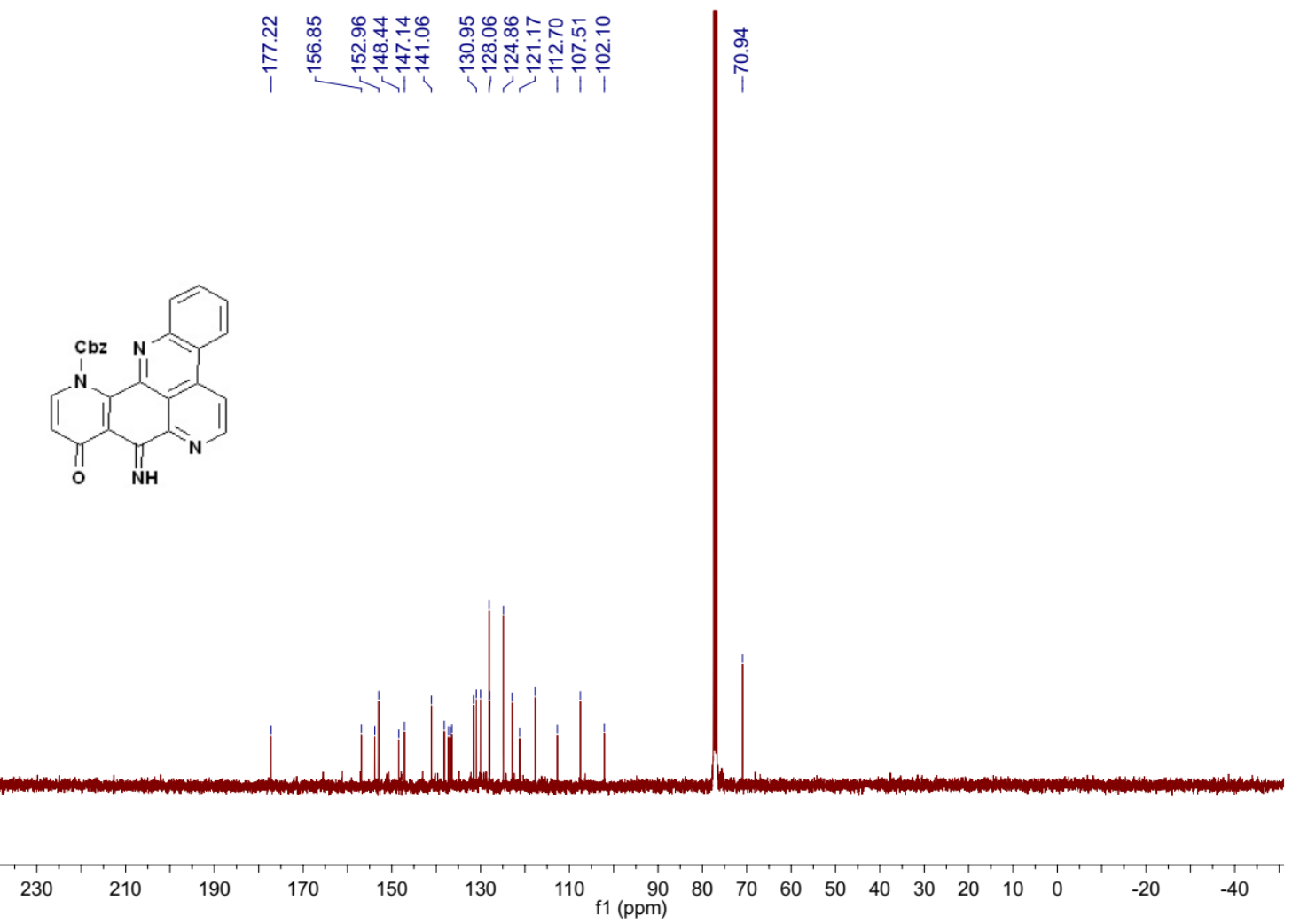

${ }^{13} \mathrm{C}\left\{{ }^{1} \mathrm{H}\right\}$ NMR Spectrum of Compound 9-1 (100 $\left.\mathrm{MHz}, \mathrm{CDCl}_{3}\right)$ 


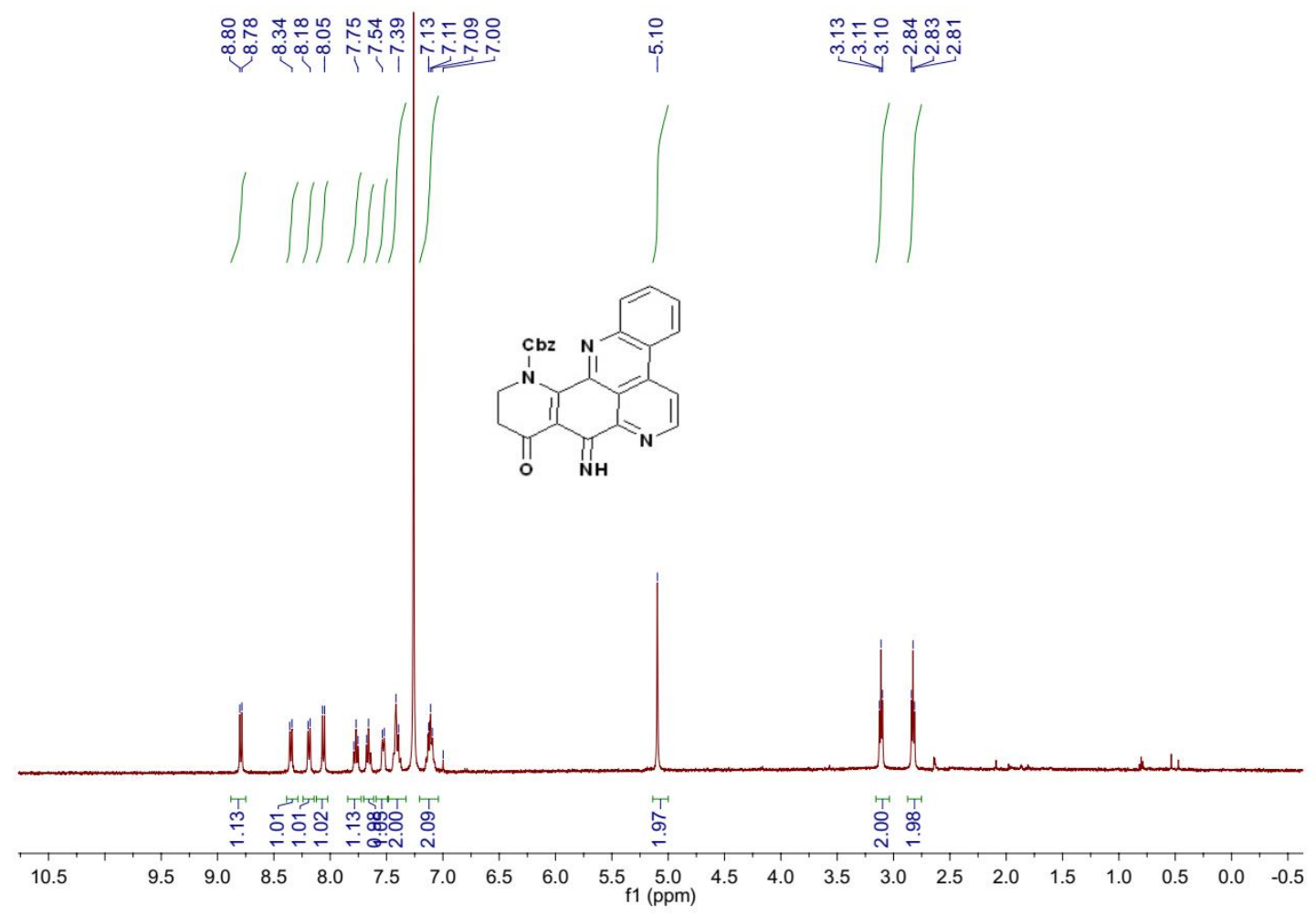

${ }^{1} \mathrm{H}$ NMR Spectrum of Compound 9-2 (400 $\left.\mathrm{MHz}, \mathrm{CDCl}_{3}\right)$
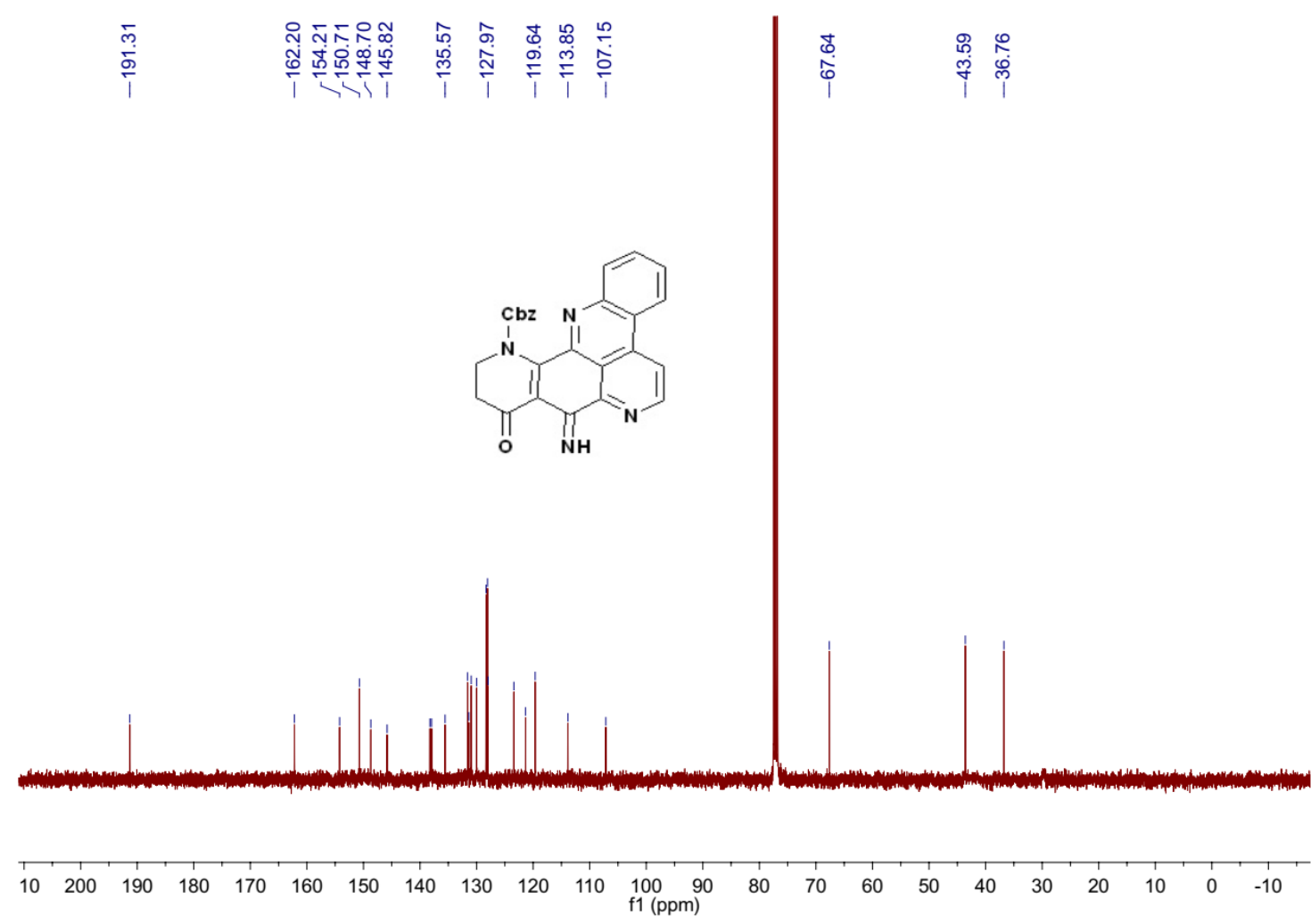

${ }^{13} \mathrm{C}\left\{{ }^{1} \mathrm{H}\right\}$ NMR Spectrum of Compound 9-2 (100 MHz, $\left.\mathrm{CDCl}_{3}\right)$ 


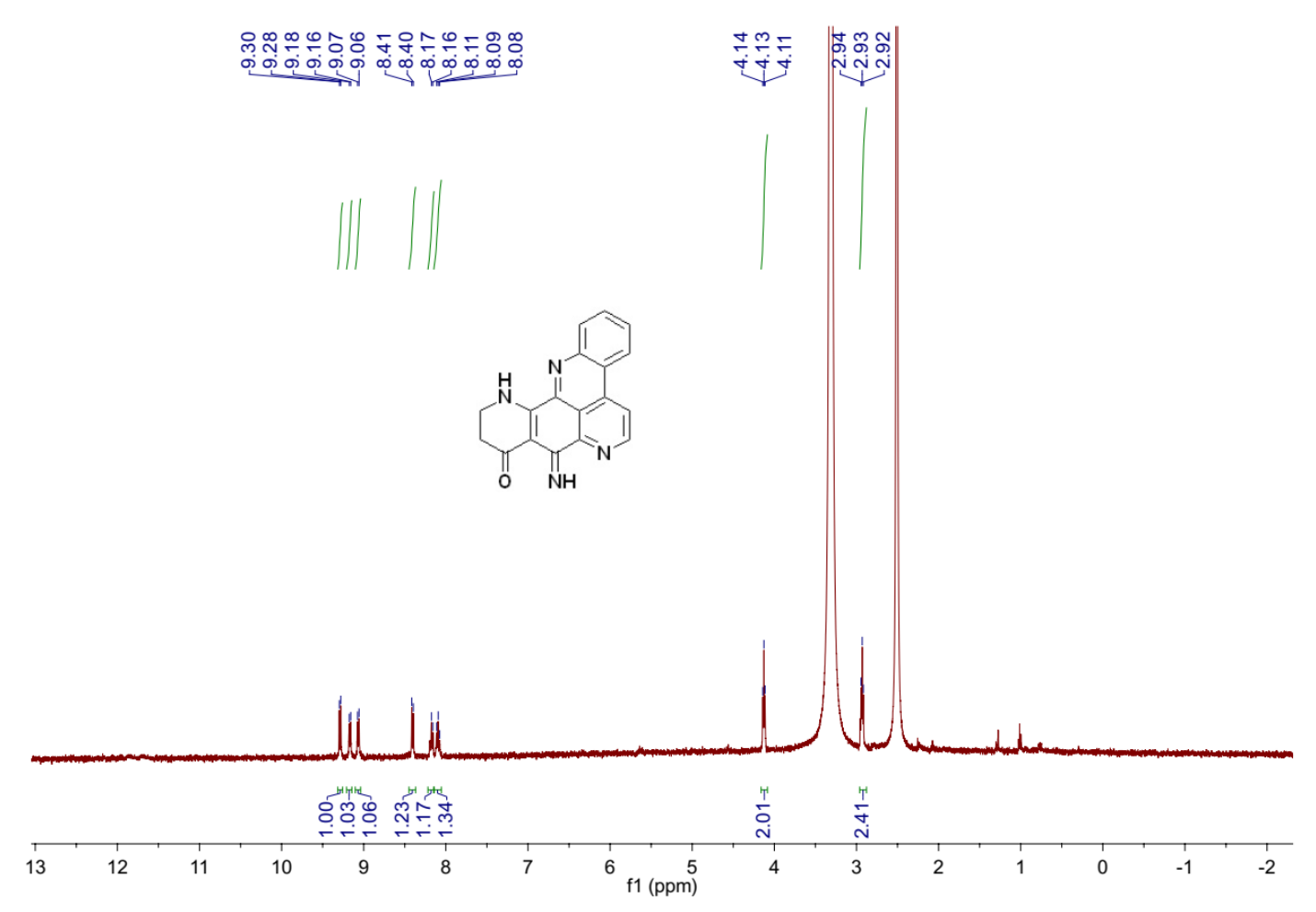

${ }^{1}$ H NMR Spectrum of Ecionine A (9) (400 MHz, DMSO- $\left.d_{6}\right)$

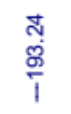

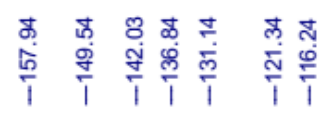
范

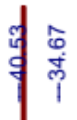
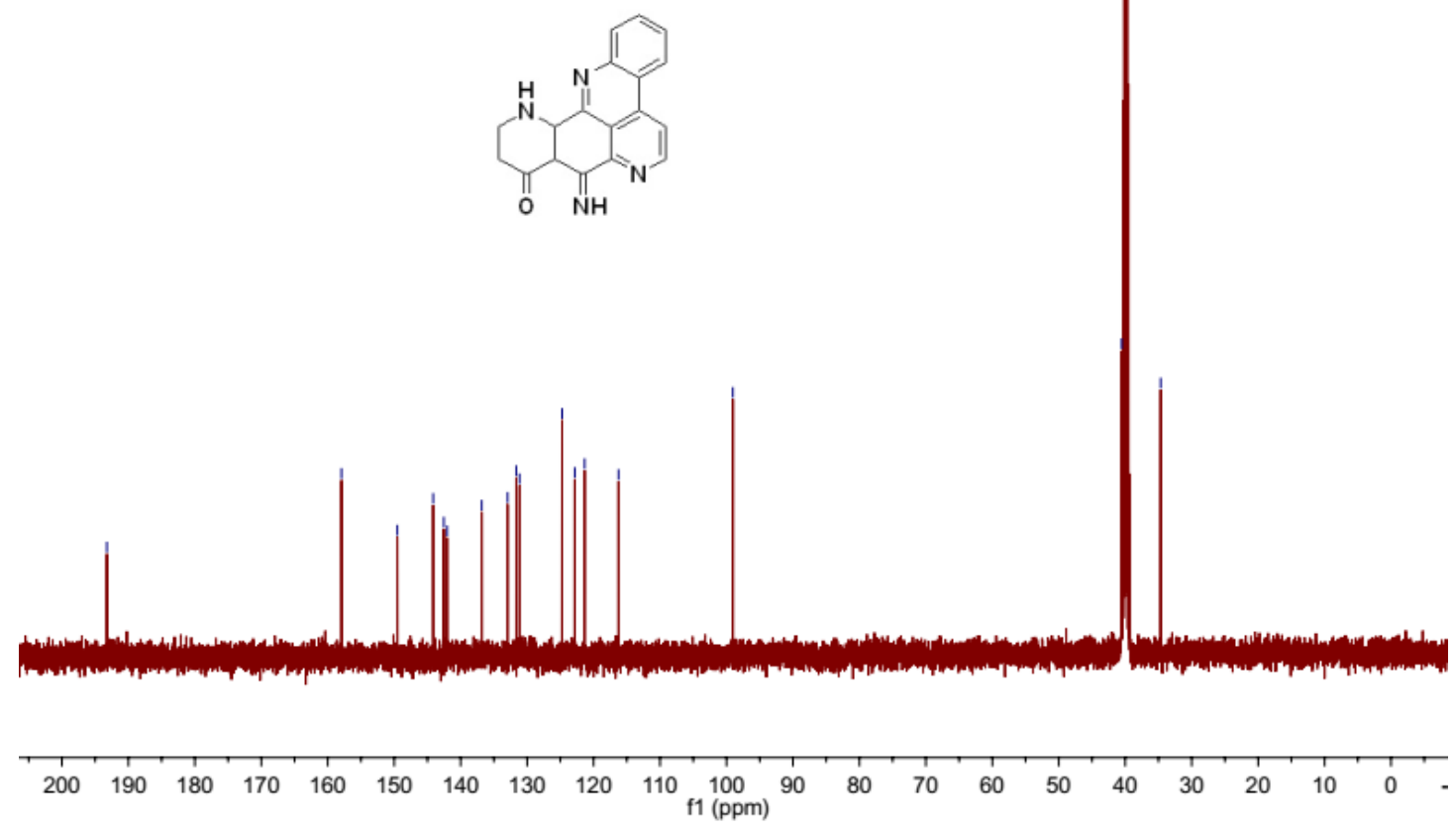

${ }^{13} \mathrm{C}\left\{{ }^{1} \mathrm{H}\right\}$ NMR Spectrum of Ecionine A (9) (100 MHz, DMSO- $\left.d_{6}\right)$ 


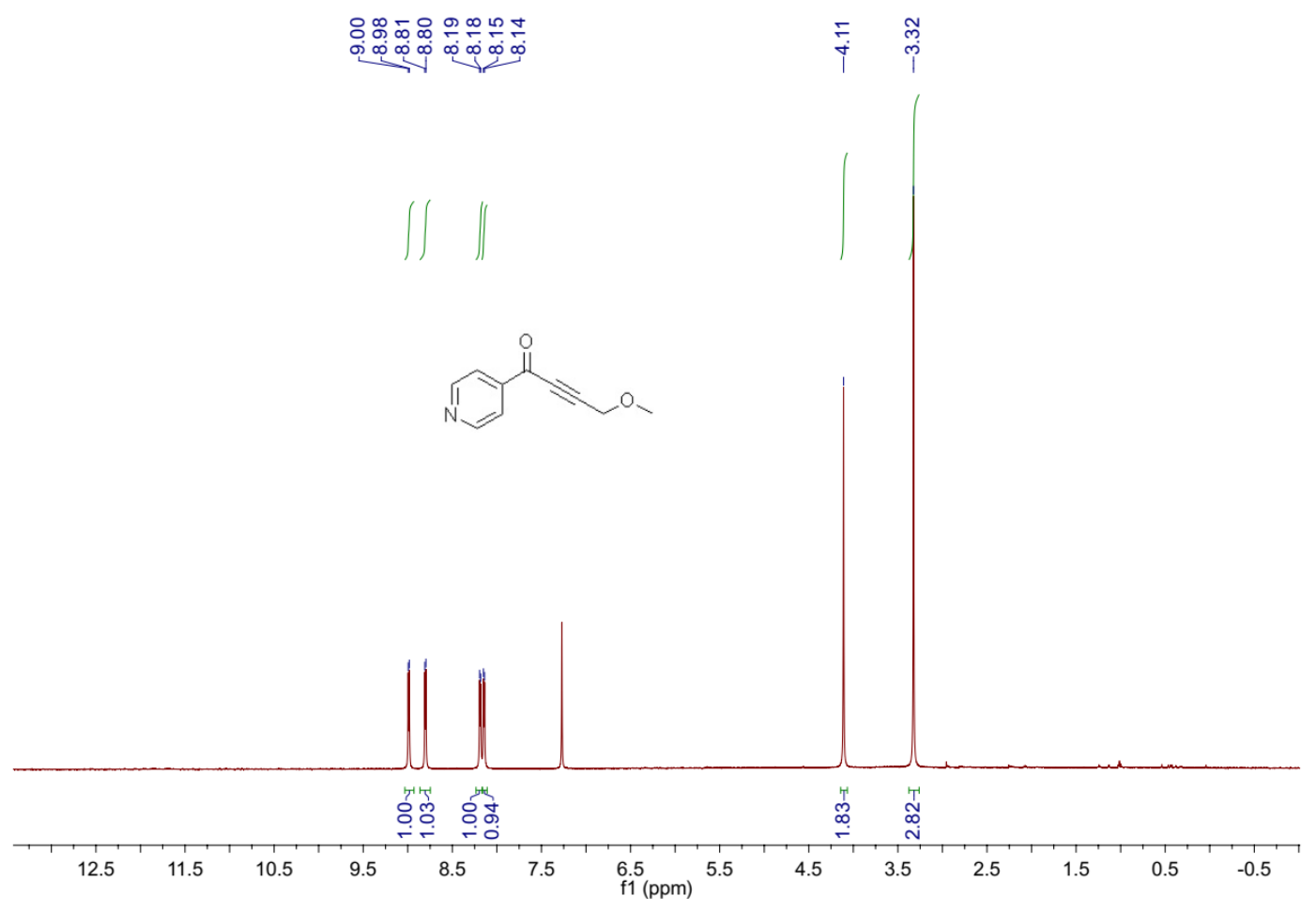

${ }^{1} \mathrm{H}$ NMR Spectrum of Compound $10 \mathrm{aa}\left(400 \mathrm{MHz}, \mathrm{CDCl}_{3}\right)$

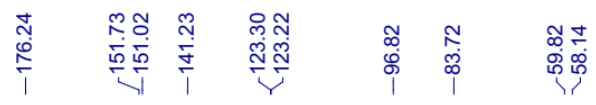

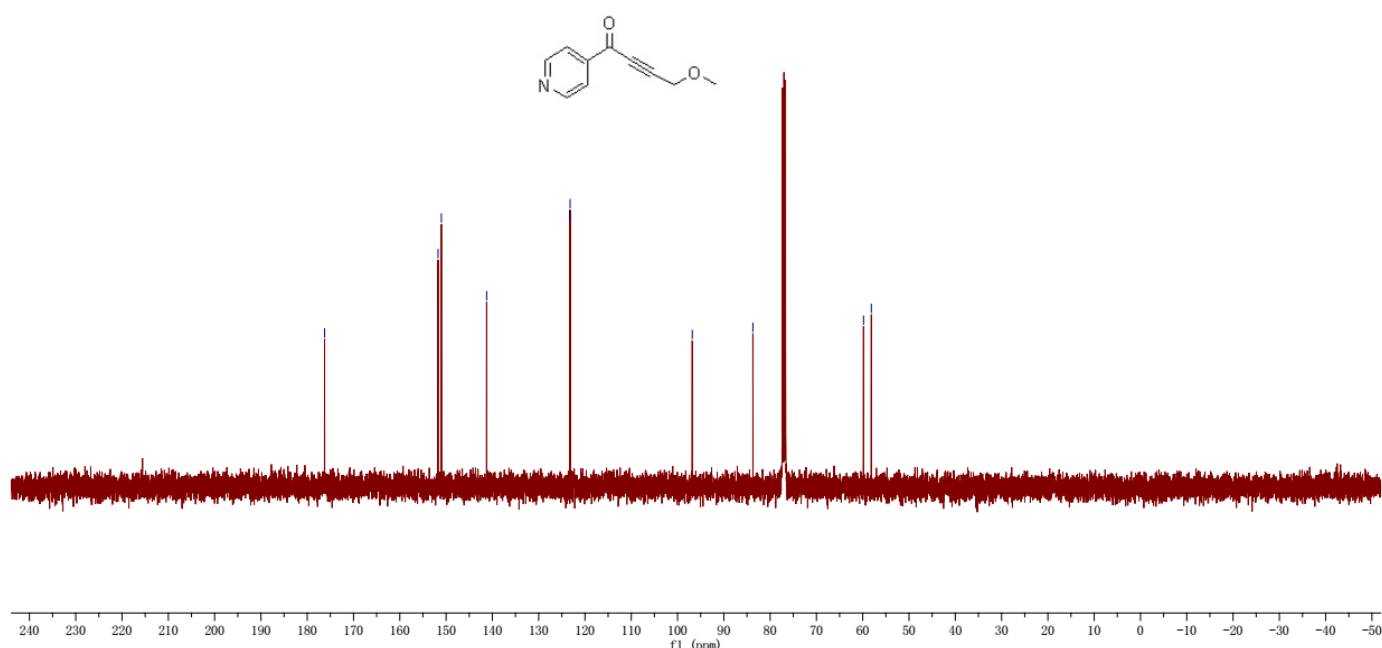

${ }^{13} \mathrm{C}\left\{{ }^{1} \mathrm{H}\right\}$ NMR Spectrum of Compound 10aa $\left(100 \mathrm{MHz}, \mathrm{CDCl}_{3}\right)$ 

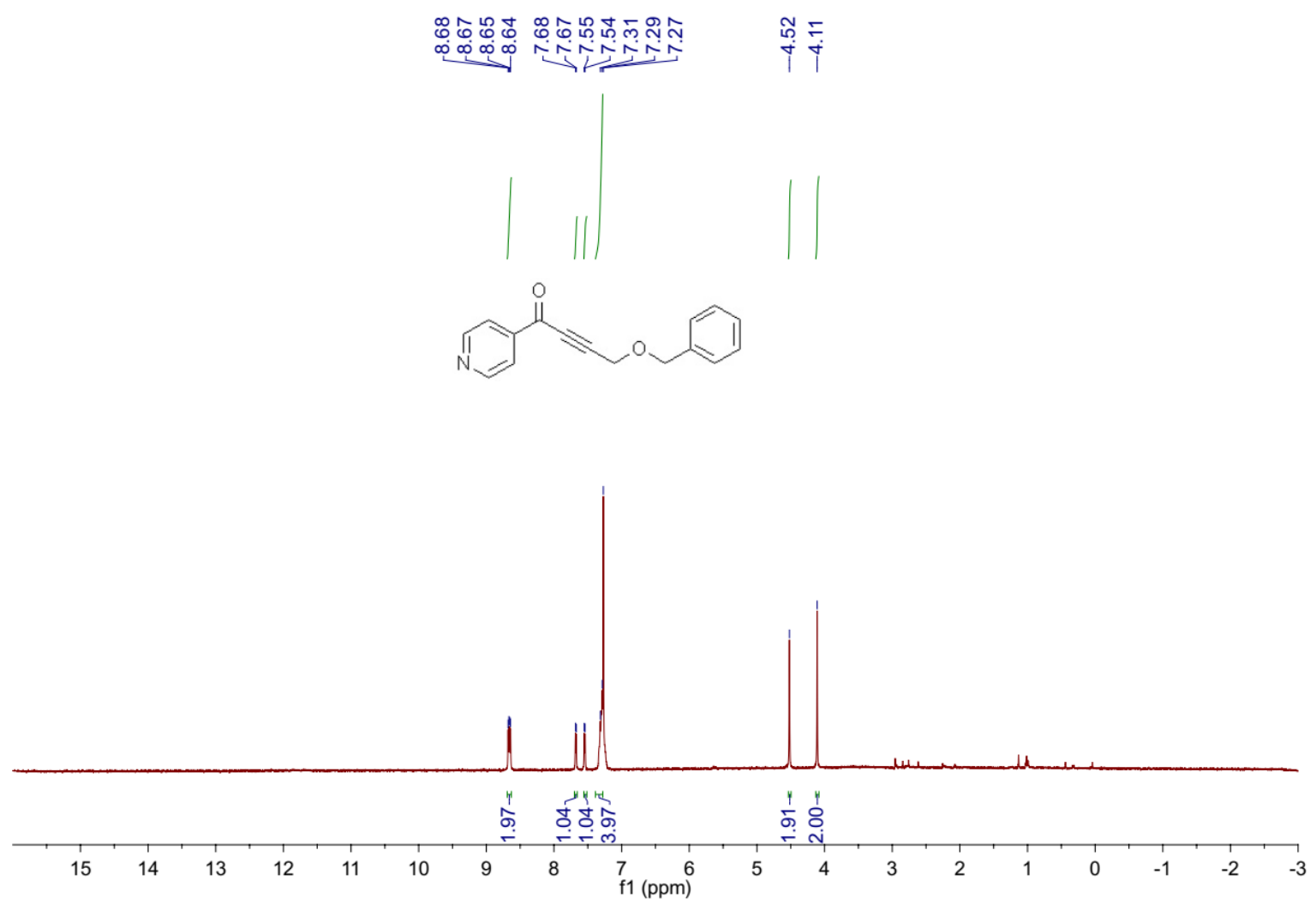

${ }^{1} \mathrm{H}$ NMR Spectrum of Compound 10ab (400 $\left.\mathrm{MHz}, \mathrm{CDCl}_{3}\right)$

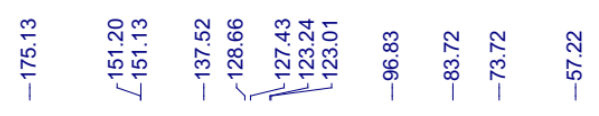
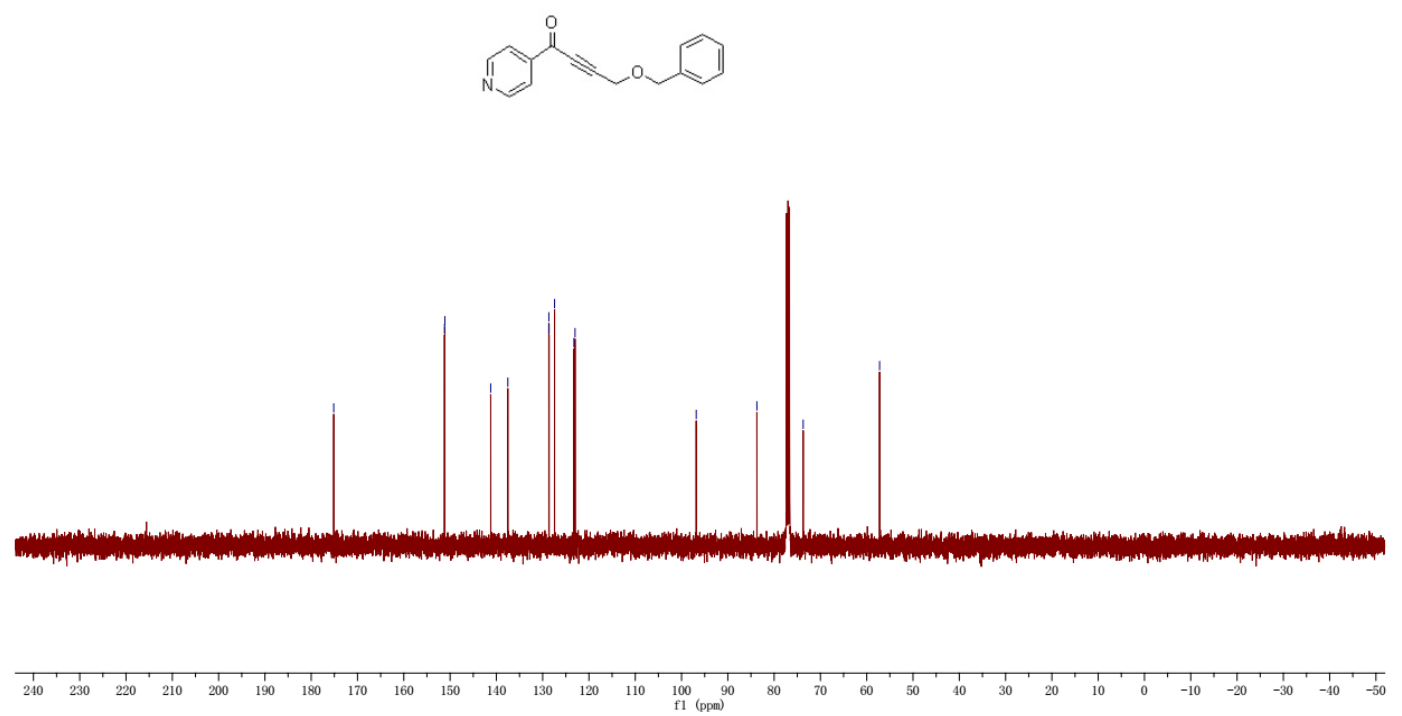

${ }^{13} \mathrm{C}\left\{{ }^{1} \mathrm{H}\right\}$ NMR Spectrum of Compound 10ab (100 MHz, $\left.\mathrm{CDCl}_{3}\right)$ 


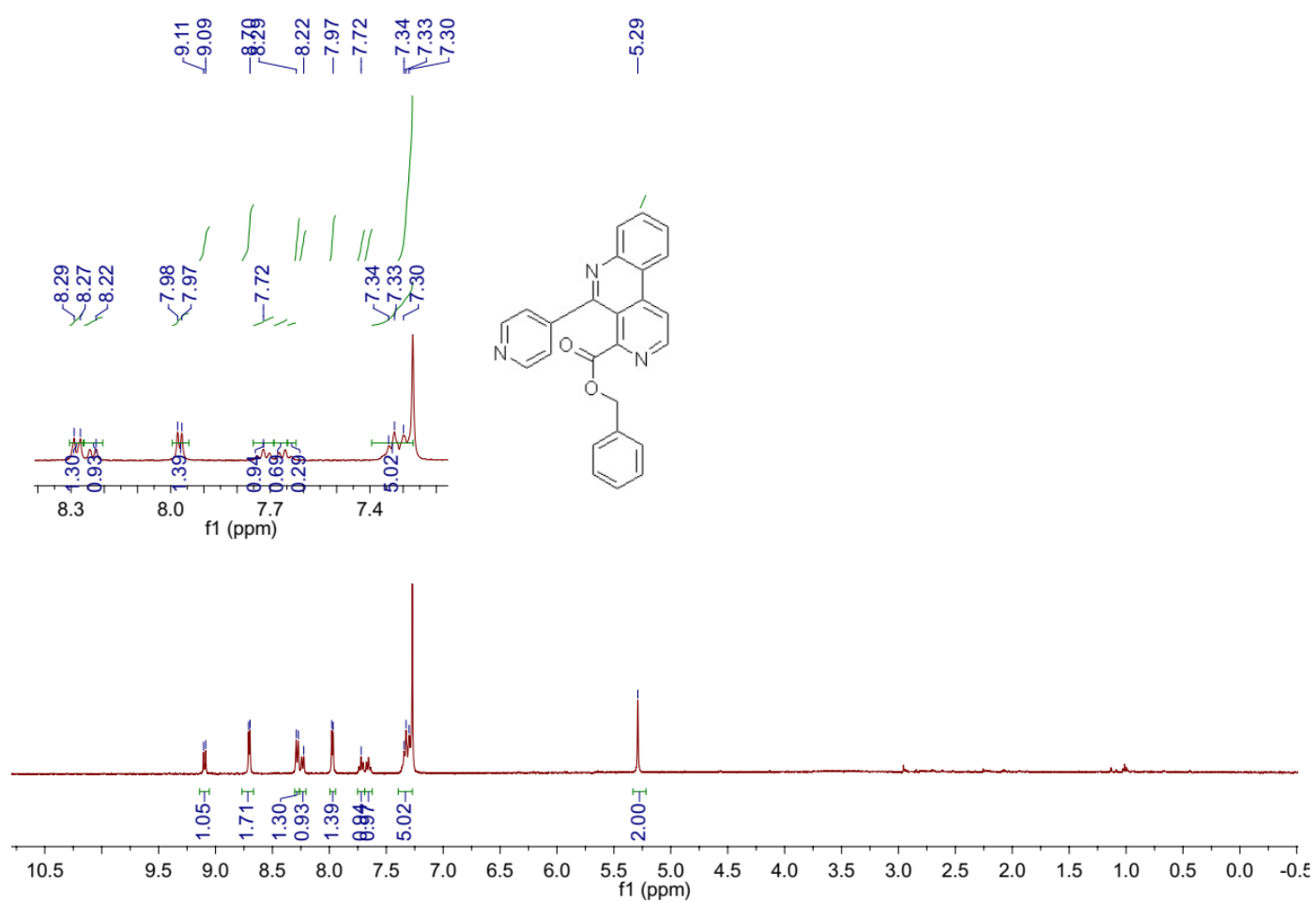

${ }^{1} \mathrm{H}$ NMR Spectrum of Compound 11ab $\left(400 \mathrm{MHz}, \mathrm{CDCl}_{3}\right)$

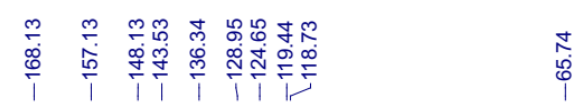
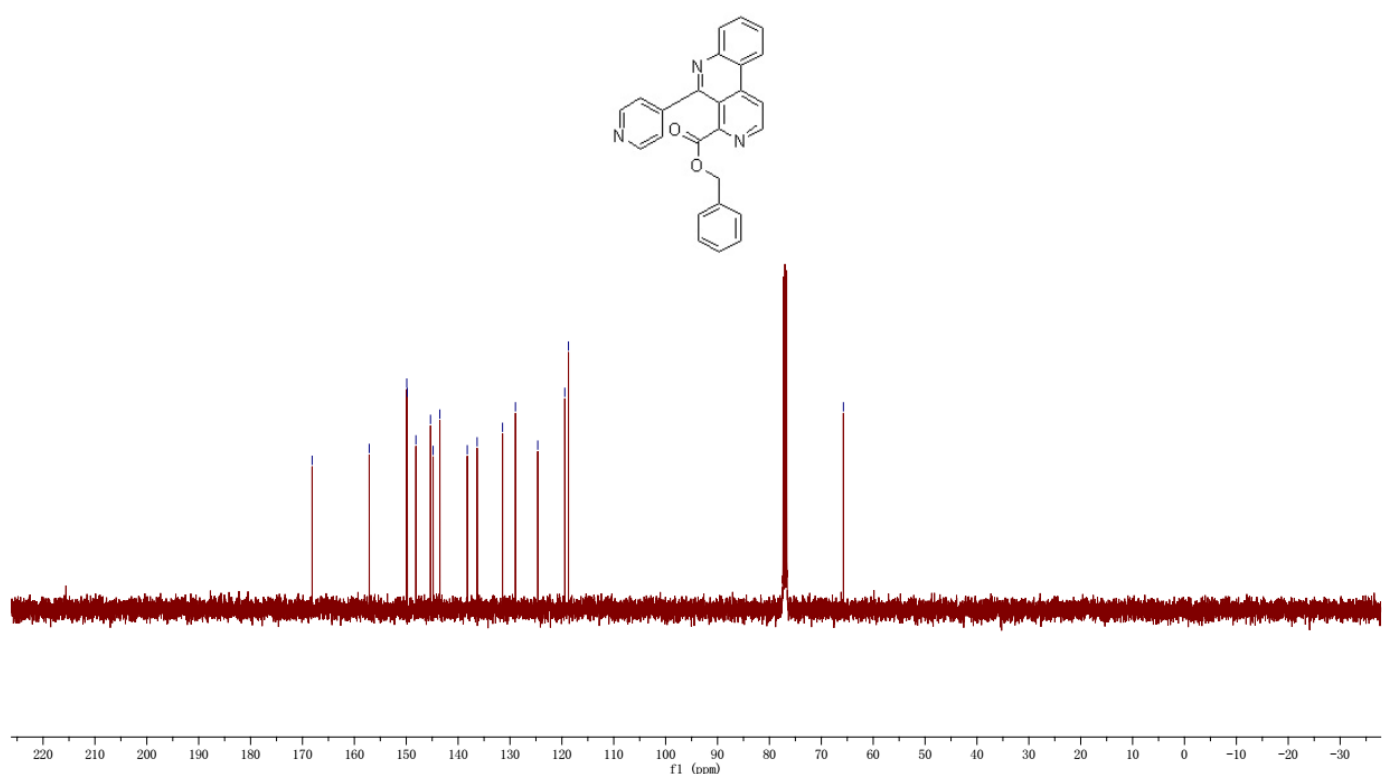

${ }^{13} \mathrm{C}\left\{{ }^{1} \mathrm{H}\right\}$ NMR Spectrum of Compound 11ab (100 MHz, $\left.\mathrm{CDCl}_{3}\right)$ 


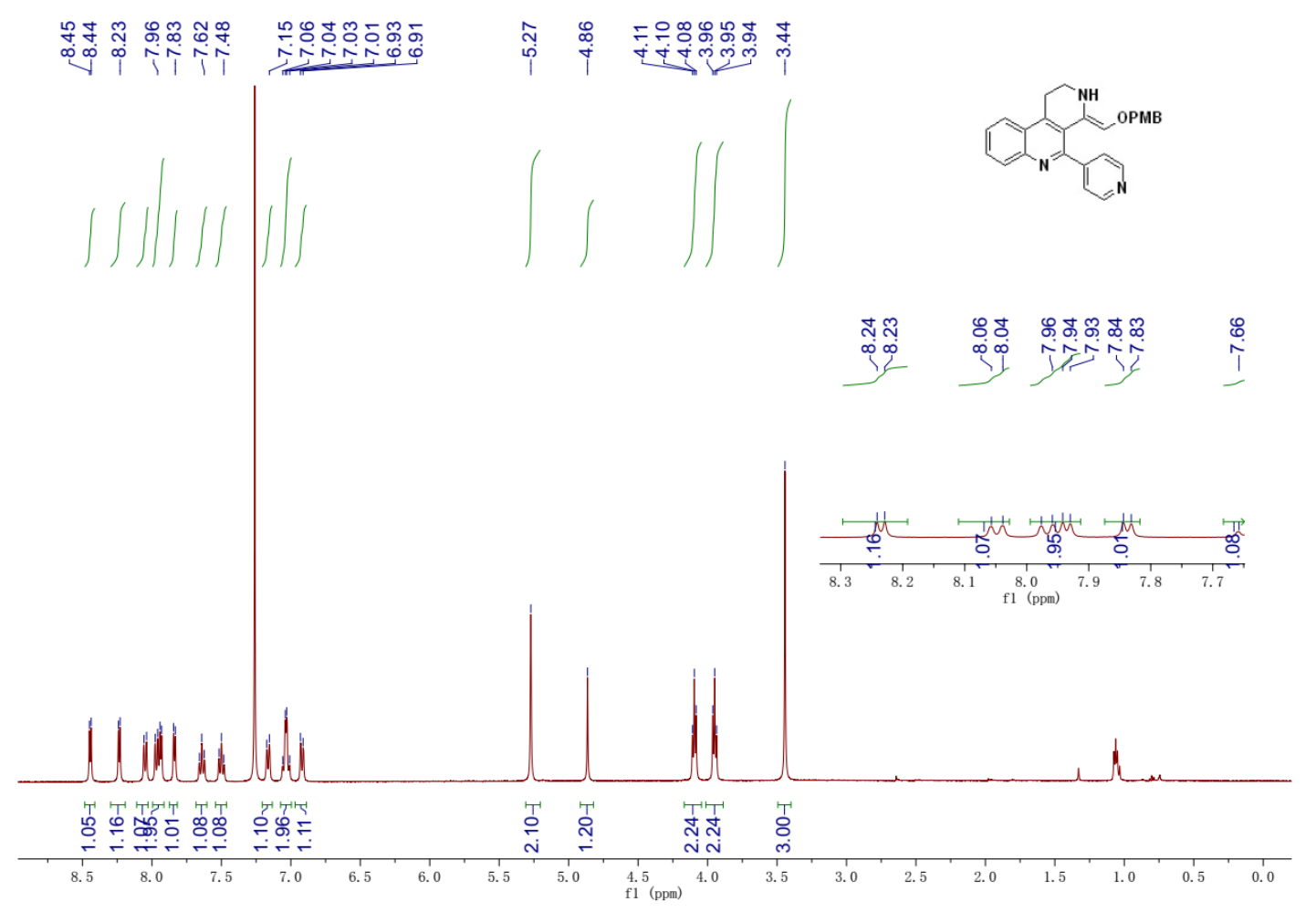

${ }^{1} \mathrm{H}$ NMR Spectrum of INT1 (400 $\left.\mathrm{MHz}, \mathrm{CDCl}_{3}\right)$

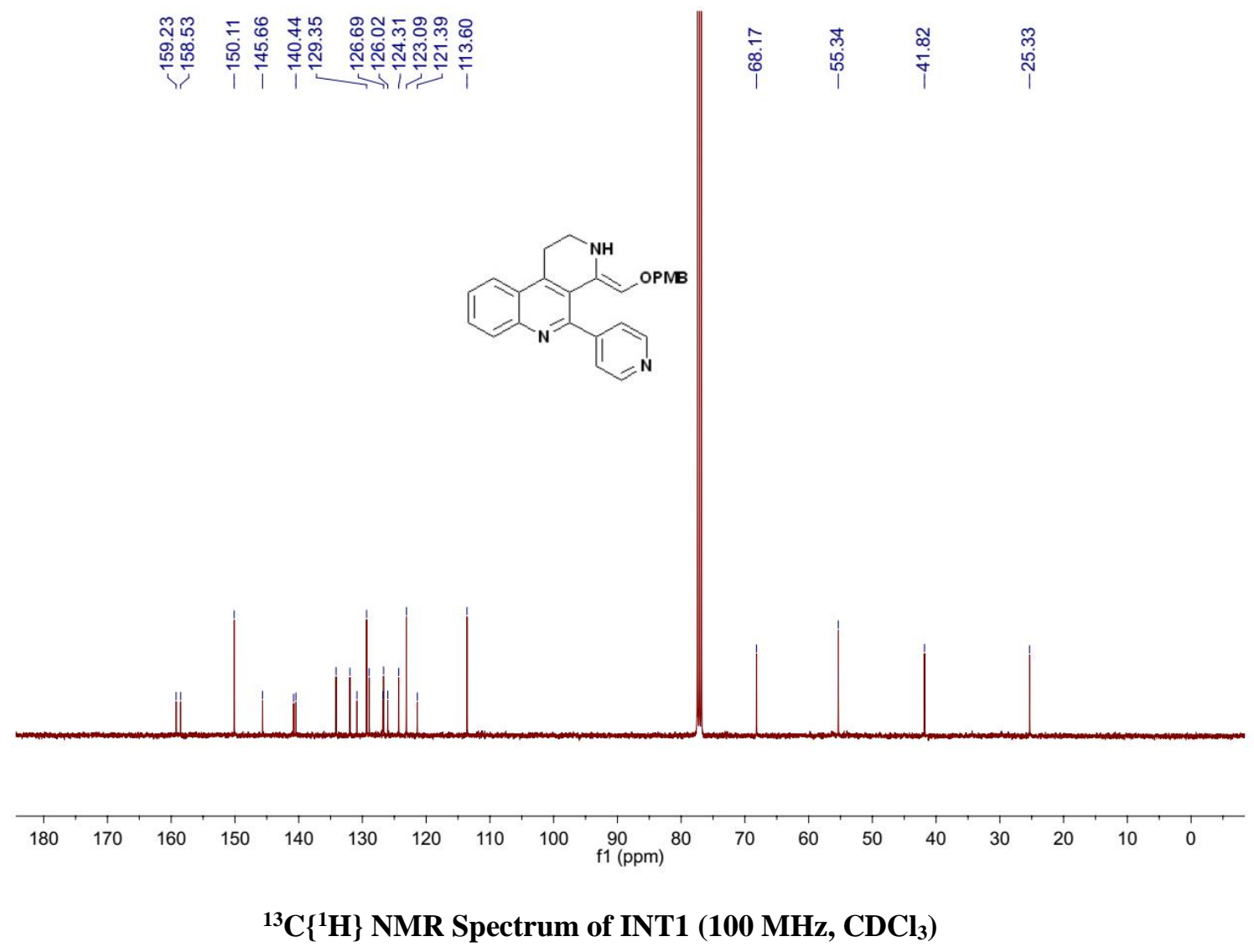




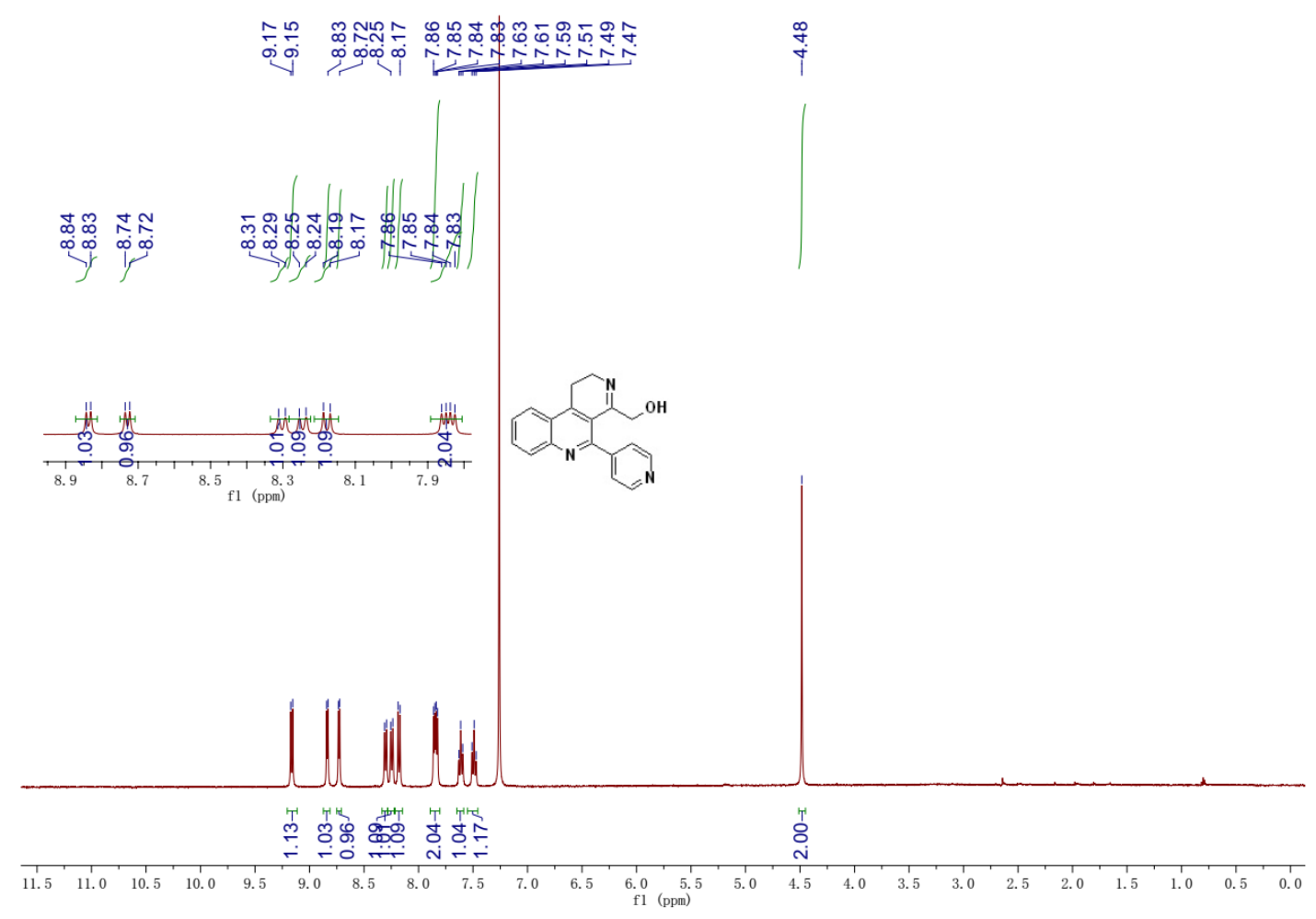

${ }^{1} \mathrm{H}$ NMR Spectrum of INT2-1 (400 MHz, $\left.\mathrm{CDCl}_{3}\right)$
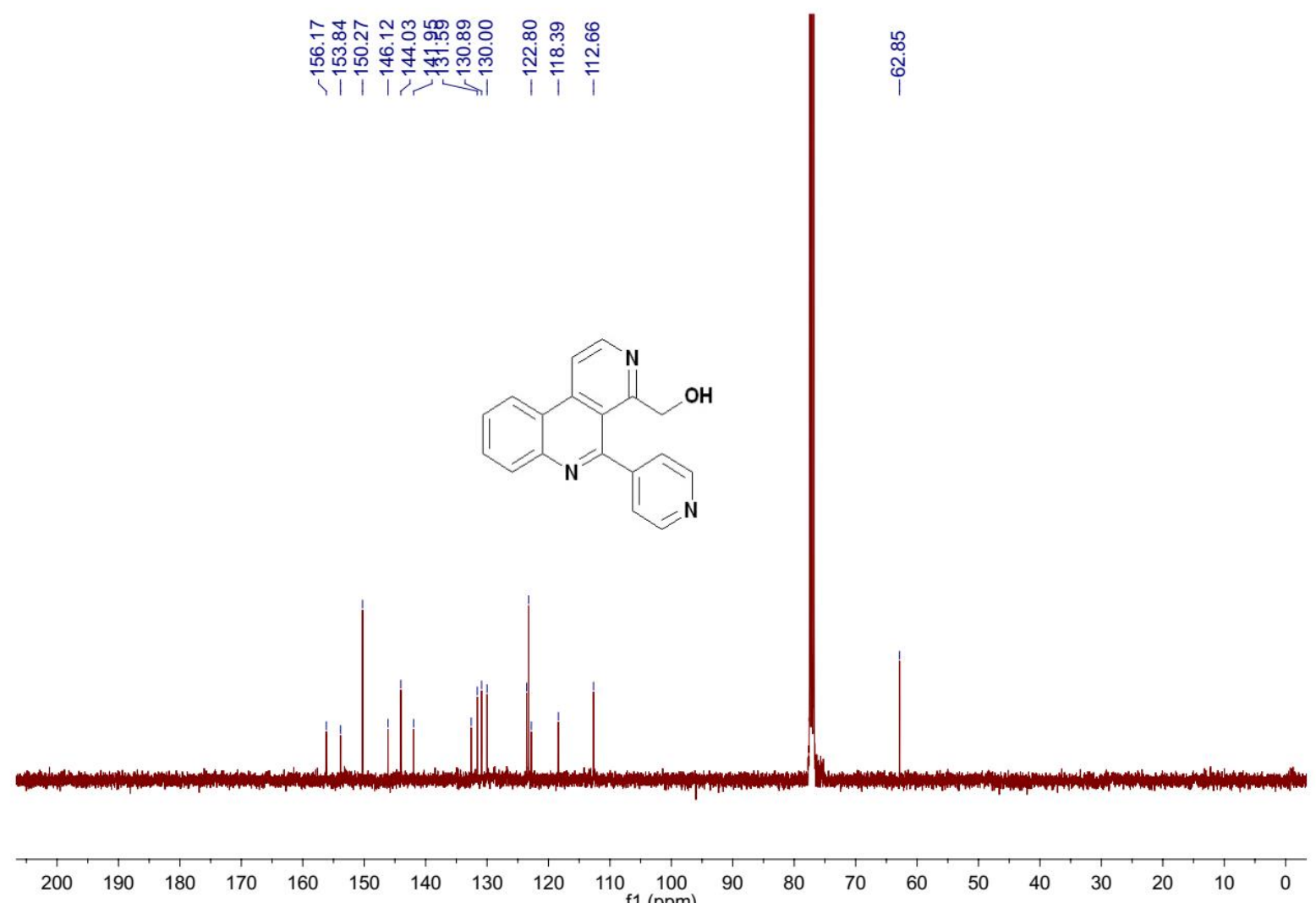

${ }^{13} \mathrm{C}\left\{{ }^{1} \mathrm{H}\right\}$ NMR Spectrum of INT2-1 (100 MHz, $\left.\mathrm{CDCl}_{3}\right)$ 


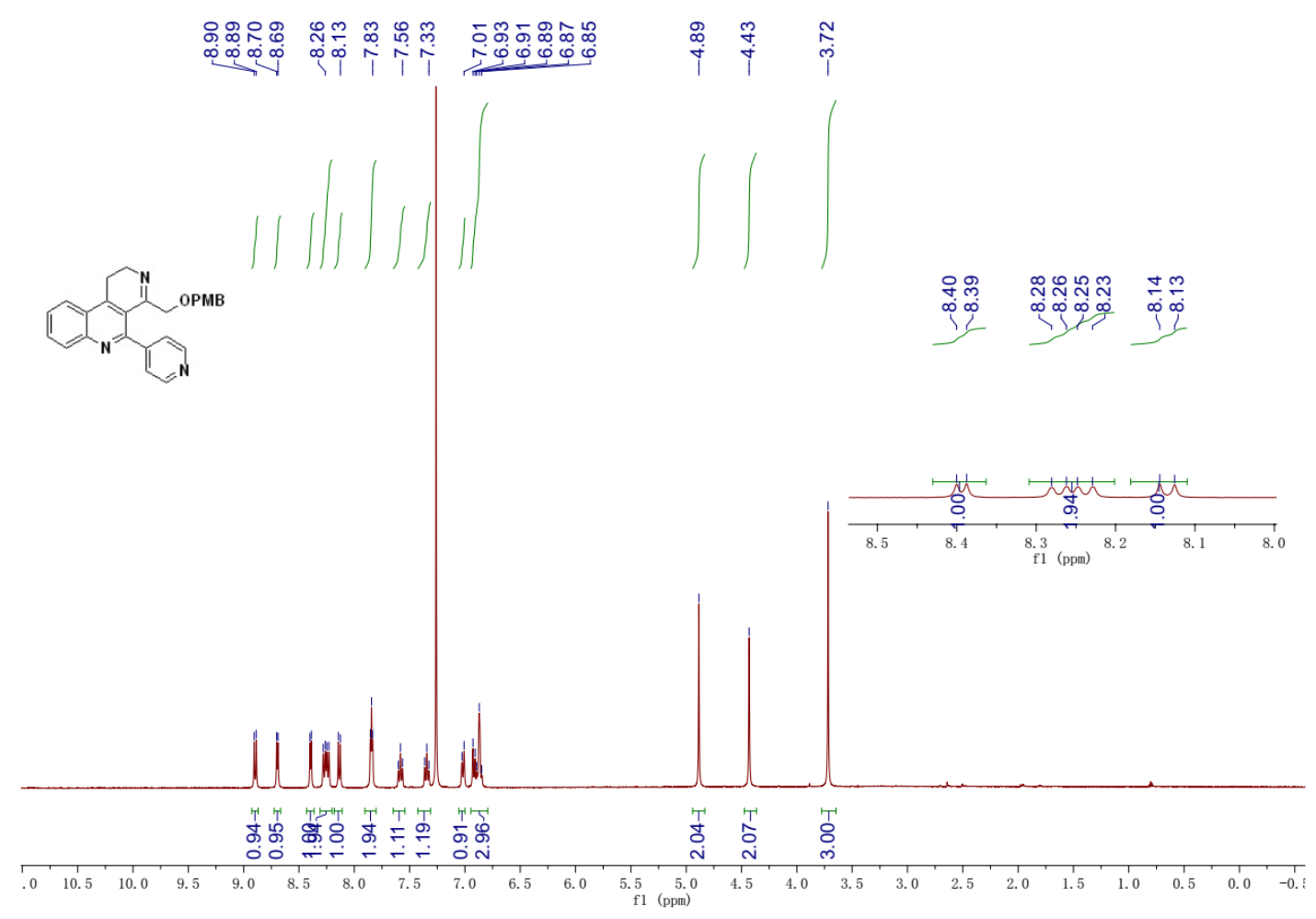

${ }^{1} \mathrm{H}$ NMR Spectrum of INT2 $\left(400 \mathrm{MHz}, \mathrm{CDCl}_{3}\right)$

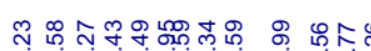

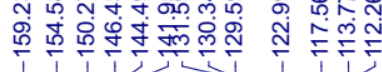

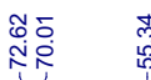
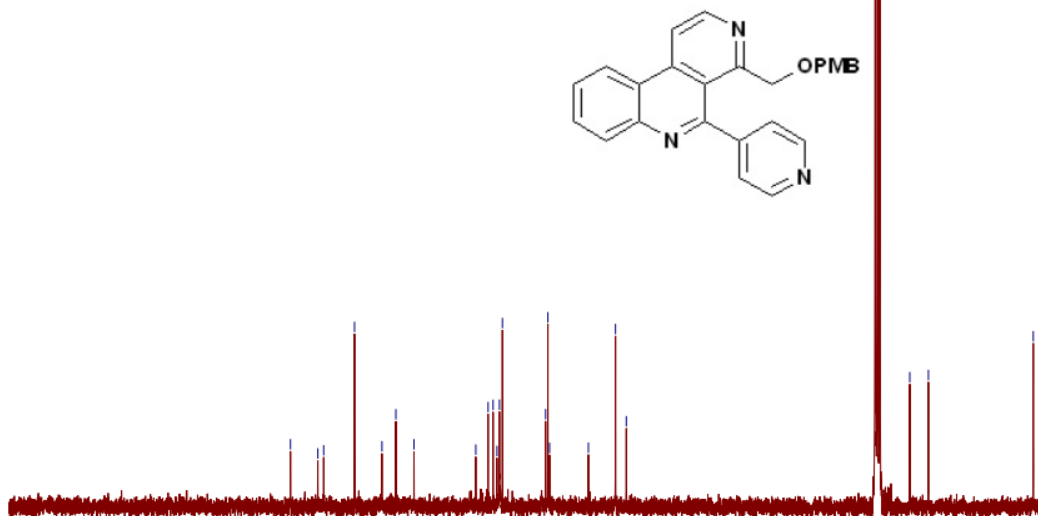

$\begin{array}{lllllllllllllllllllll}190 & 180 & 170 & 160 & 150 & 140 & 130 & 120 & 110 & 100 & 90 & 80 & 70 & 60 & 50 & 40 & 30 & 20 & 10 & 0 & -10\end{array}$

${ }^{13} \mathrm{C}\left\{{ }^{1} \mathrm{H}\right\}$ NMR Spectrum of INT2 (100 MHz, $\left.\mathrm{CDCl}_{3}\right)$ 